\title{
LA IGLESIA DE SAN PEDRO DE LA NAVE (ZAMORA). ARQUEOLOGÍA Y ARQUITECTURA ${ }^{1}$
}

\author{
POR \\ LUIS CABALLERO ZOREDA Y FERNANDO ARCE \\ Centro de Estudios Históricos. CSIC. Madrid
}

\section{RESUMEN}

Se publica una nueva documentación planimétrica y el análisis de las etapas constructivas de la iglesia de $\mathrm{S}$. Pedro de la Nave (prov. Zamora), llegando, entre otras, a la conclusión de que el edificio primitivo pertenece a un solo proyecto, probablemente abovedado en su totalidad.

\section{SUMMARY}

We release here new planimetric documents and the analysis of the construction stages of the church of San Pedro de la Nave (province of Zamora), concluding among others that the original building was based on one single projet, very likely to be entirely vaulted.

\section{INTRODUCCIÓN}

Nuestra arquitectura altomedieval forma un conjunto excepcionalmente rico e importante. Sin embargo, muchas de las iglesias que lo conforman es-

1 La dirección de los trabajos es de Luis Caballero. La planimetría fue dirigida por Pablo Latorre y Leandro Cámara, realizada por fotogrametría terrestre, efectuada por Esperanza Ducar y Carlos Sánchez-Garnica. La lectura de paramentos fue efectuada por los firmantes del artículo, Santiago Feijoo que tuvo un papel sobresaliente en su desarrollo, $\mathrm{Pa}$ blo Latorre, Margarita Fernández Mier y Leandro Cámara (a quien se debe la reconstrucción de la fig. 20), con la colaboración de Alaitz Echeverría de la Universidad del País Vasco. El tratamiento de planos se efectuó en el gabinete de fotogrametría del Departamento de Historia Antigua y Arqueología, $\mathrm{CEH}$, CSIC, por Santiago Feijoo (a quien se deben las figs. 16 a 19 y 21) y Fernando Arce. En el texto se han incorporado las aportaciones efectuadas por todo el equipo en el desarrollo de los trabajos. Agradecemos a Agustín Azkarate sus siempre preciosas sugerencias, así como la ayuda imprescindible de Hortensia Larrén, arqueóloga territorial de Zamora. El trabajo se ha efectuado con una ayuda del estudio Latorre \& Cámara y una beca del Instituto de Estudios Zamoranos de la Diputación de Zamora y se encuadra en los proyectos de investigación Las iglesias de repoblación del antiguo reino de Navarra. Documentación y análisis, DGICYT PB940062 y Las iglesias castellanas de Reconquista, convenio de colaboración de la Junta de Castilla y León y el CSIC. La documentación original está depositada en el Departamento de Historia Antigua y Arqueología, CEH, CSIC, y una copia en la Junta de Castilla y León. tán aún deficientemente estudiadas y conocidas. Tras la documentación y estudio de la de Sta. María de Melque (Toledo; Caballero y Latorre 1980), se ha efectuado un avance notable con las de La Nave (Corzo), Quintanilla de las Viñas (Burgos) y S. Juan y Sta. Basilisa de Zalduendo (Vitoria; Arbeiter 1990 y 1994), S. Pedro de Arlanza (Burgos; Caballero, Cámara, Latorre y Matesanz), S. Miguel de Lillo y S. Salvador de Valdediós (Asturias; Noack-Haley y Arbeiter), S. Román de Tobillas (Vitoria; Azkarate) $\mathrm{y}$, sobre todo, con el importante esfuerzo realizado por Arias sobre las iglesias asturianas (1992, 1993 y 1995, entre otros trabajos). Otras se encuentran actualmente en vías de publicación por estos equipos.

Con este estudio, realizado con una metodología, la Arqueología de la Arquitectura, en cuyo desarrollo hemos colaborado (Caballero y Fernández Mier) no pretendemos ni una mera descripción del edificio, ni mediar en la problemática que aún plantea su cronología (Caballero 1994/1995), sino dar a conocer un corpus de datos tratados de modo que aporten nuevos argumentos a esta discusión y ayuden en el futuro a su adecuada adscripción. Nuestra pretensión es publicar una planimetría más exacta y objetiva que las existentes (debidas a Esteban, en Mateos y Esteban y a Alfonso Jiménez, en Corzo), aportar la lectura de paramentos o sea la secuencia relativa de etapas constructivo-cronológicas que han dejado su testimonio en el edificio, definiendo a la vez todos los elementos que lo componen, y discutir con brevedad, sobre una información nueva, algunos caracteres y problemas constructivos, hasta hoy dudosos y sometidos a controversia y que son fundamentales para la comprensión adecuada de esta arquitectura. Mientras que la secuencia del edificio creemos que será en gran medida definitiva, no ocurre lo mismo respecto a los problemas de carácter constructivo, pendientes aún de análisis futuros ${ }^{2}$.

${ }^{2}$ La secuencia cronológica aportada es de valor relativo y, por lo tanto, ayuda a solucionar el problema cronológico, quedando pospuesta su solución a los resultados de otros proyectos analíticos, como el de dendrocronología y radio carbono que en el momento actual está en marcha financia- 


\section{HISTORIOGRAFÍA}

La iglesia de San Pedro de la Nave tuvo una temprana divulgación entre los eruditos tras su inclusión en Monumentos Arquitectónicos de España (1872) en forma de dos láminas de pulcros dibujos que, pese a sus inexactitudes, fueron a lo largo de casi 40 años la única documentación gráfica para los diferentes estudiosos que se preocuparon por la iglesia.

El conocimiento de la entonces parroquia y cementerio rural dio un giro completo con la visita efectuada por Gómez Moreno - tal vez animado por las someras referencias de los eruditos que databan este edificio en el siglo $\mathrm{x}$, por tanto candidato a ser integrado en el grupo mozárabe que Gómez Moreno estaba organizando y que culminaría con la publicación del libro Iglesias Mozárabes, 1919- y la subsiguiente publicación de un artículo en el que expresaba sus opiniones y valoración de lo visto allí (1906). Pero le fue imposible encuadrar esta iglesia dentro del marco de referencia de lo mozárabe por él definido, mientras que todo lo que era divergencia por su técnica muraria y estilo decorativo en su comparación con los edificios bien documentados en el siglo $\mathrm{x}$ era sintonía al cotejarlo con el todavía exiguo, pero afianzado, grupo visigodo. Las afinidades técnicas, formales y epigráficas de La Nave con iglesias como San Juan de Baños (Palencia) y Santa Comba de Bande (Orense), unido a una serie de consideraciones de tipo histórico, obligaban a pensar en el visigotismo de la iglesia. Esta adscripción cultural y temporal propuesta por Gómez Moreno supone un hito fundamental en la historiografía altomedieval hispana.

Con La Nave convertida en ejemplo paradigmático del arte visigodo, años después respaldado por el descubrimiento de Quintanilla (Orueta 1928), los estudiosos posteriores, amparándose en el principio de autoridad del granadino y profundizando en el conocimiento material del edificio, fueron reforzando su posición. Este es el caso de Camps Cazorla (1940, 1940-41), testigo junto al propio Gómez Moreno del desmonte, traslado y reubicación de la iglesia por el arquitecto Ferrant en 1930-31 (Torres Balbás 1933). Esta peculiar circunstancia permitió conocer en profundidad el edificio, obtener nuevos datos y devolverle el aspecto que el equipo técnico pensaba era el más parecido al que tendría en origen. Si el artículo de Gómez Moreno de 1906 se

do por la Junta de Castilla y León, dirigido por Fernán Alonso, Instituto Rocasolano, CSIC; Luis Caballero, $\mathrm{CEH}$, CSIC; y Eduardo Rodríguez Trobajo, INIA. convirtió en un hito historiográfico, la restauración supuso un hito para la percepción material del edificio y para la historia de la restauración. La interpretación llevada a cabo por los restauradores ha sido generalmente admitida, siendo escasas y puntuales las divergencias. San Pedro de la Nave dejó de ser un edificio resultado de su propia historia para convertirse en un «monumento» de tiempos visigodos.

Dentro de la corriente dominante visigotista, aunque no única como veremos más adelante, apenas se hicieron nuevas aportaciones que reafirmasen la pertenencia de la iglesia a este horizonte cultural. No hay duda que los argumentos de Gómez Moreno eran abundantes y difícilmente mejorables, por lo que, a excepción de Schlunk (1945, 1970a y b), nadie manejó nuevos elementos de juicio, contentándose con lo ya expuesto por el maestro. Tomando como base la datación epigráfica de Baños y su escultura decorativa y comparándola con la de los capiteles historiados de La Nave, el arqueólogo alemán supuso la existencia de una miniatura visigoda que incidiría técnica y temáticamente en la escultura de la época y que tendría su continuidad en la miniatura mozárabe, de ahí su parecido con los capiteles de la iglesia. También se basó en sus caracteres morfológicos para suponerla precedente de lo asturiano (1971b: 444-5). En esta misma línea de afianzamiento de la corriente visigotista hay que citar el estudio de la epigrafía efectuado por Navascués (1937) y las matizaciones del propio Gómez Moreno (1966: 128-31) que propone la existencia de dos maestros decoradores, el segundo de los cuales abovedó el edificio.

Hasta los años 80, de la mano de Corzo (1986), no volveremos a encontrar ningún estudio monográfico de San Pedro de la Nave. Alineado con la tesis visigotista, este autor acomete un estudio minucioso del edificio para tratar de demostrar la secuencia constructiva ya intuida por Gómez Moreno. Para este autor, la iglesia primitiva sería el resultado de dos etapas edilicias marcadamente diferenciadas en aspectos espaciales - planta cruciforme frente a estructura basilical-, funcionales -iglesia monacal frente a templo abierto al culto públicoy decorativos - primer maestro frente al segundo- . La segunda fase sobrevendría por la imposibilidad técnica de rematar el primer proyecto $\mathrm{y}$ consecuentemente por un repentino cambio de planes.

Ya hemos dicho anteriormente que la postura visigoda respecto a La Nave es lą más consensuada pero no exclusiva. Antes de la entrada en escena de Gómez Moreno se manejaban fechas más tardías 
- siglos x y xI-, si bien alguno de aquellos autores que así se habían expresado no dudaron en rendir inmediata sumisión a los postulados de Gómez Moreno una vez que éste dio a la luz su célebre artículo (Agapito y Revilla 1906). Pero, tras sentar las bases de su teoría, tampoco faltaron voces discordantes abogando por una cronología y horizonte cultural posterior. Tal es el caso de Selgas (1909-10) y Puig i Cadafalch $(1937,1961)$. Ambos estudiosos ven en San Pedro de la Nave elementos y formas heredadas del inmediato precedente asturiano que, para el segundo, se revitalizaría con aportaciones del mundo islámico. Otro destacado mentor del postvisigotismo de la Nave fue Camón Aznar (1963), el mismo que pondría los cimientos del paradigma historiográfico que podemos llamar continuista, aunque sus actuales defensores prefieran admitir el visigotismo de la iglesia zamorana antes que la datación apuntada por Camón (Bango 1974). En los últimos años los trabajos de Caballero (1994-95, 1995: 36-71) vuelven a proponer una adscripción cronológico-cultural post-711 del edificio. Partiendo de un punto de vista rupturista en el que la experimentación musulmana supondría una auténtica renovación de las soluciones constructivas y plásticas peninsulares, La Nave encontraría sus paralelos entre las creaciones asturianas y mozárabes antes que entre lo que él considera como propio del mundo visigodo, más cercano a lo paleocristiano que a lo prerrománico.

\section{LA LECTURA ESTRATIGRÁFICA}

La aplicación del método de lectura estratigráfica de paramentos a un edificio como San Pedro de la Nave, dadas sus peculiares circunstancias, podría parecer improcedente. El hecho de que la iglesia haya sido desmontada, eliminados muchos de los elementos que no eran originales y posteriormente reconstruida y restaurada, ha supuesto una pérdida irreparable de información, a pesar de que gracias a esta remoción se pudieron conocer una serie de importantes datos que hubiera sido imposible obtener mediante los procedimientos habituales. La actual iglesia es, por tanto, un edificio que está «interpretado», al igual que ocurre en muchas fábricas modernamente restauradas. ¿Es pertinente el empleo del método arqueológico de lectura de paramentos o debemos renunciar a él y considerar que el edificio, en una aplicación estricta del método, pertenece unitariamente a la etapa de restauración al margen de que la mayor parte de los elementos que lo componen sigan siendo históricos?
Planteado este dilema decidimos llevar a cabo la lectura muraria porque, siendo de nuevo estrictos, la restauración no deja de ser una solución de continuidad más dentro de la historia del edificio, por lo tanto susceptible de ser conocido y diferenciado su impacto respecto a lo ya existente. La pulcra actuación de Ferrant impidió la pérdida de gran cantidad de información en lugares, como la zona de las naves, donde se mezclaban elementos de diferentes fases que le hubiera sido fácil uniformar. Incluso en estos sitios respetó la amalgama de aparejos, alguno muy irregular, y las huellas de la existencia de estructuras eliminadas por el restaurador, como el coro alto, poniendo el mismo cuidado en su reintegración que el utilizado en los paramentos originales. A pesar de ello en ningún momento debemos dejar de ser conscientes de que la información aportada por los elementos y actividades del edificio han llegado a nosotros a través del tamiz de la restauración de Ferrant.

El método seguido es el ya conocido de lectura de paramentos o estratigrafía arquitectónica (Mannoni; Parenti; Brogiolo; Caballero y Latorre 1995; Caballero y Escribano). Acompañamos a la descripción de las distintas etapas diferenciadas y a su estudio, dos juegos de planos, los de estado actual del edificio y los analíticos con períodos y actividades, así como el listado de las actividades (A), instrumentos imprescindibles para contrastar -y en su caso rectificar - nuestro análisis. Publicamos sólo los juegos de planos imprescindibles — planta a nivel de ventanas, alzados exteriores, secciones principales y tres secundarias-, a escala $1 / 100$ aunque lo óptimo hubiera sido hacerlo a 1/50-, enfrentando al plano documental el analítico con su diagrama de zona y el código de etapas. En la lectura inicial diferenciamos unidades estratigráficas, posteriormente reducidas a actividades a la vez que se realizaban los diagramas y el listado definitivo, con las simplificaciones correspondientes. En este texto sólo nos referimos a las actividades para simplificar y facilitar la comprensión, por lo cual son ellas las diferenciadas en los planos y recogidas en el listado, ordenadas por períodos, con su nombre/definición, las relaciones directas de antero/posterioridad que cada una posee con las demás y su ubicación en el plano correspondiente. La imposibilidad ni siquiera hipotética de adscribir muchas a un período concreto nos obliga a ordenarlas por su relación temporal, usando (como ya se hizo en Arlanza, Caballero y otros 1991-92: 140-2) los signos = como coetáneo, < como anterior y $>$ como posterior al período que sirve de referencia. 


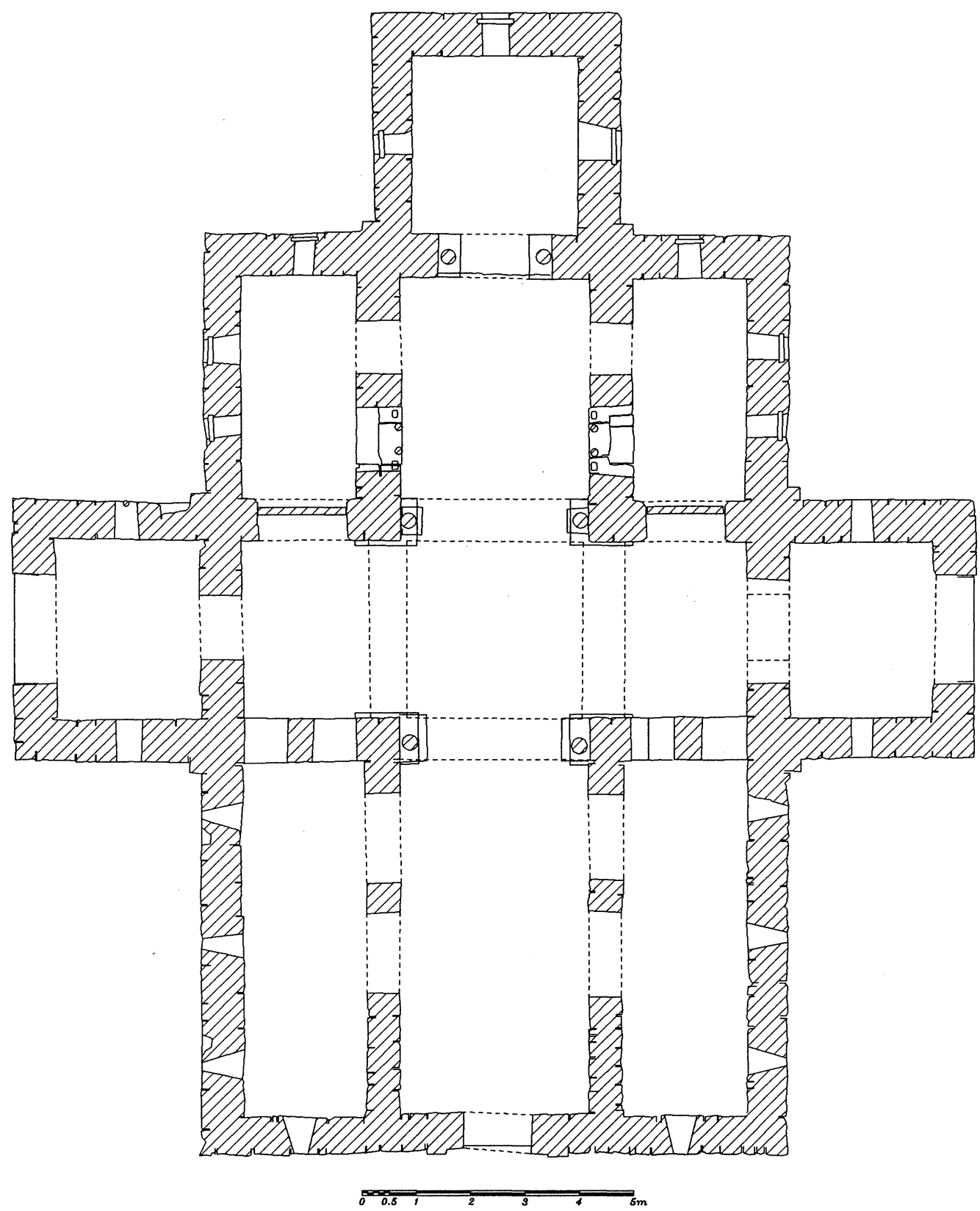

Fig. 1.-S. Pedro de la Nave. Planta a nivel de ventanas. Escala 1/133. .

\section{PERÍODOS}

PERÍODO O. MATERIAL REUTILIZADO (A 1001, fig. 8 y 10). La evidencia de utilización de material de acarreo o reaprovechado en las partes más antiguas de los muros de la iglesia es insignificante. Las estelas de época romana en su día integradas en la construcción y hoy desarraigadas, no pudieron pertenecer a la construcción primitiva, pues no queda ninguna en su restauración actual, donde tampoco hay sillares nuevos que los hubieran sustituido, y no pudieron formar parte oculta de la construcción pues todos los sillares dan cara. Por lo tanto tuvieron que pertenecer a alguna reparación posterior (Corzo: $137^{3}$ ). Las pocas evidencias de reaprovechamiento son las del zócalo de la colum-

3 Arbeiter 1995: n. 42, apoyándose en Navascués: 61, acepta que, aunque la gran mayoría de los sillares se han obtenido de cantera, una parte de ellos son estelas funerarias romanas reutilizadas. 
na nororiental del crucero, un bloque prismático de granito que tiene abiertos sendos huecos en sus caras oriental, rectangular y occidental, circular. El otro elemento anterior a la construcción del edificio es un hueco abierto en un sillar que se halla tras el fuste de la columna S. del arco de entrada al ábside, un lugar inaccesible desde el momento de la colocación de la columna.

PERÍODO I. EL EDIFICIO PRIMITIVO (A 1002; figs. 2 a 11). La fábrica conservada que corresponde a esta fase representa la mayor parte del edificio. La encontramos repartida a lo largo y ancho de toda la iglesia, desde el ábside hasta los pies y desde el suelo hasta la cesura de las etapas posteriores, que equivale en su mayoría a la restauración de Ferrant. Su mayor presencia se da en el espacio comprendido desde el crucero hasta el presbiterio y disminuye hacia los pies, salvo en las arquerías de la nave central, que no poseen ningún resto de este momento. La unidad de esta fase, y por tanto la confirmación de que la actual planta de la iglesia corresponde con la original, se percibe por la continuidad de los muros perimetrales; por una razón estrictamente estratigráfica, al no encontrar ninguna solución de continuidad dentro de ella; y por criterios de homogeneidad constructiva.

El material dominante en los muros levantados en esta fase es una arenisca de grano fino y tonalidad rojiza. También encontramos, en un porcentaje muy pequeño, sillares de granito utilizados simétricamente para funciones de mayor resistencia o desgaste: los dinteles interiores de las ventanas que comunican las habitaciones con el anteábside; el zócalo de la columna NE. del crucero ya mencionado; y las esquinas exteriores de las habitaciones, a la altura de la primera hilada, la de la habitación $\mathrm{N}$. de granito y la de la S. de conglomerado que debió considerarse con la misma función que el granito. El mármol está también presente en forma de fustes y basas de las columnas del crucero y del ábside - éstas sin basa-.

La talla de la piedra, en las caras visibles de los sillares, ha dejado huellas que forman «abanicos», resultado de un desbaste a base de hacha o destral aplicado desde diferentes ángulos efectuado en el suelo, antes de colocarlos en su situación definitiva. También se aprecia en los bordes de los sillares la talla de guías de careado que pudieron efectuarse con cincel, del mismo modo que 'se observó en los paramentos exteriores de S. Pedro el Viejo de Arlanza, donde se pensó que habrían sido realizadas una vez colocados los sillares «in situ». Sin embargo en los paramentos interiores de La Nave parece que debieron ser efectuados a pie de obra, quizás trazando una línea auxiliar en la cara frontera, luego tallando las guías y finalmente rebajando las caras de modo que su desbastado se pueda efectuar, como hemos dicho, desde diferentes ángulos, lo que sería difícil conseguir con los sillares una vez colocados en el muro (La Nave y Quintanilla, Hauschild: lám. 43 c,d y 46 b; Quintanilla, Arbeiter 1990: lám. 56a; en Arlanza, Caballero y otros 1991-92: 151 y Caballero y Cámara: 84 y fig. 2b; en Tobillas, Azkarate: prerrománico I y II, 199 y 201, figs. 11 a y b y 12a y b). En la hilada de cimiento los sillares presentan un tipo de rebaje que deja sobresaliente la parte inferior o de apoyo del muro. Es otra técnica corriente que, por ejemplo, se observa igual en S. Pedro el Viejo (Caballero y otros 1991-92: 151 y 142) y en Melque.

Los sillares resultantes están muy bien cortados y escuadrados, siendo de aparejo uniforme en su altura dentro de cada hilada, aunque no en su largura. Encontramos desde grandes bloques predominantemente de $1,4 \mathrm{~m}$ de largo que excepcionalmente llegan a los 1,5 y $1,6 \mathrm{~m}$, preferentemente en las partes bajas, hasta estrechas lajas en las líneas de regularización. Los muros son de doble hoja, sin relleno central, predominantemente «a soga y tizón», esto es alternando sillares largos con otros estrechos, pero sin seguir un ritmo reiterativo. Es posible contar en una misma hilada hasta 11 sillares estrechos consecutivos - segunda hilada muro E. ábside exterior - y verlos desaparecer casi completamente en otras. Los sillares de mayor tamaño suelen colocarse en las hiladas inferiores, alternando con amplias series de sillares estrechos, parecidos a tizones, en la segunda o tercera hilada, mientras que en las hiladas superiores los sillares tienden a ser de tamaño medio. Los codos son poco numerosos y de pequeño tamaño; no existen grandes codos que dividan las hiladas en dos, y sólo en cinco ocasiones son tales que llegan a interrumpir la continuidad de la hilada, aunque en estos casos se trata de sillares de forma - por estar decorados o tratarse de dovelas o impostas- encajados en las hiladas. Estas tienden a la horizontalidad aunque no son extrañas las sinuosidades, sin que por ello se vea afectado el ajuste de los bloques, por cierto en extremo preciso en todas las juntas ya sean estas verticales, horizontales, curvas o diagonales y en los pequeños codos. Se observa que el friso inferior, del primer maestro, se inclina ligeramente hacia los pies de la iglesia y hacia el N. (figs. 7, 8 y 10).

La cohesión de las hojas de los muros se logra mediante sillares de atado y grapas de madera. Si se contraponen los dibujos de las caras de un mismo 


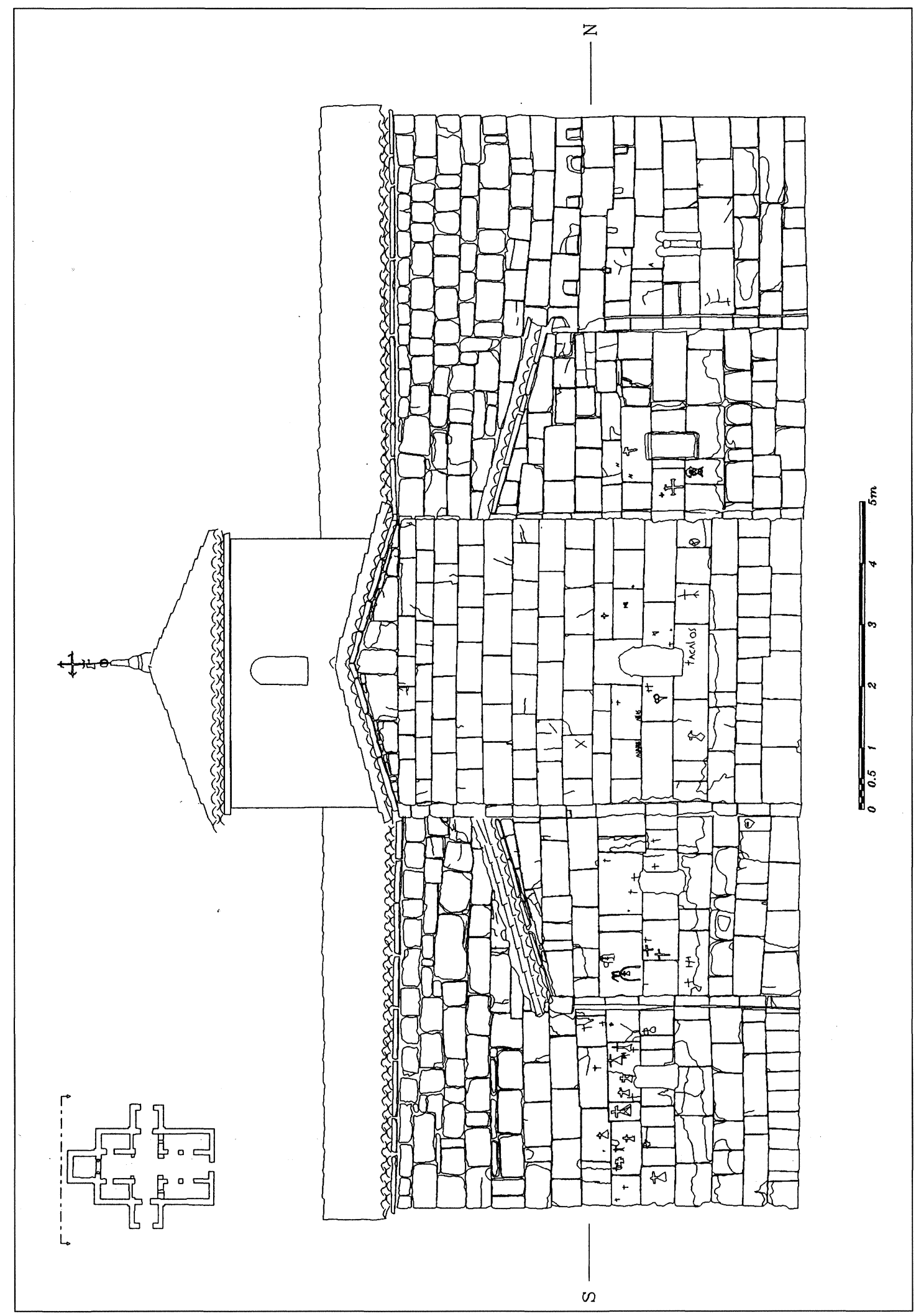




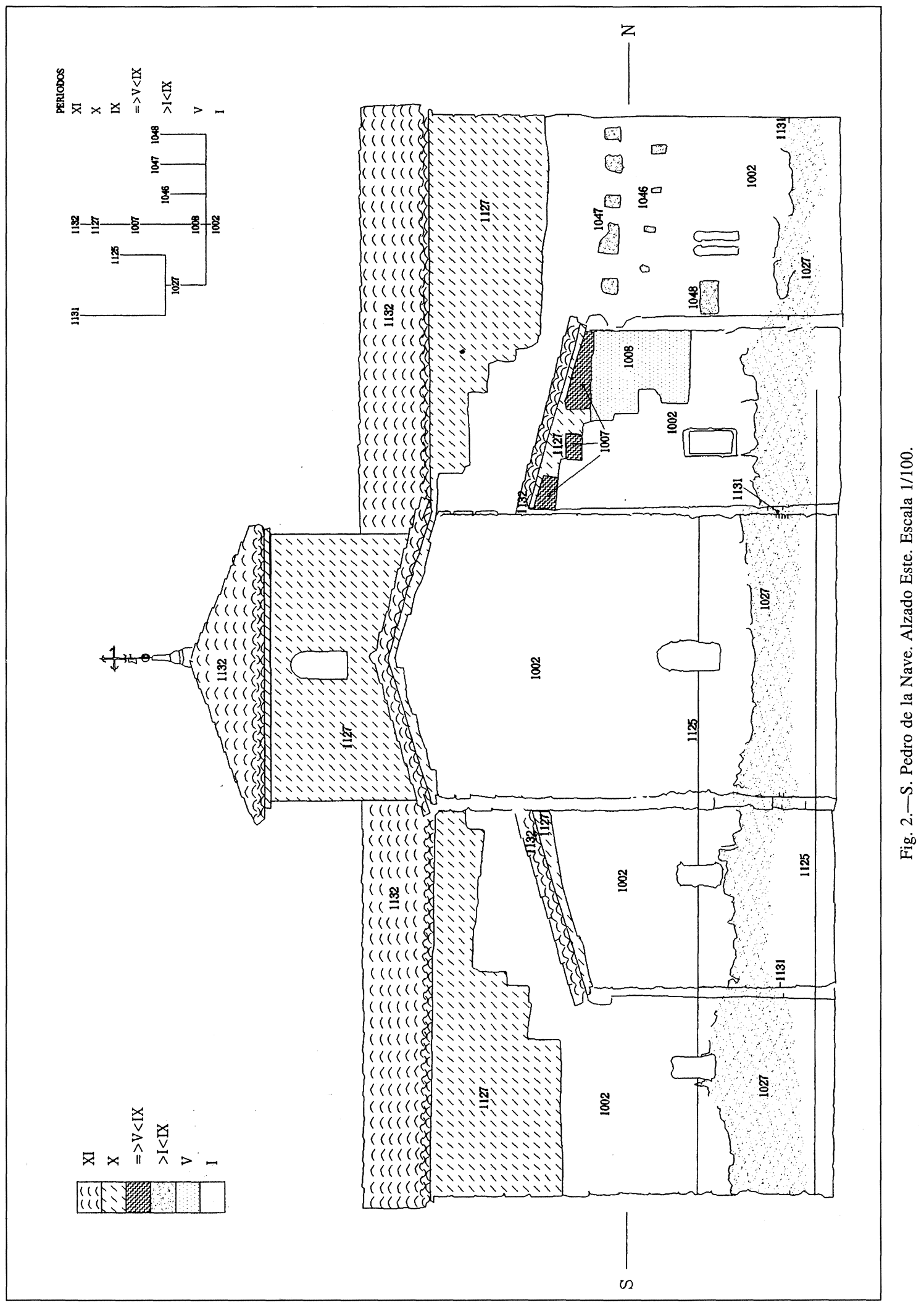




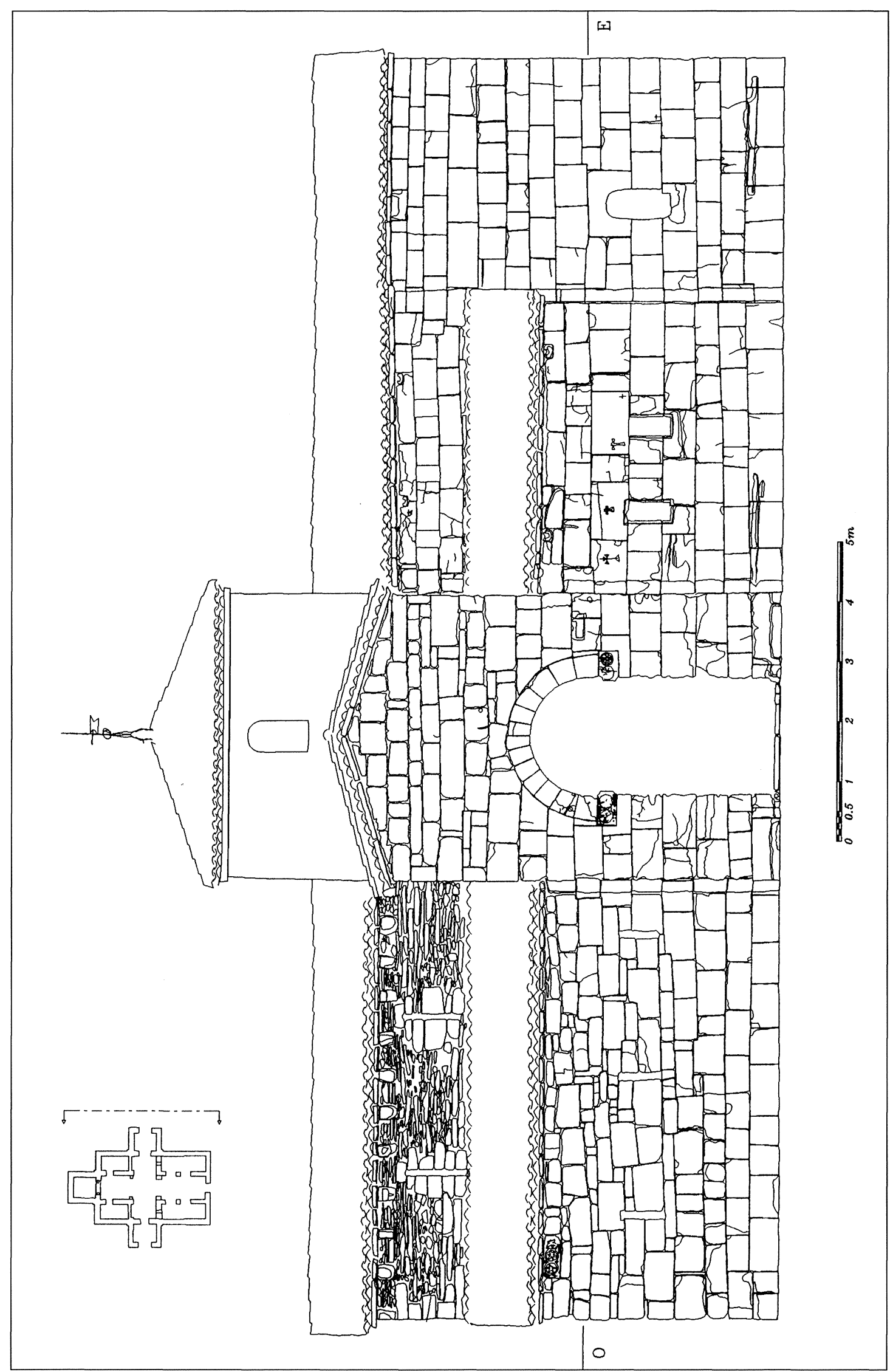




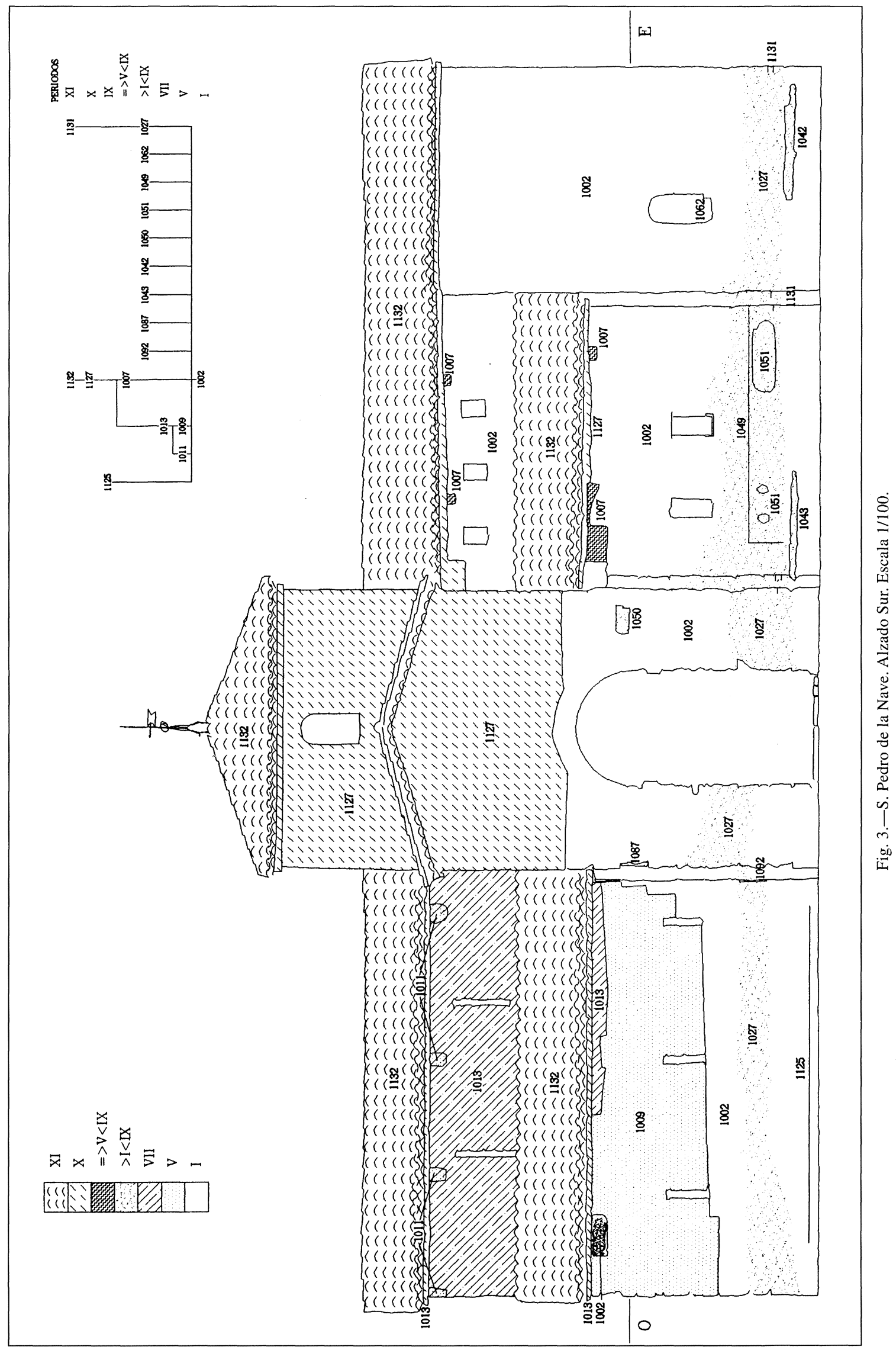




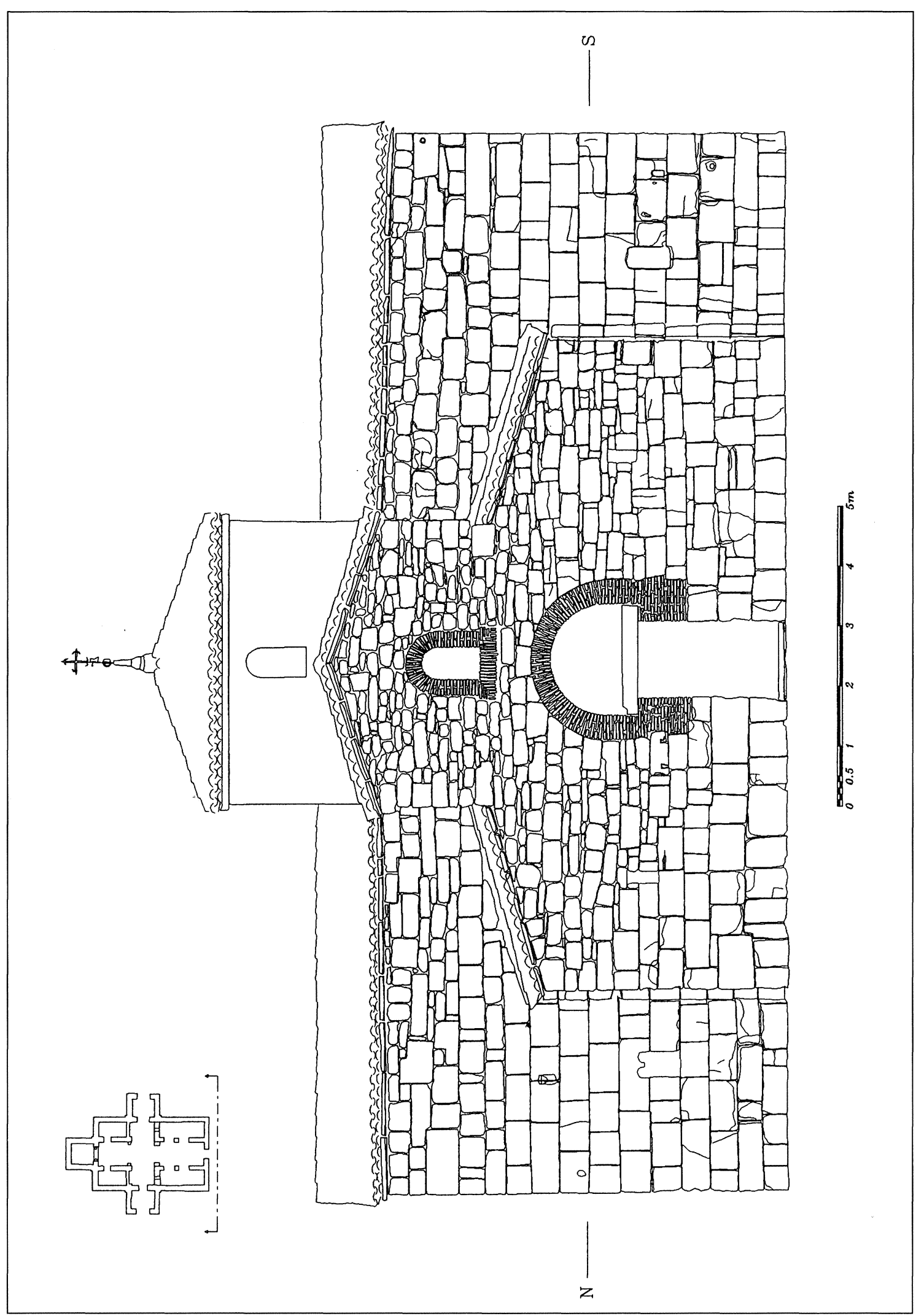




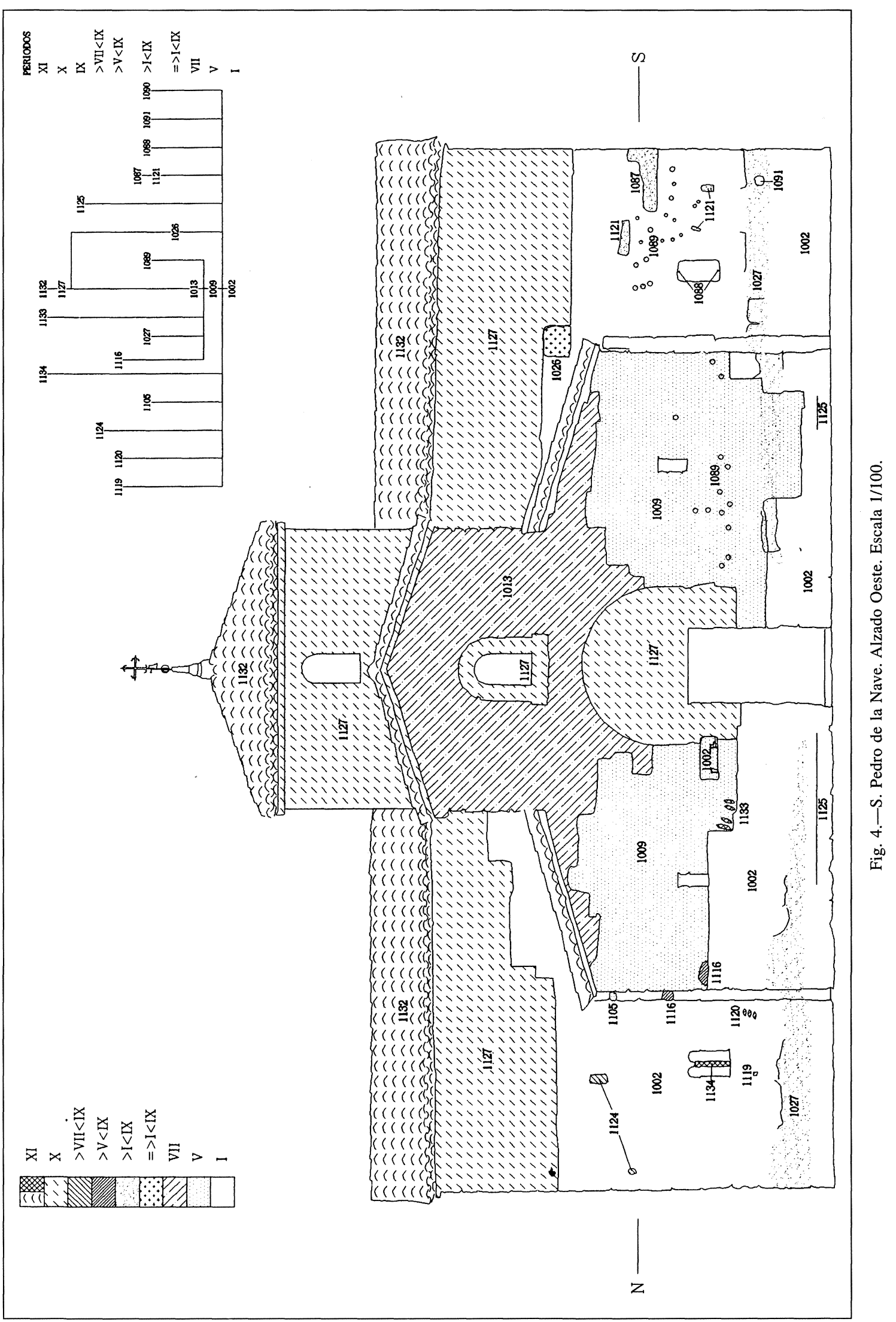




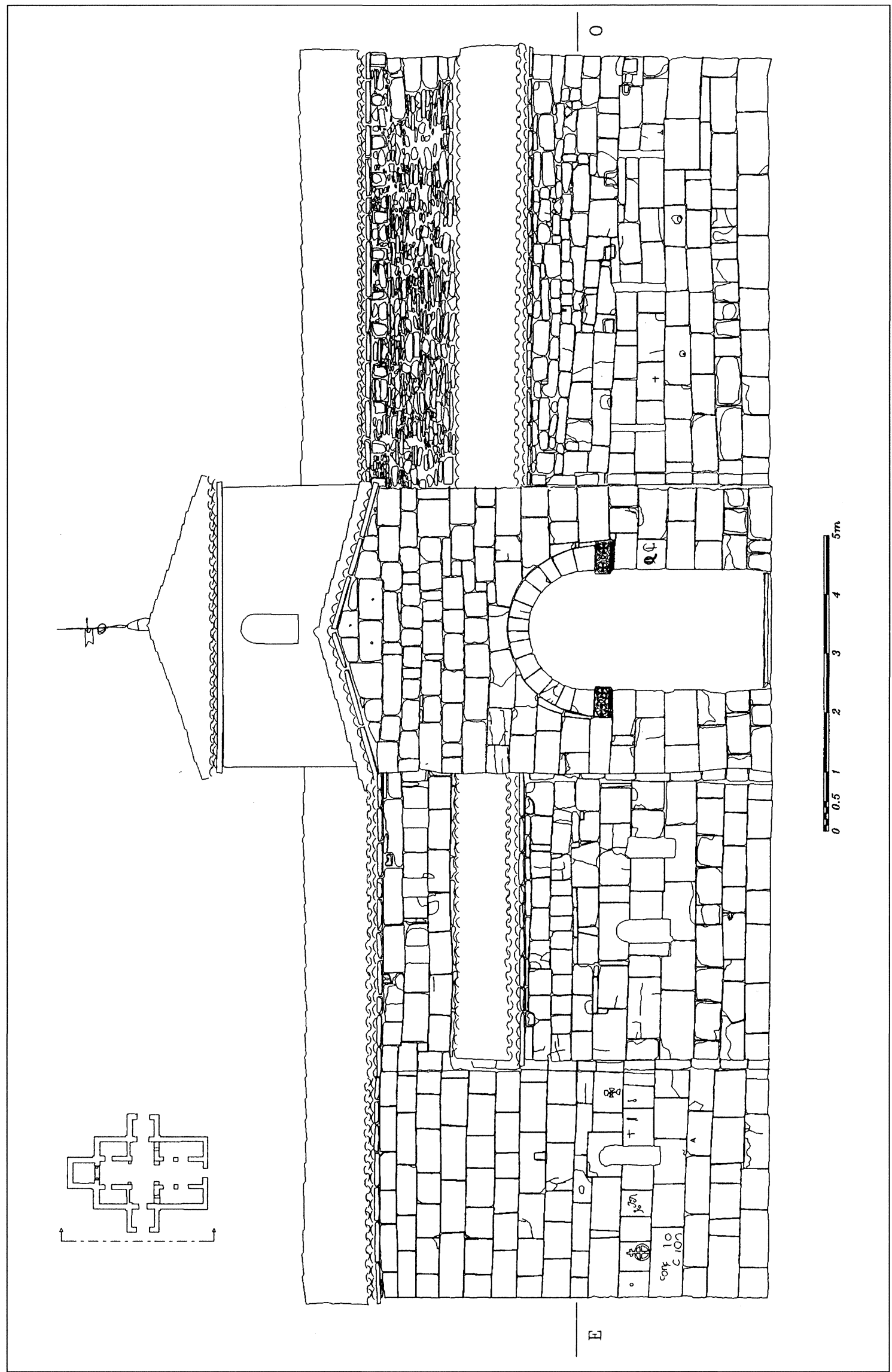




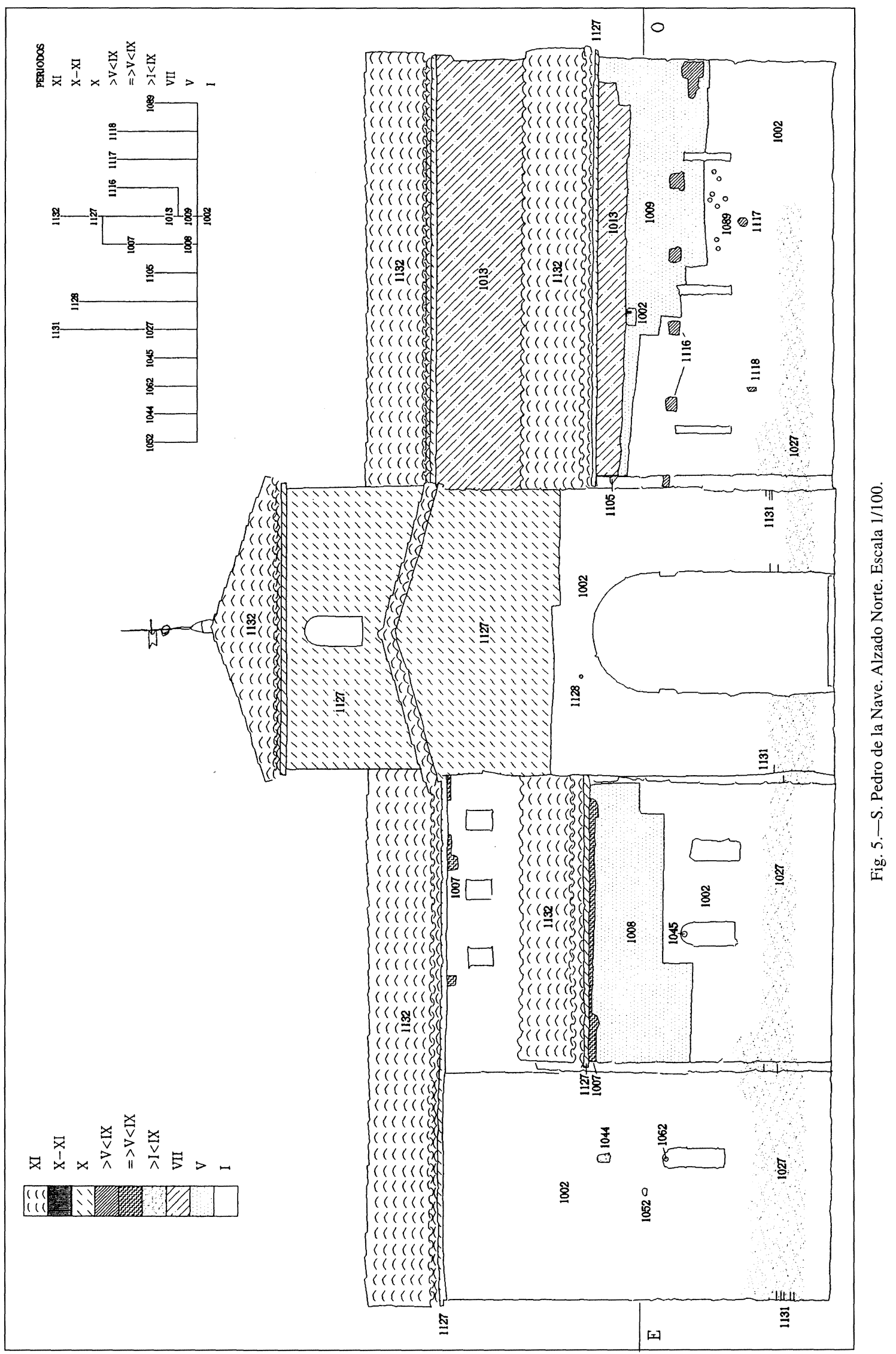




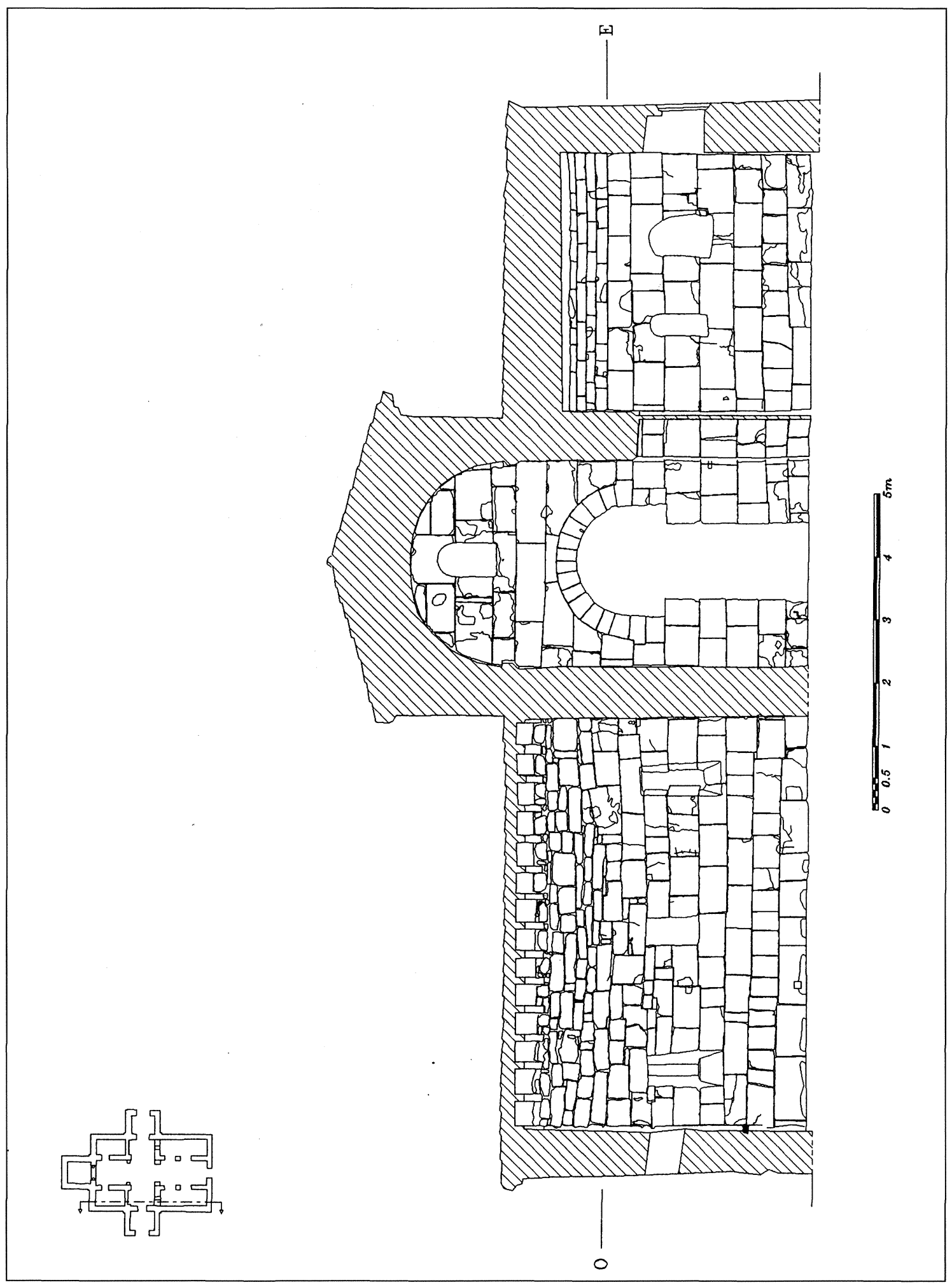




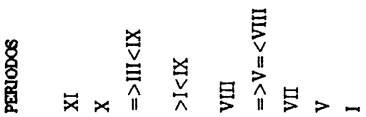
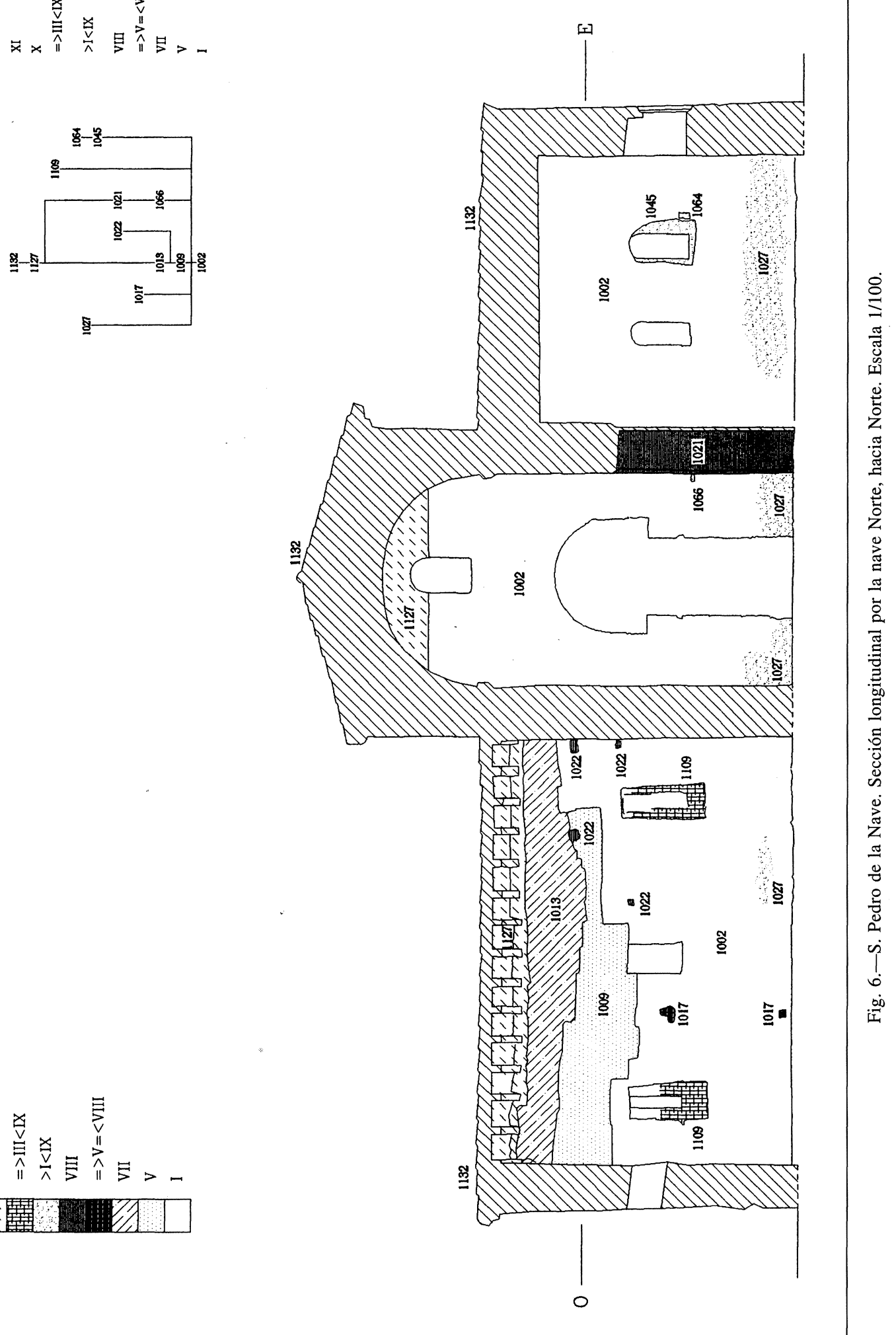


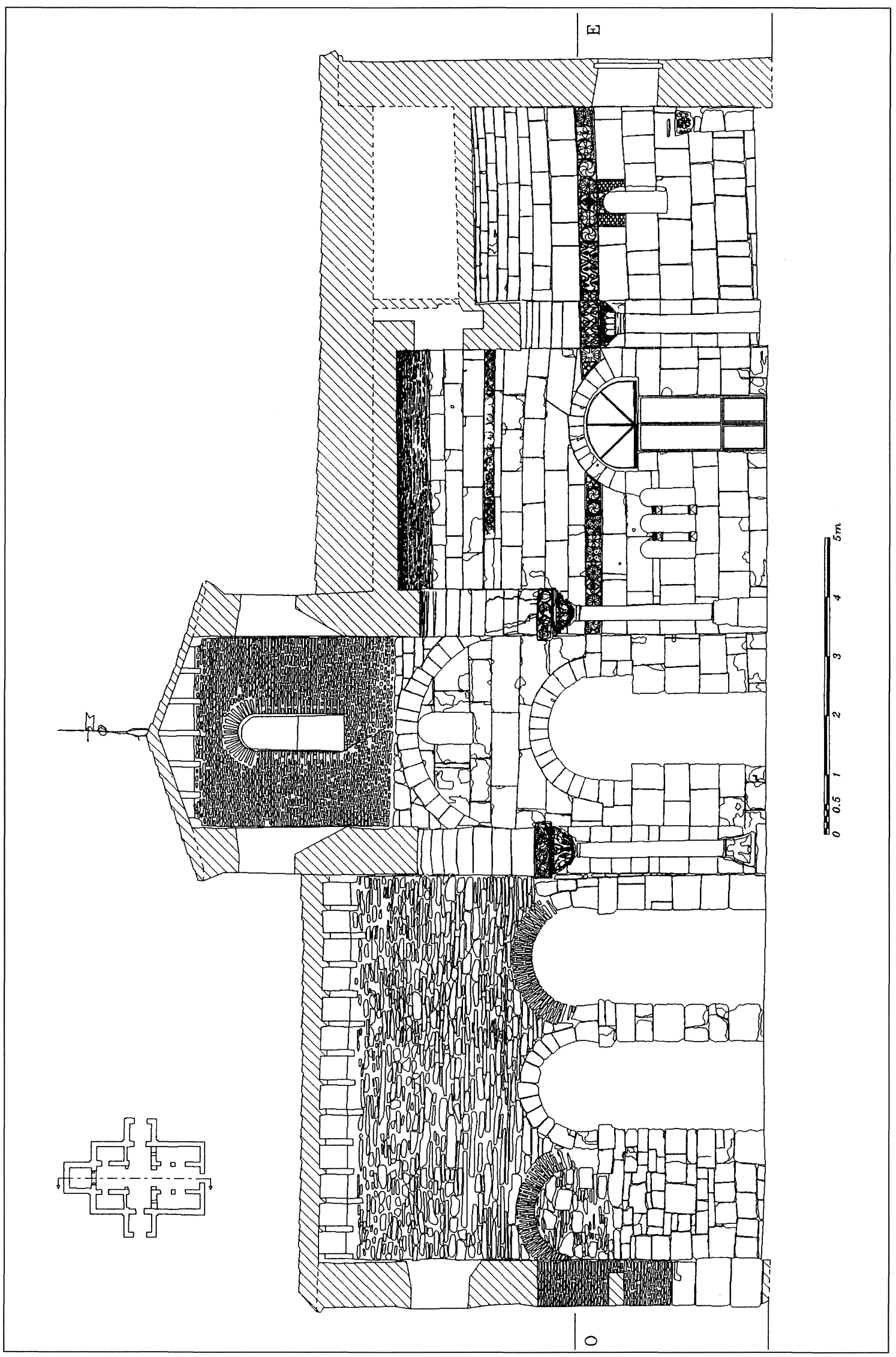




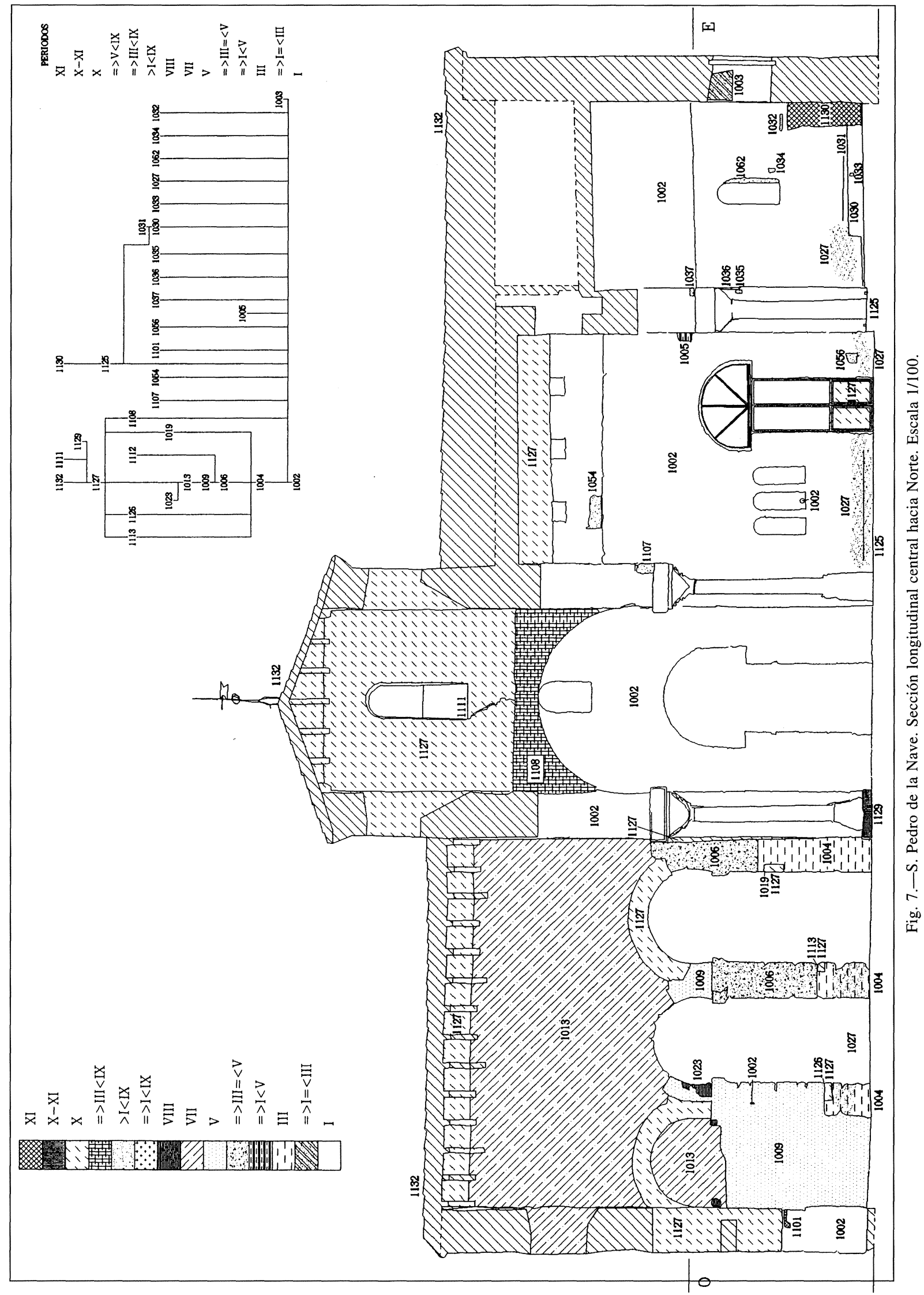




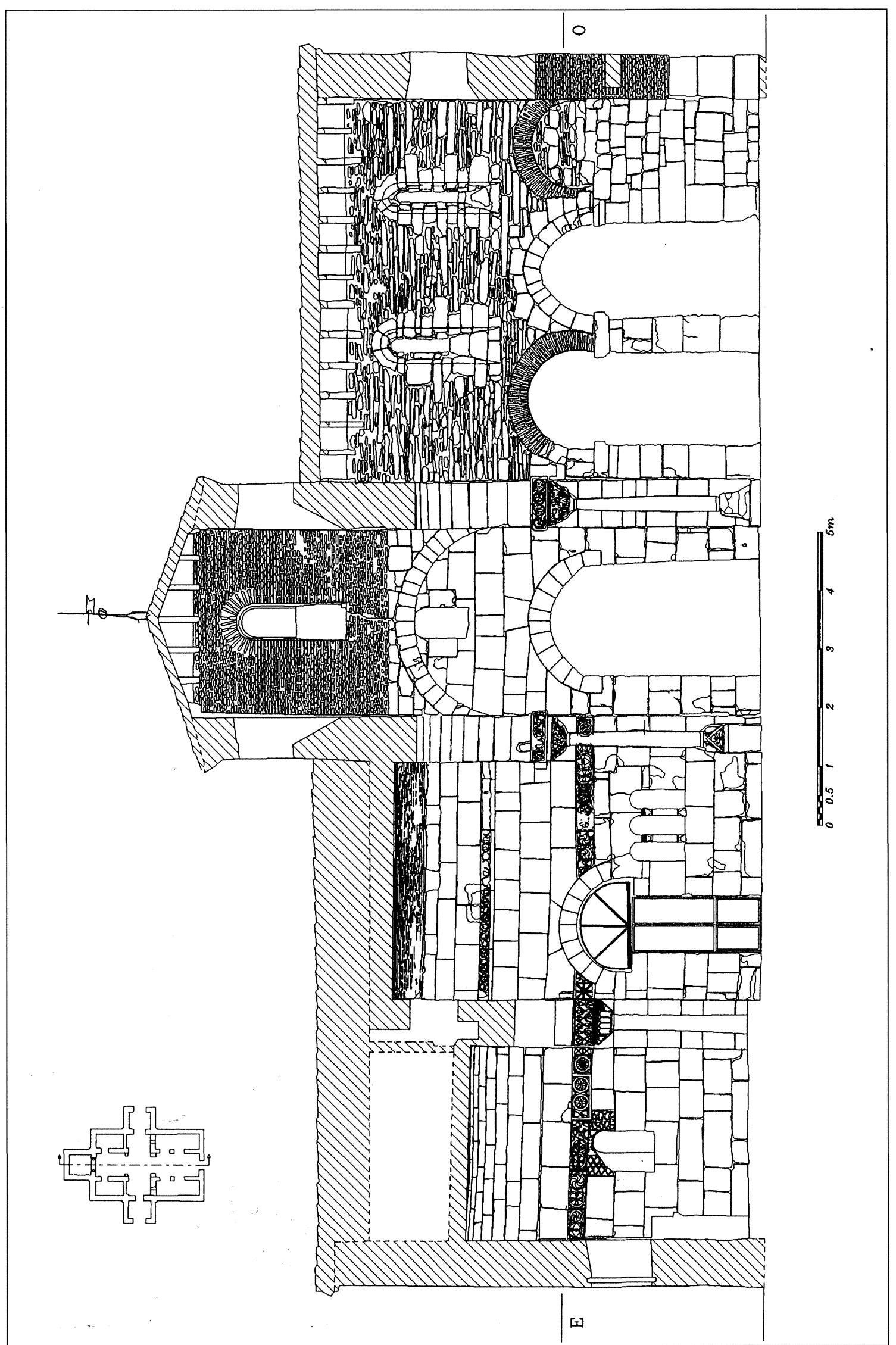




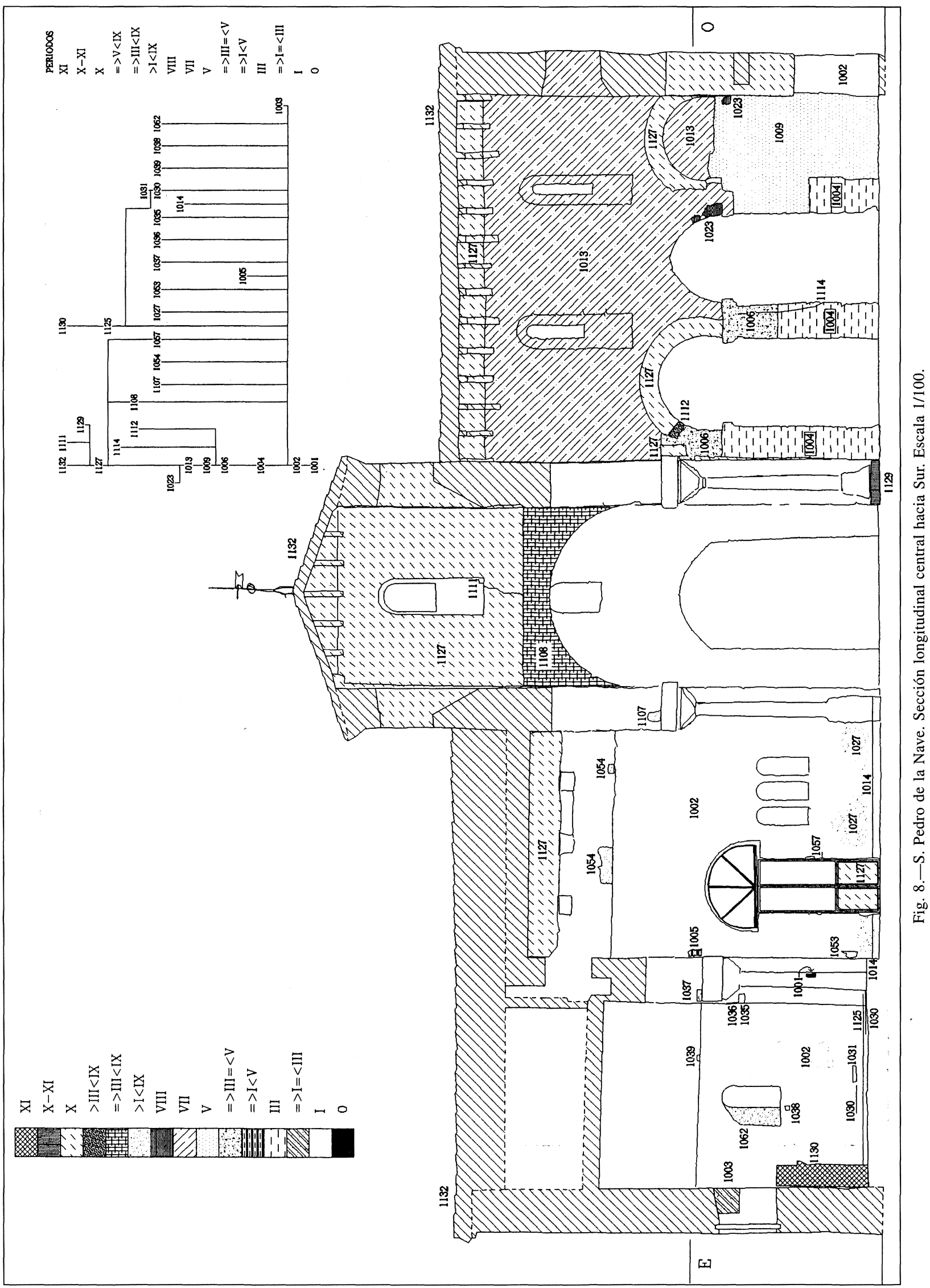




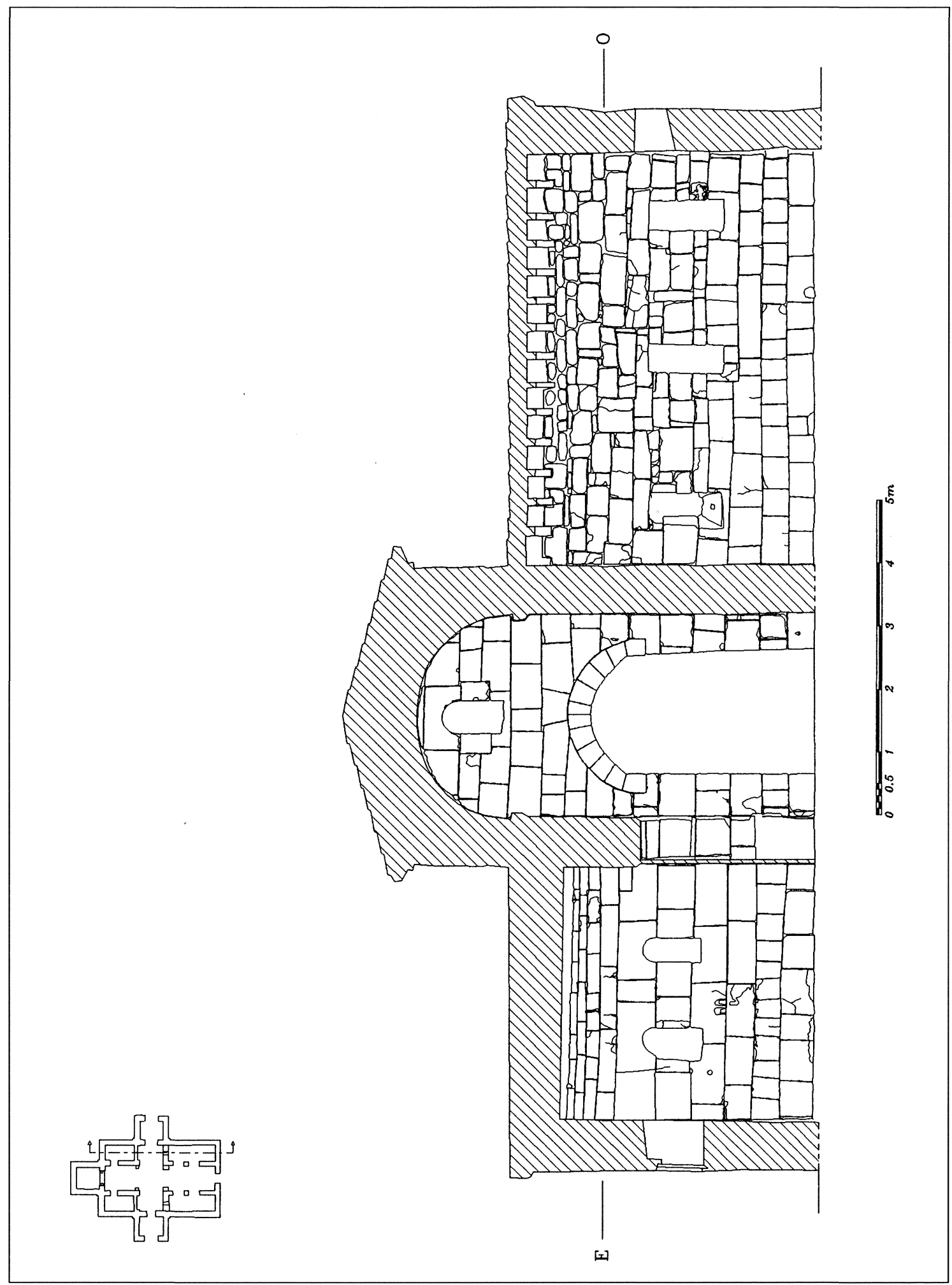



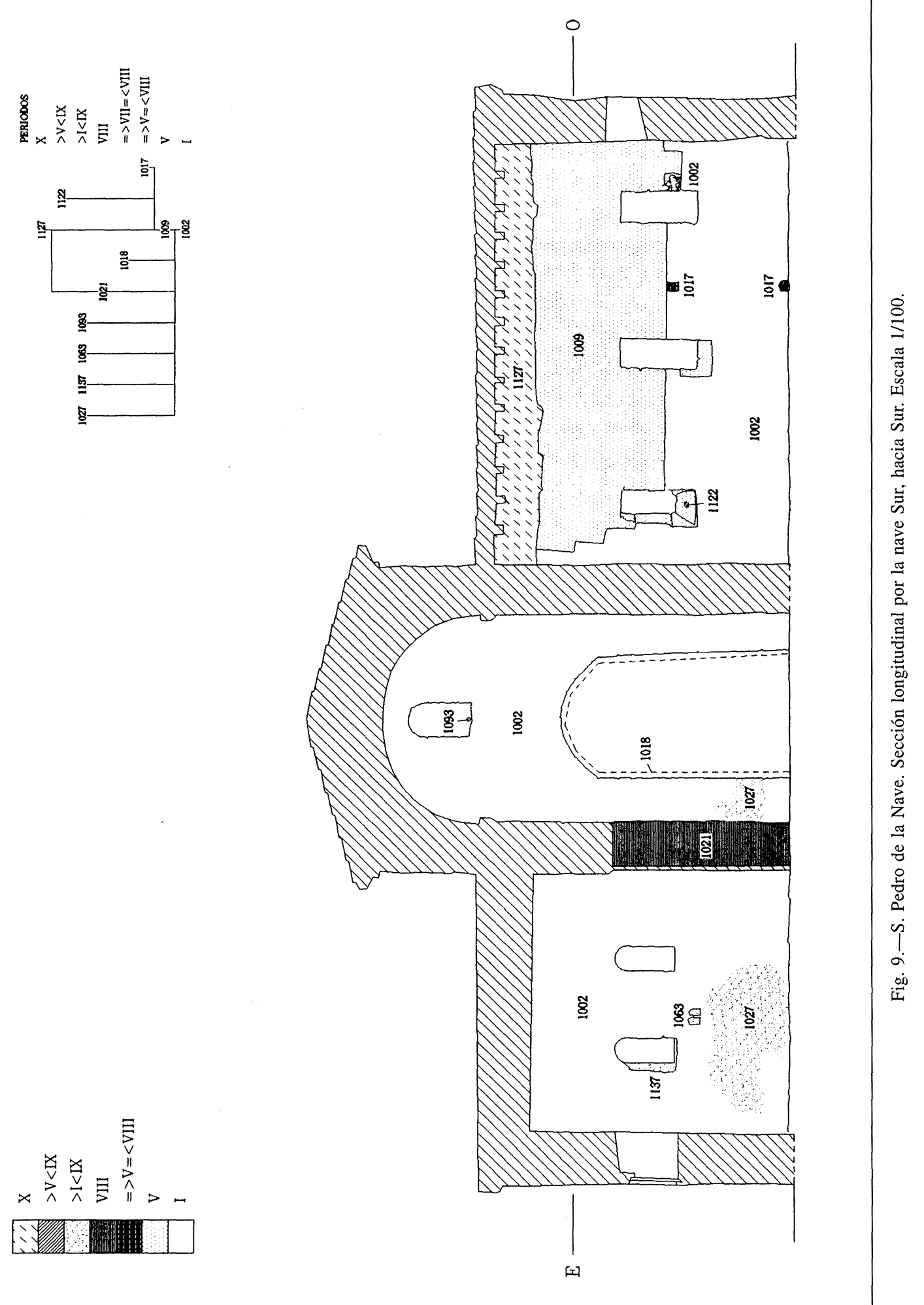


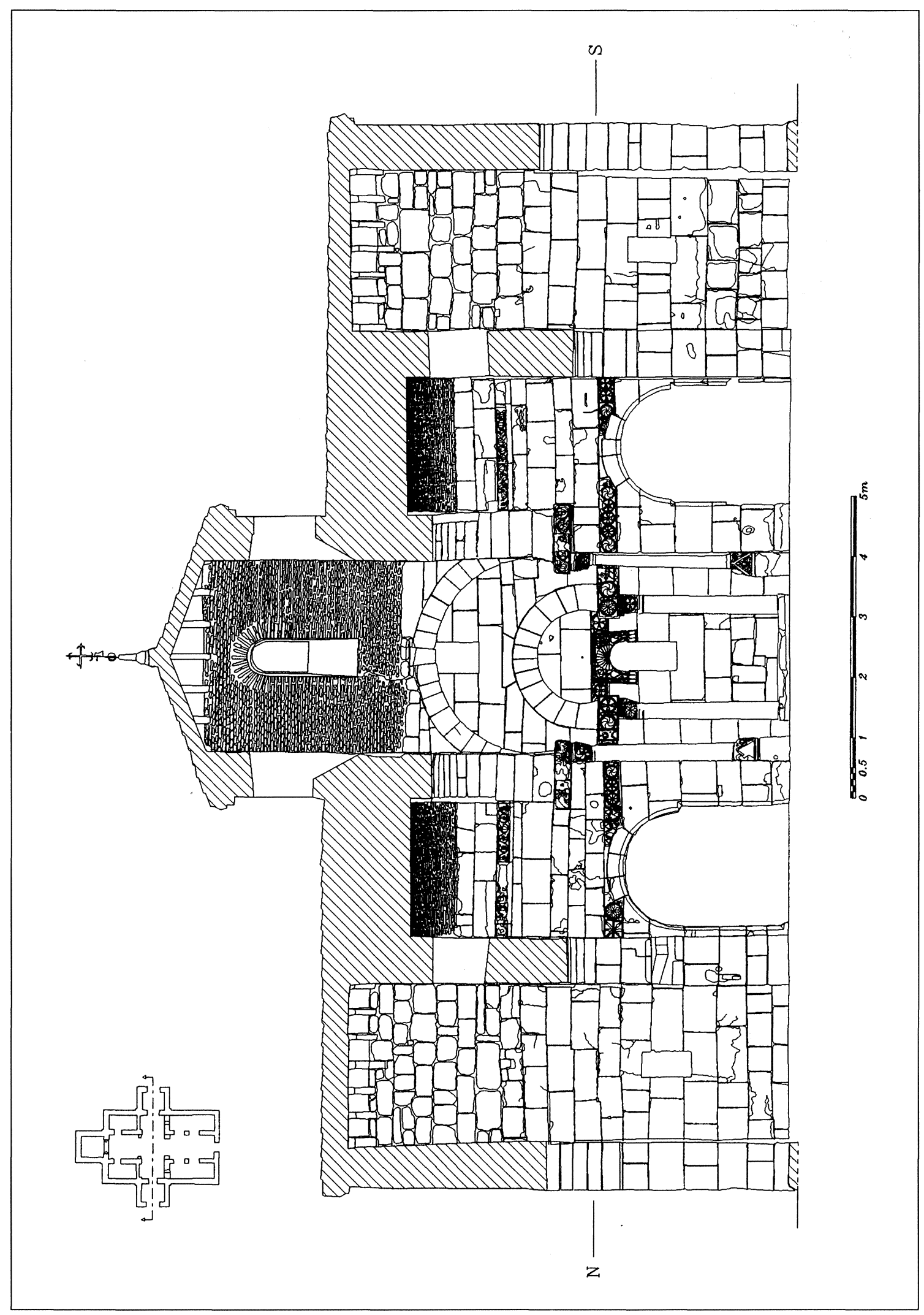




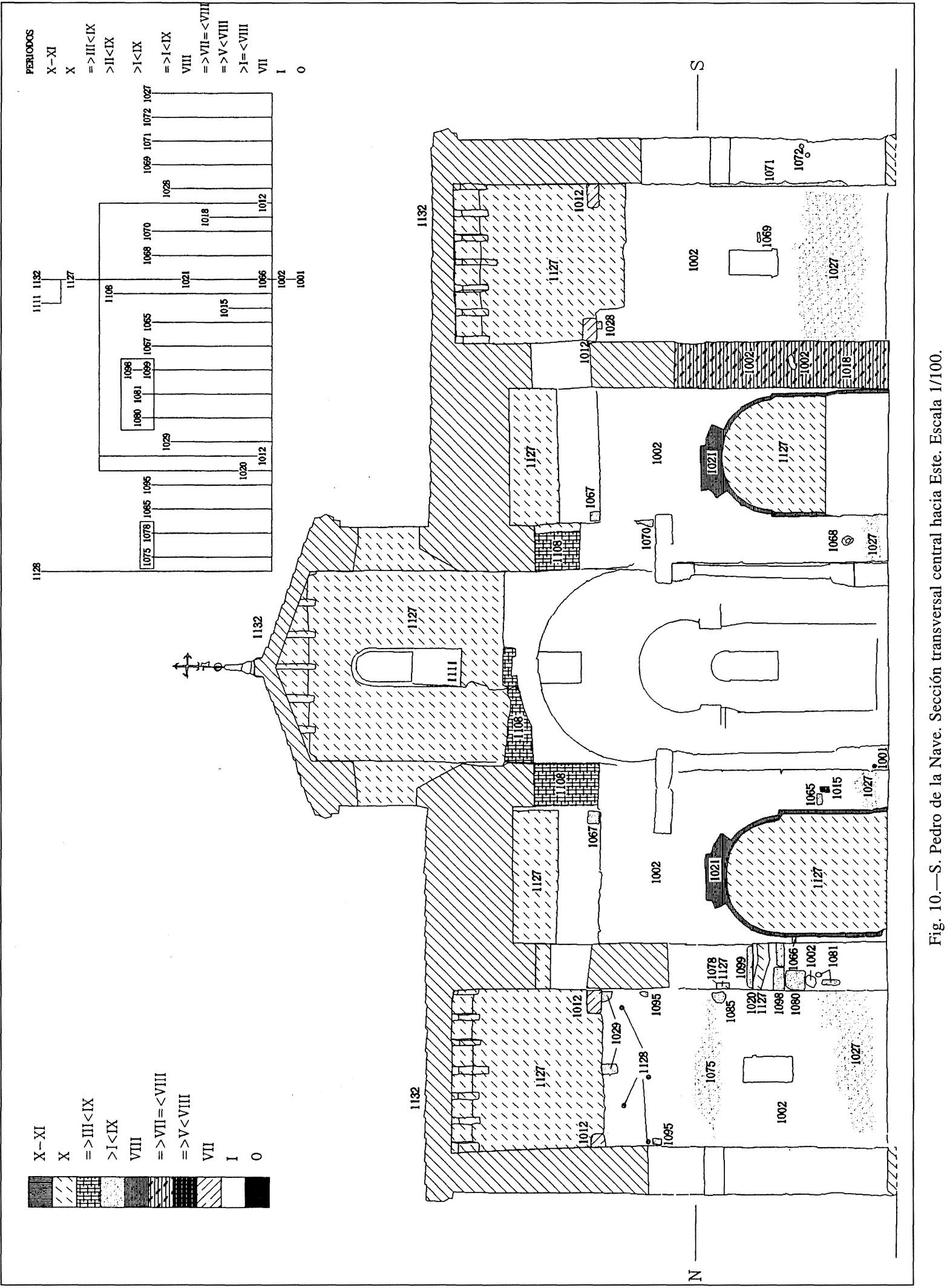




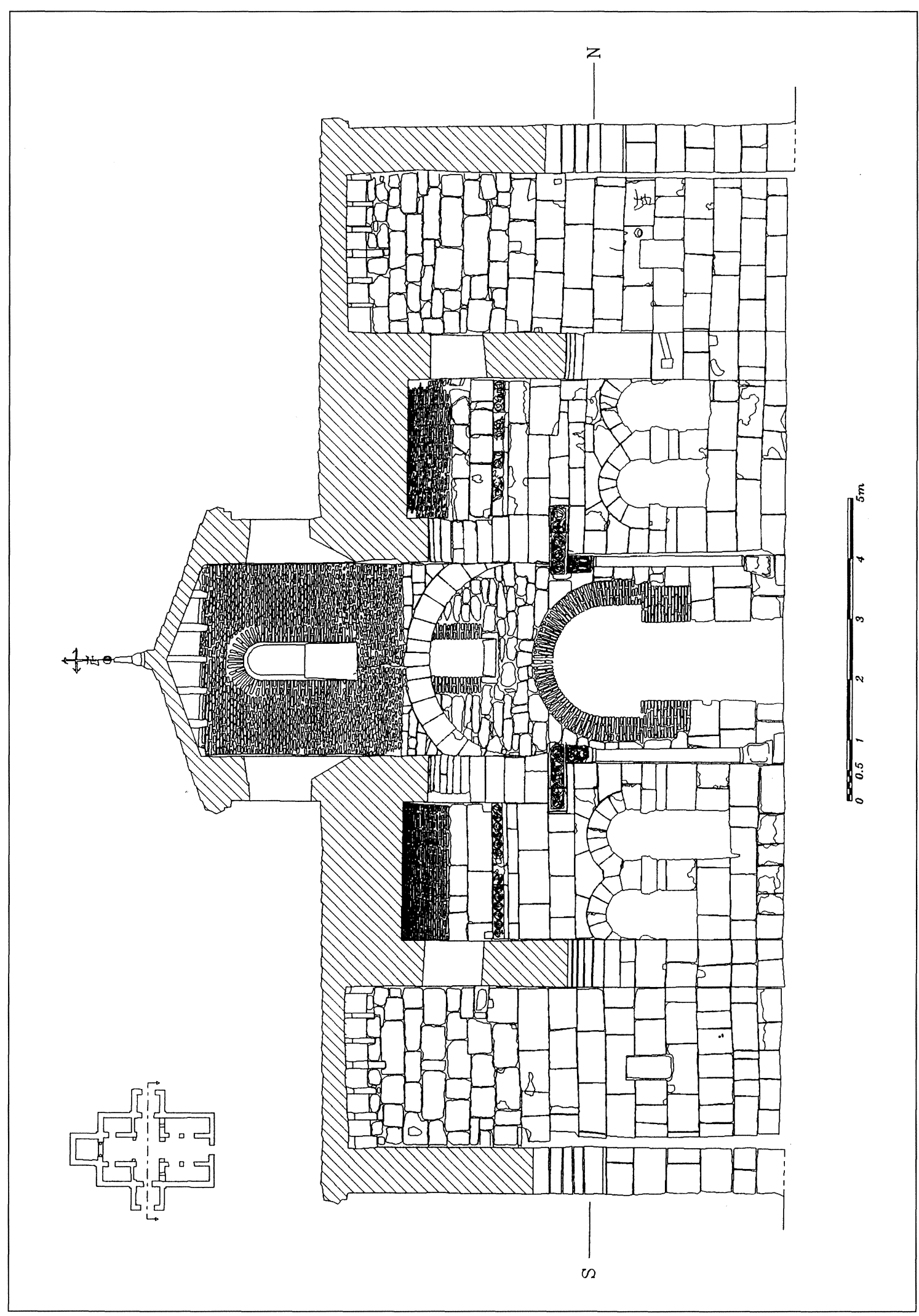




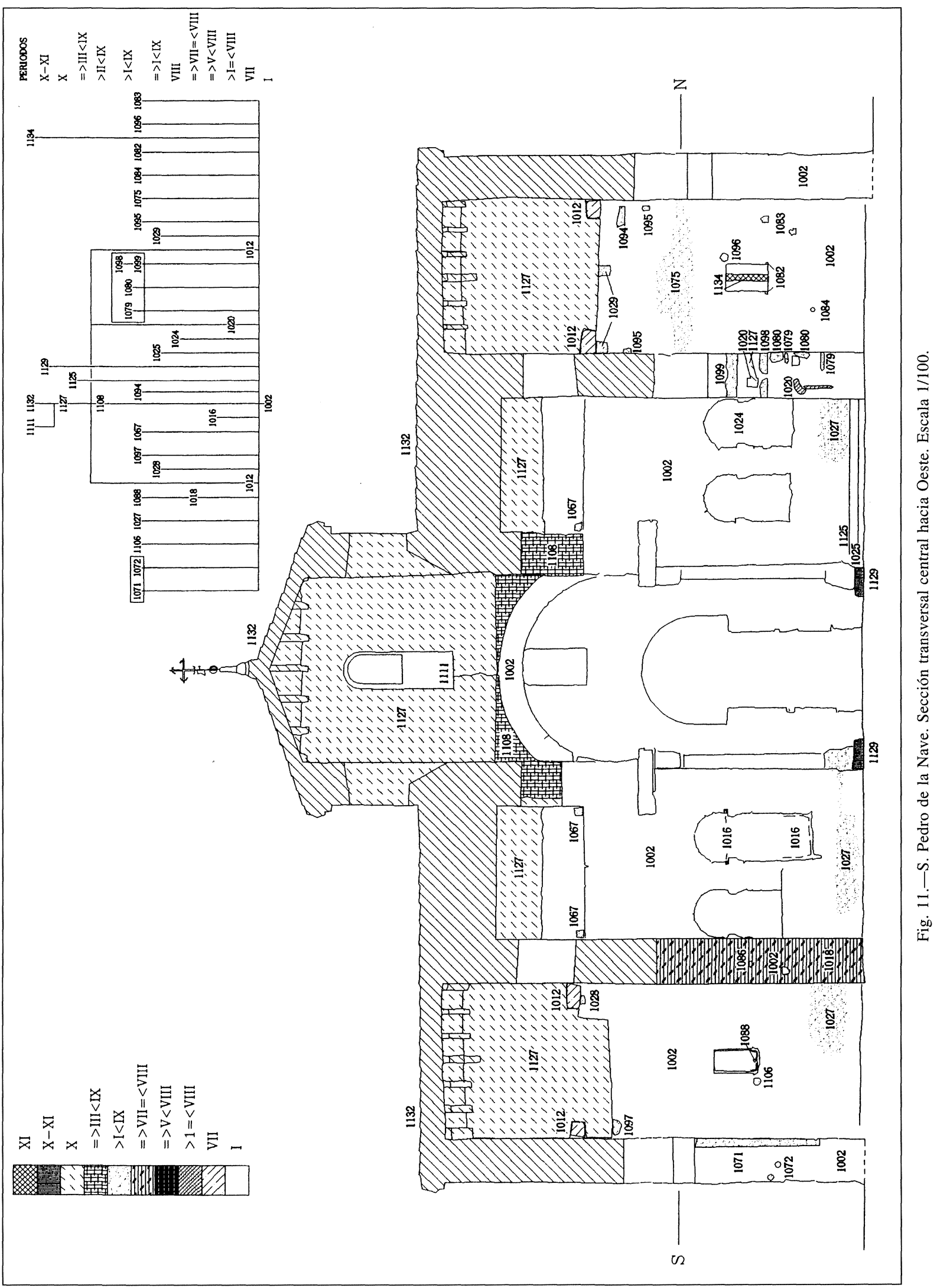


muro se observa que las hiladas de ambos lados coinciden exactamente en altura, incluso con sus sinuosidades, mientras que sólo coincide el despiece lateral de algunos sillares que debemos pensar que, en su mayoría, sean piezas enterizas de atado. Así ocurre con los dinteles monolíticos de las ventanas, algunos tizones e incluso algunos grandes sillares, como por ejemplo el colocado encima de la ventana oriental del ábside. A título de ejemplo, en el alzado oriental (fig. 2) vemos que en el ábside coinciden horizontal y verticalmente seis tizones de la segunda hilada, los sillares que conforman la ventana y los que están encima de ella; en las habitaciones, de nuevo los sillares que conforman la ventana y algún tizón de las hiladas inferiores; y en los porches parece existir un trazado simétrico a uno y otro lado, un tizón en el centro de la hilada inferior, sendos sillares a la altura del alféizar y otros dos en la jamba exterior. Además la mayoría de las dovelas de los arcos son enterizas. Se puede resumir que esta coincidencia, que asegura la existencia de piezas enterizas, aparece en tizones situados en el centro de las hiladas inferiores, en los sillares que conforman ventanas y arcos y en sillares inmediatos, tendiendo a desaparecer por encima de las ventanas.

Según la lista efectuada por Ferrant y documentada por Corzo (p. 52), existían grapas en todas las hiladas excepto en las primera, segunda y $14^{\mathrm{a}}$. La mayoría de ellas no debían llegar a los $40 \mathrm{~cm}$, aunque al menos una doblaba este tamaño llegando a los $70 \mathrm{~cm}$ y grapando tres sillares. La viga de $278 \times 38 \times 30 \mathrm{~cm}$, que apareció encima del arco de triunfo, debió estar colocada en el hueco documentado por Alfonso Jiménez, pues los $38 \mathrm{~cm}$ de altura de la viga vienen a coincidir con su altura y la de la hilada del umbral del hueco de entrada a la habitación sobre el ábside (Torres Balbás: 131; Camps 1940: 607; Gómez Moreno 1966: 128, lám. IX; Corzo: 54 y 84-85, plano XVI sección C, nuestras figs. 7 y 8; Cámara. Hauschild corrige en su plano, calco del de Gómez Moreno, la situación de la larga grapa atando dos en vez de tres sillares en el ángulo SE. del ábside, plano luego utilizado por Corzo).

Otros recursos son los sillares de corte adovelado con función de dintel de descarga encima de los trasdoses de todos los arcos; en las esquinas, la presencia de sillares doblados, de planta en «L» recortados en un sólo sillar; y las hiladas de arranque de las bóvedas de las habitaciones, ligeramente retranqueadas en su línea de imposta, y talladas directamente sobre las dovelas de la puerta y el dintel de la ventana que dan al anteábside para rebajar lo más posible su altura.

Arcos peraltados de arranques retraídos o jambas resaltadas se ubican en las puertas de las habitaciones y en las que dan paso desde los porches al transepto. Debemos considerarlos de descarga de dinteles (Gómez Moreno 1906: 369) si atendemos a la impronta que recorre todo el intradós del arco en la puerta de la habitación S., separándose de su borde algo menos de $5 \mathrm{~cm}$, y que ha de corresponder a la huella de un tímpano perdido y ligeramente remetido respecto al plano del muro. Es muy probable que esta huella fuera la del cierre primitivo, pues cuando la iglesia se desmonta este tímpano estaba vacío y su intradós encalado. En la puerta N. del crucero existen evidencias de que los sillares de imposta tenían forma de «L», como ocurre en las puertas de las habitaciones, de modo que la imposta estaba más alta que en la actualidad. Posteriormente se recortaron bajando la imposta a la hilada inferior.

En relación con las puertas creemos identificar con este período una serie de huecos en las jambas correspondientes al alojamiento de las trancas que inmovilizarían las hojas. Estas cajas son visibles en las puertas, de jamba recta y sin mocheta o telar, entre los porches y el transepto y en la puerta del hastial, igualmente primitiva y que ya existía en el edificio original (también documentadas por Gómez Moreno 1966: 129). Faltan en las de las habitaciones (a pesar de la contradicción de Gómez Moreno, ibíd., posiblemente influenciado por su propia opinión genérica de que los arcos se cerraban con puertas de madera con los quicios alojados en perdidos dinteles) y en las exteriores de los porches que, por lo tanto, en época antigua serían siempre accesibles.

Se conservan un buen número de ventanas en los muros antiguos, si bien han sido retocadas o parcialmente rehechas. Las tres del ábside, las abiertas en los hastiales del transepto para iluminarlo desde los porches cuando el paso entre ambos estaba cerrado y la del hastial del anteábside que sirve de acceso a la habitación sobre el ábside, son de dintel monolítico -y normalmente enterizo, esto es ocupando todo el grueso del muro, con alguna excepción como la ventana S. del ábside-, tallado con arco de medio punto y de jambas rectas, con la única diferencia de que las primeras se cerraban con celosía pétrea colocada durante el proceso de construcción de los muros, alojándose en carriles tallados en los sillares. Los vanos de las seis ventanas exteriores de las habitaciones son rectangulares al exterior y rematadas en medio punto al interior, formando un conoide para aprovechar la luz, cerradas también por celosía colocada en la cara exterior. En el aula existían al menos tres ventanas laterales en forma de tronera y una pareja abocinada en la fachada oeste -sólo documentada parcialmente la N.—, sin que, 
por encontrarse muy retocadas, sea posible conocer cómo se cerraban ${ }^{4}$. Las ventanas de los pórticos eran ajimeces con vano rectangular al interior, igual que las que comunicaban las habitaciones con el anteábside, aunque en este caso son de tres arcos, no monolíticas sino talladas en tres sillares, con el vano interior rectangular y con un banco y sendas repisas. Estas ventanas no tenían cierre.

Quedan por tratar los lucernarios cuadrados de la bóveda del anteábside. No parecen originales debido a su rareza tipológica en edificios altomedievales pero es aún más extraño que Ferrant se los inventara, por lo que se debe pensar que pertenecen a una restauración moderna.

El corte practicado en el intradós de la ventana $E$. del ábside, por su cuidado y limpieza —en contraste con la rudeza de los hechos en las ventanas N. y S.-, hace pensar en su posible antigüedad, aunque no se puede justificar su adscripción efectiva a este período. No se puede aceptar la idea propuesta por Cruz y Cerrillo (p. $199^{5}$ ) de la existencia aquí de una placa-nicho, ni la de Morín y Barroso (p. 72) de que posteriormente sería cortada para realizar la ventana actual. Es cierto que se rebajó parte del arco y de su decoración (fig. 12), pero allí no pudo existir una placa nicho porque sólo está cortada la parte semicircular superior, no todo el vano que es lo que daría la forma de placa; porque el rebaje no llega a todo el ancho de la ventana, acusando un ligero abocinado cuando el resto de la ventana es recta; por existir, ccmo en las demás ventanas, una carrilera para celosía, indudablemente original, lo que sería ilógico sin ventana; y porque su tipología coincide con la de las otras dos ventanas, abiertas en un sillar monolítico y definidas por un arco, lo que está a favor de que el esquema fuera similar. Tampoco debemos dejarnos confundir por la aparente semejanza de la venera decorando la parte alta del alfiz con los remates de las placas nicho, ya que en ninguna de éstas aparece bajo la venera otro arco como sería el caso aquí. Por lo tanto parece que simplemente se rebajó la decoración, por encima del friso de arquillos u hojas estilizadas. La decoración perdida parece que era simétrica a cada lado, formada por dos pequeñitos arcos como los que aparecen en el friso de hojas estilizadas de su base, con dos puntos encima y el resto hasta la clave liso. Se puede

${ }^{4}$ Se conservan cuatro dinteles tallados para ventanas abocinadas que pudieron pertenecer a estas ventanas del aula, con aberturas de 20, 23, 36 y $40 \mathrm{~cm}$. Corzo: 137.

5 Puede que quieran referirse a su significado más que a su forma, aunque no es esto lo que se deduce exactamente de su texto: la pieza encajada en el fondo de la cabecera de $S$. Pedro de la Nave es una más de la serie de las placas-nicho. aventurar que se decidiera ampliar la ventana por no seguir la decoración un esquema adecuado.

Las ventanas tríforas de las habitaciones presentan en sus alféizares unas cajas, rectangulares alargadas en la dirección del muro, algo retranqueadas respecto a la línea del muro, de $13 \times 8,5 \mathrm{~cm}$ (representadas en nuestra planta, fig. 1). Las huellas de la ventana $\mathrm{N}$. se diferencian de la $\mathrm{S}$. en que apenas se observan al estar rebajada la superficie del alféizar, rebaje que tiene que pertenecer a la etapa constructiva de la iglesia, dado que coincide con las jambas de la ventana, de modo que la altura del escalón en el alféizar N. es justamente la altura que tienen las cajas en la ventana S. De ser así, las cajas visibles son previas a la ventana definitiva y coetáneas a la construcción del edificio. Además las parejas de columnitas de las dos ventanas tienen su propia caja, dado que debieron tallarse sobredimensionadas y ajustarse luego al tamaño real de la ventana encajándolas en los alféizares. ¿A qué pudieron deberse? Por su cercanía a las de las actuales columnitas se puede pensar que sirvieran para una ventana de forma distinta a la actual pero de similar ubicación. Es imposible una ventana de tres vanos iguales, pues cada vano tendría algo más de $70 \mathrm{~cm}$ y en total la ventana resultante sería el doble de la actual, de cerca de 2,40 m de longitud, llegando por el $\mathrm{E}_{\text {; }}$ hasta la jamba de la puerta y por el O. rebasando la esquina de la habitación. Otra solución es la de una ventana con arco central mayor y laterales más pequeños, sólo algo mayor que la actual lo que recuerda soluciones asturianas como las de Santullano y San Tirso de Oviedo ${ }^{6}$. En cualquier caso esta propuesta es una hipótesis sin posible demostración y tiene en contra la planta rectangular de las cajas - que para columnillas se esperarían cuadradas-, de las que no conocemos paralelo.

A esta fase corresponde igualmente la puesta en obra de todo el aparato escultórico del edificio, el cual, cuando fue necesario, sacrificó parte de su integridad con el fin de ajustarse a la construcción, tal como podemos observar en las fotografías del tras-

${ }^{6}$ Las ventanas actuales recuerdan a su vez otras asturianas, como la principal del ábside de Valdediós, trífora exteriormente y adintelada y recuadrada en su interior, y la ventana de la cámara sobre el ábside de Santullano (Arias 1995: 49,219 y 230). Las ventanas con alféizar rebajado en la cara superior de la hilada de base, columnitas monolíticas de altura equivalente a la hilada intermedia y arcos recortados en los sillares de una tercera hilada son similares a los arquillos ciegos de los frisos que decoran los alminares cordobeses de la gran mezquita (946 d.C.) y de S. Juan de los Caballeros (fines del IX, inicios del X) y a los de las iglesias de S. Fructuoso de Montelios (considerada visigoda con dudas) y $\mathrm{S}$. Pedro de Lourosa (considerada mozárabe del 912; Hernández: figs. 7, 8, 23 y 24 y láms. XXXVIII y XXXIX). 

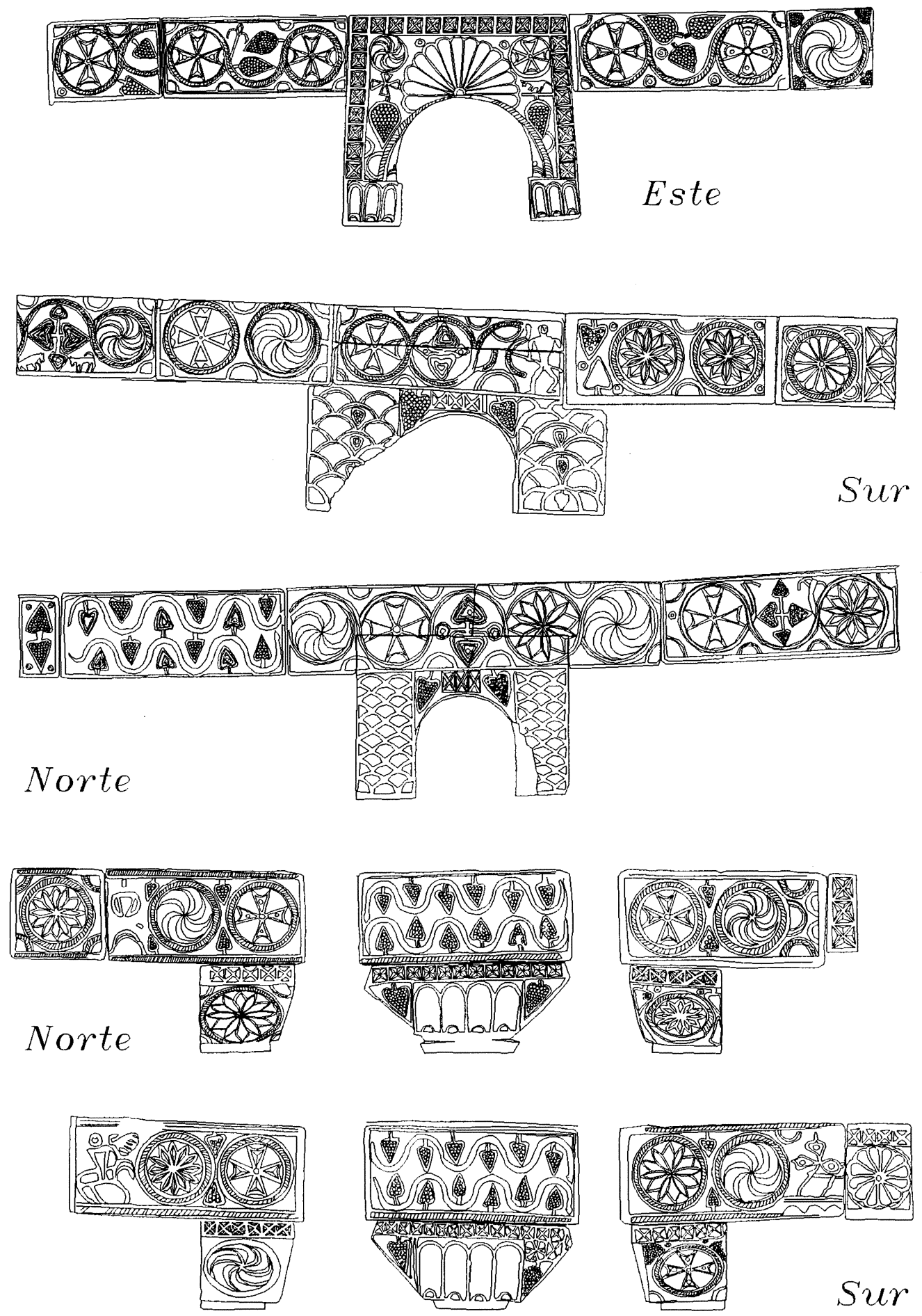

\section{Abside}

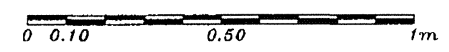

Fig. 12.-S. Pedro de la Nave. Decoración del ábside. Escala 1/25 

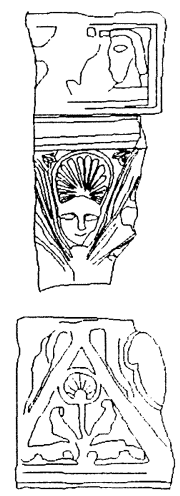
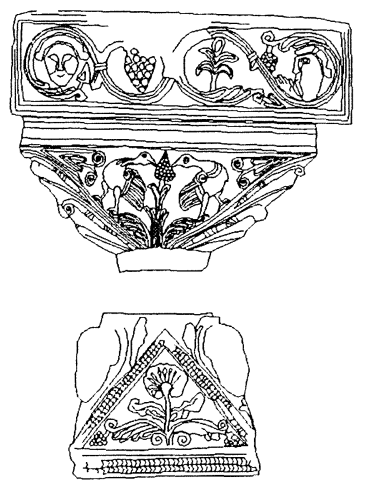
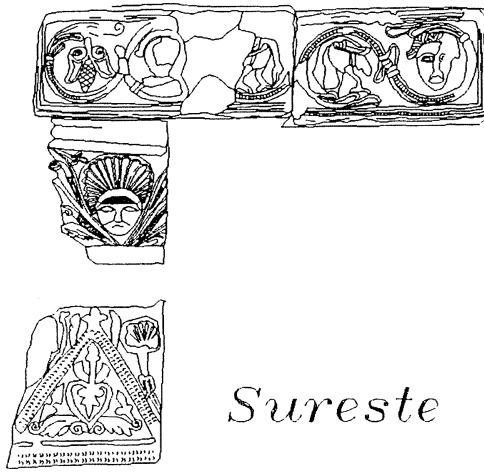

Sureste
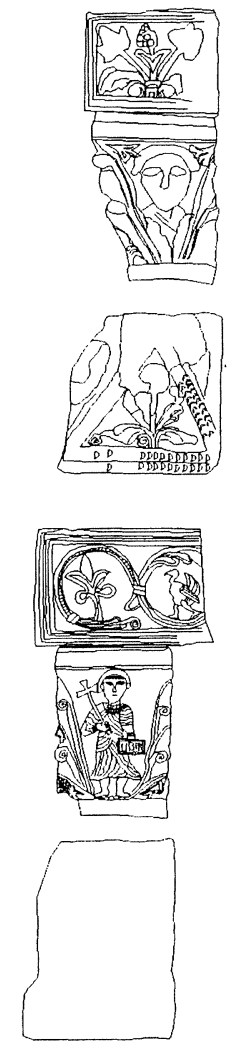

Suroeste
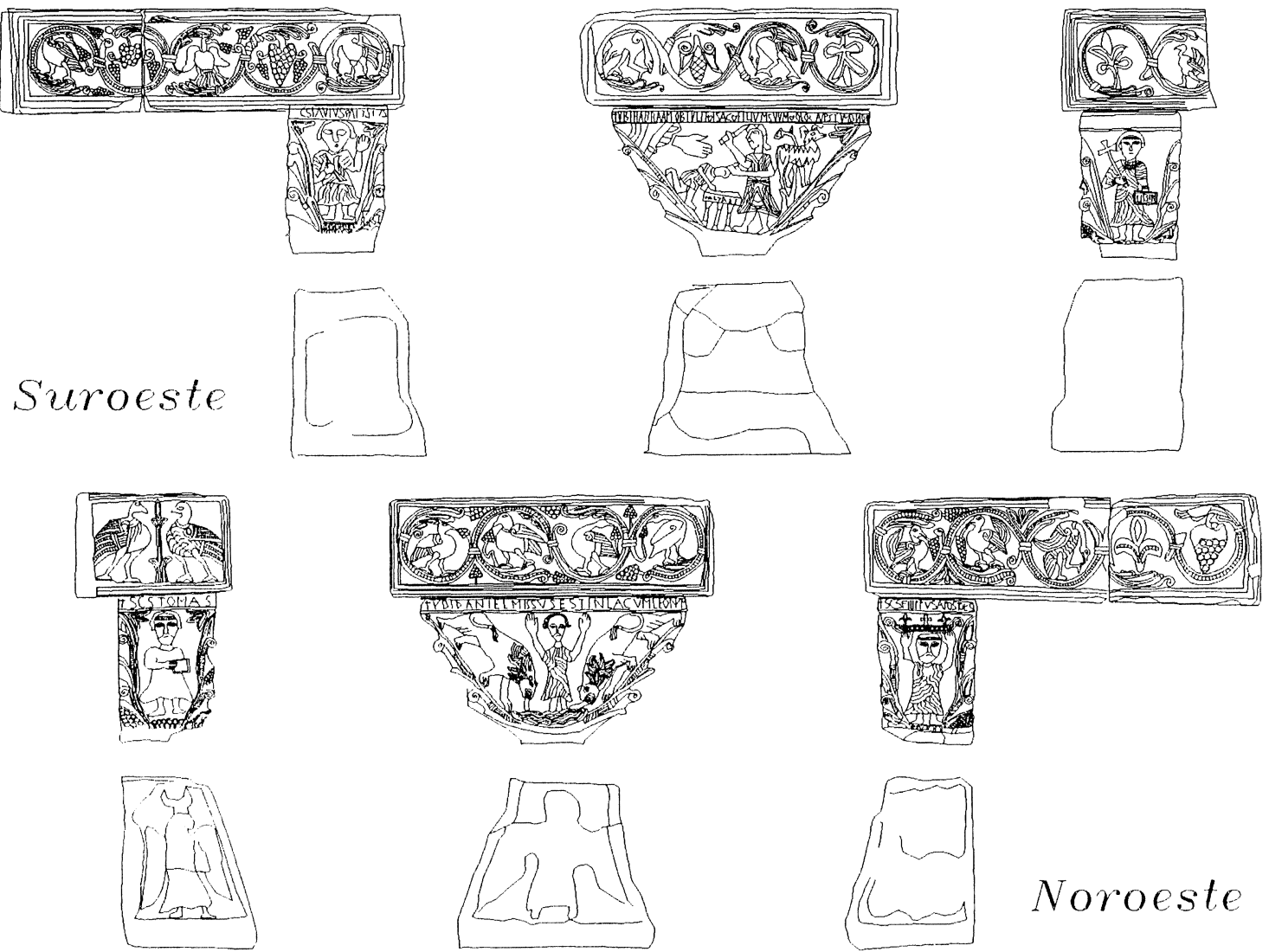

Noroeste
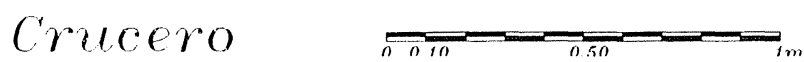

Fig. 13. - S. Pedro de la Nave. Decoración de las columnas del crucero. Escala 1/25. 
lado, donde la pieza más oriental del friso que recorre el muro $\mathrm{S}$. del ábside ocultaba parte de su decoración por el encuentro con el muro de cierre de la cabecera (Corzo: fig. 119). Lo mismo debió ocurrir, como veremos, en las caras de las impostas del crucero que dan a las arquerías del aula. De hecho se comprueba que todos los sillares decorados del primer maestro no continúan su dibujo unos en otros, sino que son independientes entre sí (fig. 12-3). Sólo en las ventanas N. y S. del ábside comparten decoración tres y dos sillares respectivamente. Las impostas de las naves sobre las que arrancan las bóvedas están talladas a medida, de modo que se componen de una parte recta que continúa la cara del muro y que varía en altura y de una media caña y el friso, de altura constante. Ciertas partes de la decoración del segundo maestro están inacabadas, así la cornisa SE. del transepto y las caras O. del cimacio NE. del crucero. En el primer caso la decoración queda interrumpida en su extremo derecho, presentando la pieza contigua su superficie lisa, a la espera de ser decorada (Corzo: fig. 133, nuestras figs. 10 y 13). En los cimacios queda lisa, sin decorar, la zona a la izquierda de los pájaros afrontados (Caballero 1990: foto 10, con la ubicación equivocada, y nuestras figs. 10 y 14). Esta parte final de los sillares probablemente debía ser rebajada al plano del paramento, como se observa en el cimacio NO., lo que no llegó a realizarse.

El sillar en el que está inscrito el horologio es indudable que fue puesto allí en esta fase constructiva. La apariencia inconclusa de la inscripción, normalmente aceptada (Navascués: 64, someramente escrita), o la de reutilizada, defendida por Puig i Cadafalch (p. 133), no es en realidad tal sino más bien el desgaste producido por un roce no deliberado ni abrasivo, de ahí lo terso de su superficie (Caballero 1995: 409 a medio borrar), producido por la acción de descorrer la cortina que cerraba el arco de triunfo y que colgaba de una trabe acomodada en dos cajas colocadas en los muros laterales del anteábside, en su parte más próxima a su encuentro con el testero, encima del friso decorado. Es posible que esta cortina pertenezca a la primera etapa de la iglesia, pero no existe una evidencia definitiva. Observemos también que, excepto estos huecos y otros similares que veremos más adelante, no ha llegado a nosotros ninguna huella para alojar canceles o cierres.

PERÍODO II. PRIMERA RUINA. El edificio, quizás recién terminado (Torres Balbás: 131), sufrió una fuerte ruina, por un impropio abovedamiento, de modo que su aula, desde el crucero hasta el has- tial, colapsó de forma violenta. La inclinación del muro oeste del transepto tuvo que abrir los arcos $\mathrm{N}$. y S. del cimborrio y provocar el hundimiento de sus bóvedas. La última en hundirse fue la del anteábside, en 1895 según documenta Gómez Moreno (1906: 368), aunque pudo ser, con mucha seguridad, una restauración anterior. $\mathrm{Si}$ a ello unimos que la reparación de los arcos no presenta las mismas características técnicas que aquellas reconstrucciones que sí sabemos con certeza fueron llevadas a cabo tras el desastre en las arquerías de la nave central, podemos asegurar que, mientras que el grueso de la ruina del aula y, posiblemente, del cimborrio debió sobrevenir en este momento, las demás se prolongaron en el tiempo.

\section{PERÍODO III. RESTAURACIÓN ALTOMEDIE-} VAL. LAS ARQUERÍAS DEL AULA (A 1004; figs.7 y 8). En el período I no se trató la estructura del aula, por tener mejor acomodo en la discusión de este período. Tras la ruina se acometieron los trabajos de reconstrucción de las partes dañadas, entre las cuales se encuentra con toda certeza la zona más baja de las arquerías de la nave central. La técnica empleada para reparar los pilares, en cuanto al asiento y aparejo de sus sillares, es en todo idéntica a la utilizada en el período I. Este dato obligó a pensar si no serían en realidad restos supervivientes del colapso del período I. El argumento que invalida en parte esta idea vino de la observación de los pilares más orientales que están en contacto con el crucero. Cuando Ferrant «enderezó» la iglesia, notoriamente deformada en este lugar, volviendo los sillares a su lugar de forma exacta (Camps 1940: 598-9), tuvo que introducir una cuña de relleno, lo que indica a las claras que el pilar se adosó a un muro inclinado, para lo cual se precisó cortar con la misma inclinación la cara de los sillares adosados al crucero (Corzo: 189). Al recuperar su perfecta perpendicularidad el muro del crucero se creó el hueco rellenado por el arquitecto. En principio este argumento no es decisivo ya que podría haberse dado la circunstancia de que algunas partes de los pilares no se arruinaran quedando en el mismo lugar anterior al movimiento, con la salvedad del pilar más cercano al crucero, el cual sería reajustado mediante el pertinente recorte de los sillares. Por lo tanto, la lectura estratigráfica y la observación sobre el modo constructivo aseguran que las partes inferiores de las tres pilastras de las dos arquerías, incluyendo siempre como mínimo los dos primeros sillares a partir del suelo, pertenecieron, sin duda, a este período III y pudieron pertenecer al período I, aunque de ello no tenemos absoluta seguridad. Discutimos 


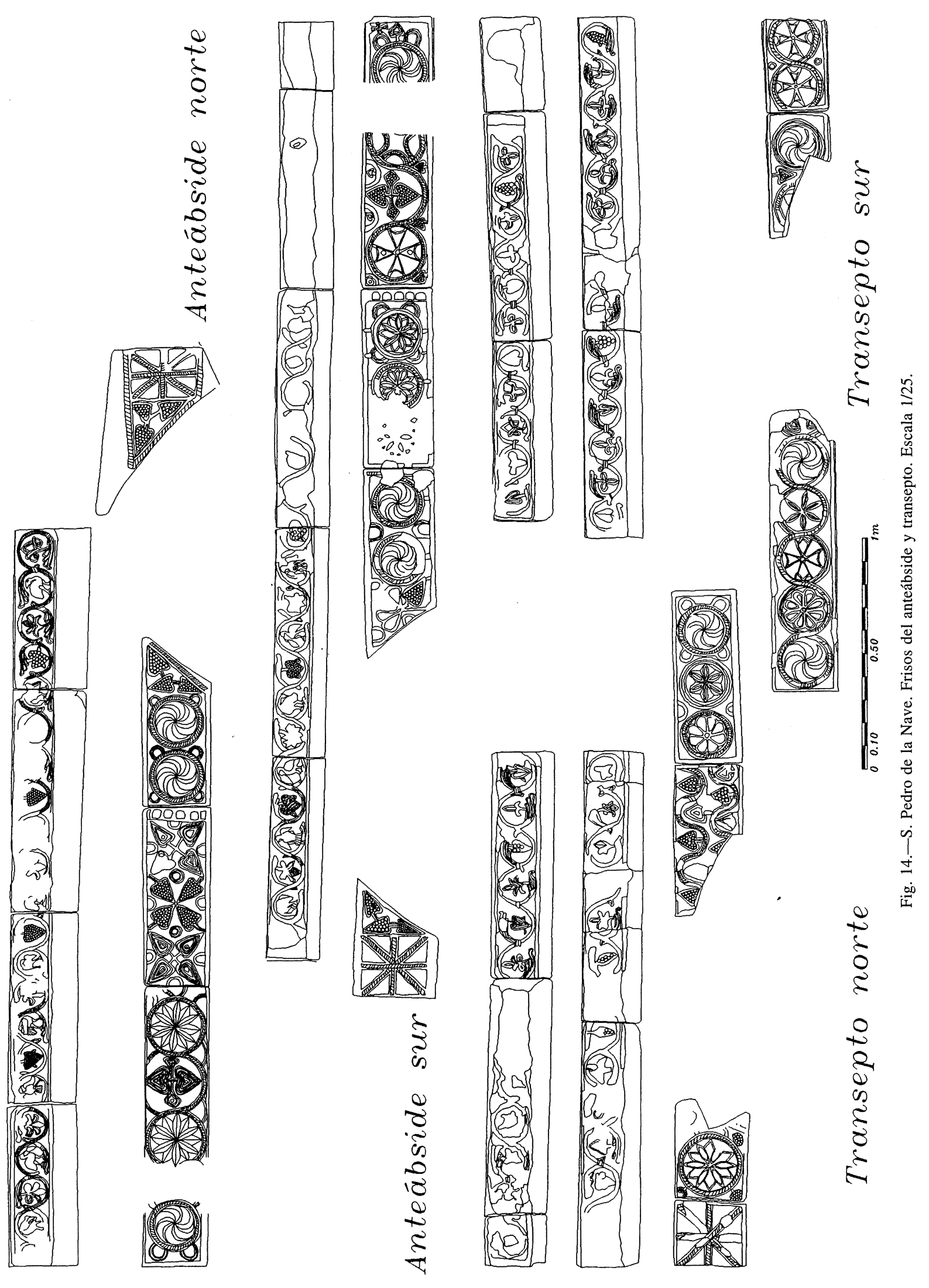


a continuación los datos que nos informan sobre el grado de seguridad y la forma que pudieron tener las arcadas en los períodos I y III.

Partimos de la idea de que en el período I el aula estaba organizada en tres naves, sin que tengamos la seguridad de que su separación se hiciera por arquerías corridas que soportaban bóvedas, aunque es probable que así fueran ambas cosas, la primera por la utilización en este período de arcadas y la segunda por el tipo de ruina producida previamente, como veremos más adelante. Tras el colapso del sistema arquitectónico - fuera como decimos o diferente-, la reforma organizó el espacio de separación de naves mediante arquerías sobre pilastras, que posiblemente soportarían ya cubierta de madera, cuyo ritmo de intercolumnio ha perdurado hasta nuestros días, aunque restauradas en épocas posteriores. Se organizan con tres arcos de 1,6 m de luz apoyados en pilares de $0,6 \mathrm{~m}$ de ancho, a excepción del occidental que, aunque perdido absolutamente - recreado por Ferrant-, tuvo que arrancar del muro de hastial dada la situación conservada de la tercera pilastra. Por lo tanto, la discusión se centra en comprobar hasta qué punto esta organización mantiene elementos pertenecientes al esquema primitivo o hasta qué punto se separó de él ensayando una nueva fórmula. El análisis se centra en dos puntos: cómo arrancaba la arquería en cada uno de sus extremos.

En el extremo oriental hay que descartar la posibilidad de que el arco partiese del cimacio-imposta del crucero (como propone Corzo: pl. XXX y admite Caballero 1995: 392), debiéndose aceptar que había de arrancar de una pilastra o semipilastra adosada al muro del transepto por las siguientes razones: es imposible colocar el salmer y las primeras dovelas del primer arco de la arcada en el lugar y con la forma de las del arco de la nave central, del que conocemos la forma del salmer por la foto del momento del desmonte, de planta trapezoidal con el lado oblicuo para adosarse a inglete ${ }^{7}$ a la pieza correspondiente al arco del transepto (Corzo: fig. 57); las caras O. de los cimacios están decoradas sólo parcialmente a sabiendas de que lo tallado quedaría oculto por el muro o la arquería que separara las naves (Corzo: fig. 71); y la pilastra, obligada por las razones dadas, había de adosarse pues sabemos que el paramento occidental del muro que cierra la nave es liso y que en él no podía enjarjar dada la situa-

${ }^{7}$ Llaman la atención dos piezas, consideradas por Corzo (p. 134) de tipo visigodo clásico, decoradas con círculos secantes y cortadas a inglete, aunque nada pone en relación su corte, que debemos suponer de reutilización, con el de las dovelas de los arcos. ción de la ventana. En consecuencia, si existía arco tenía que apoyarse en una pilastra adosada al muro del transepto tal como lo hace hoy, al margen de la altura a la que tuviera la línea de imposta. En el extremo occidental se plantea un problema semejante, si el último arco descargaba sobre el muro, directamente o a través de una ménsula entrega, o si lo hacía sobre una pilastra. La identificación de un cajeado en el paramento original de este hastial - perfectamente realizado, incluso con cajas que salen de su línea para sillares doblados, rellenas con piezas colocadas por Ferrant-y luego ocupado por un muro posterior al momento al que nos estamos refiriendo (A 1009), aboga por una pilastra perdida. De ser así - aceptando la existencia de arcadas-, la solución primitiva tendría pilastras o semipilastras a cada lado y por lo tanto un ritmo distinto del actual, de modo que la restauración del período III estuvo obligada a moverlas de su lugar en una distancia equivalente a medio o un cuarto de pilastra.

Esta solución debe corregirse con la observación que se puede hacer a partir de las ventanas laterales (Corzo: 105). Según el ritmo de sus ejes y repartiendo el espacio entre ellos con el pie forzado de los $0,6 \mathrm{~m}$ de ancho de las pilastras, resultan vanos de $1,70 \mathrm{~m}$-en vez de los actuales 1,60 - y pilastrillas laterales de $0,15 \mathrm{~m}$. Una pilastrilla de esta salida es inaceptable por demasiado estrecha para adosarla en el lado E. y habría que pensar que el ritmo de las arcadas no se sometía exactamente al de las ventanas, prorrateando al menos $0,15 \mathrm{~m}$ más para el ancho de la semipilastra de arranque.

Más allá de la organización de las arquerías no quedan otros restos pertenecientes a esta fase, abriéndose la incógnita de la forma en que fueron reparados los muros y cubiertas. Con relación a estas últimas, la ruina producida y el movimiento del transepto fue tan profundo que no es lógico que se volvieran a reconstruir las hipotéticas bóvedas en el aula, por lo que se puede asegurar que se colocaron armaduras de madera. No es extraño que la ruina del aula volviera a reproducirse a pesar de que la cubierta ya no fuera abovedada, pues, dada la inclinación de su muro O., el transepto siguió moviéndose como demuestra la posterior restauración de sus $\operatorname{arcos}$ N. y $\mathrm{S}$.

La parte superior de las pilastras (A 1006) podría pertenecer a esta misma fase aunque las hemos diferenciado de la parte inferior (A 1004) por ligeras diferencias técnicas.

Frente a la abundante decoración de la cabecera y crucero de la iglesia, esta parte no conserva ningún resto de escultura decorativa in situ. Esta ausencia es llamativa pero no existen argumentos defini- 

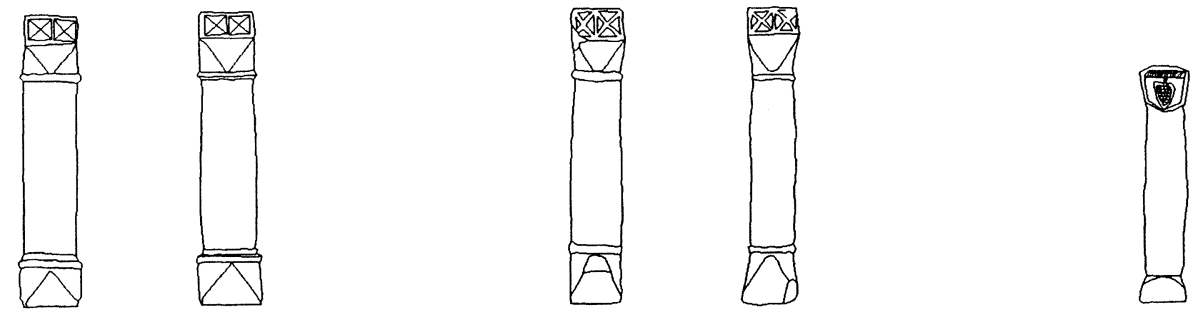

Anteábside norte Anteábside sur Crucero norte
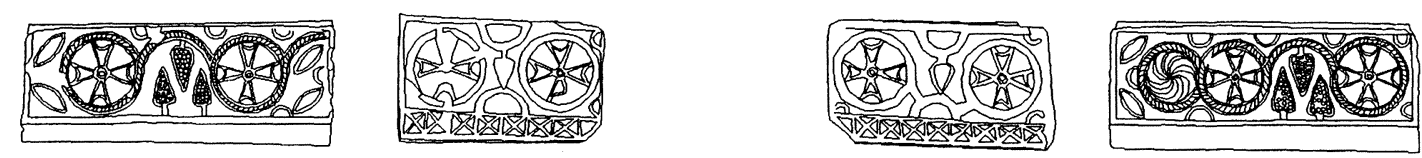

\section{Porche norte}
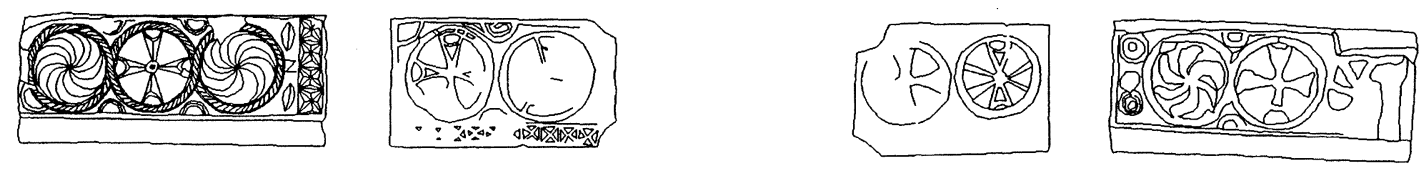

\section{Porche sur}
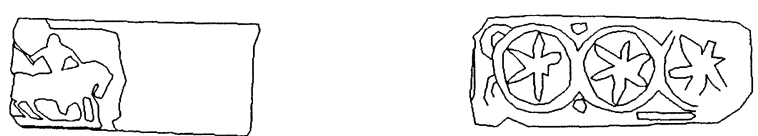

$$
\text { Piezas reutilizadas }
$$
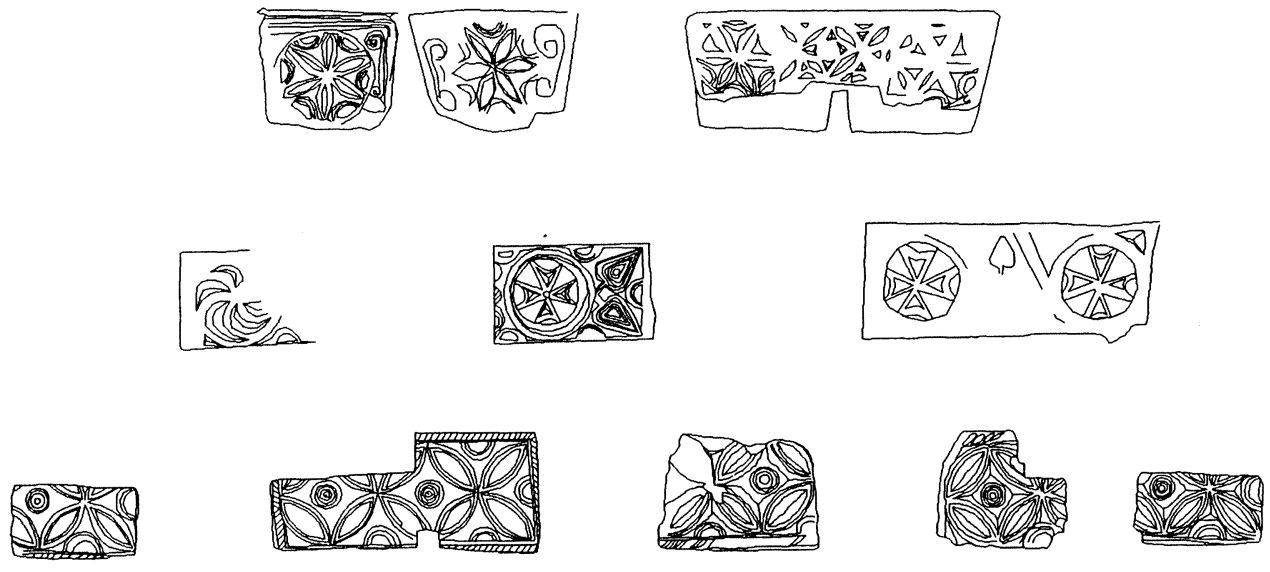

$$
\text { Piezas sueltas }
$$

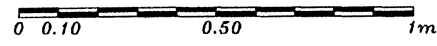

Fig. 15.-S. Pedro de la Nave. Decoración de las ventanas del anteábside, del porche y piezas sueltas. Escala 1/25. 
tivos que la contradigan. Los restos decorativos descontextualizados (Corzo: figs. 159-161) no solucionan esta ausencia.

PERÍODO IV. SEGUNDA RUINA. Una nueva solución de continuidad da constancia de otra ruina violenta que abate de nuevo buena parte del área basilical, siguiendo una pauta idéntica a la de la anterior. Las pilastras oriental y central de ambas arquerías quedaron enteras - aunque no debemos olvidar que la A 1006 pudo pertenecer o no al período anterior - mientras que de la occidental sólo las dos primeras hiladas. Los arcos central y occidental se arruinaron totalmente y el oriental conservó únicamente el salmer y la primera dovela orientales (figs. 7 y 8). En cuanto a los muros laterales y de hastial las ruinas son escalonadas, con más hiladas arrasadas hacia los pies. También se evidencia otra ruina que afecta a los muros exteriores de la habitación N. y que hemos incluido por economía en este período, aunque nada demuestre ninguna relación entre ambos desastres (figs. 2 y 5). Mientras que en el primer caso la explicación es fácil encontrarla en la precariedad de las estructuras de esa zona desde que tuvo lugar la primera gran ruina, en el segundo caso no ha sido posible hallar una respuesta plausible, más aún si tenemos en cuenta que en el interior de la habitación no aparece ninguna huella de colapso en la bóveda.

PERÍODO V. RESTAURACIÓN DE ÉPOCA PLENO/MEDIEVAL (figs. 3 a 9). Las reparaciones (A 1009) subsiguientes a la ruina, para la nave central y muros de las naves laterales, tuvieron como consecuencia un cambio en la fisonomía del espacio. Reutilizando sillería anterior, a veces sin retocar y otras cortándola, se aparejan paramentos de hiladas muy irregulares y poco precisas en el ensamble de las juntas. Aparecen numerosos y marcados codos. De las arquerías de separación de naves sólo se restauraron los arcos centrales, de los que sólo han llegado a nosotros los salmeres y primera dovela del N., y se reforzaron, también con sillares, los vanos laterales macizándolos para evitar las continuas ruinas, quedando únicamente practicable el vano central, que se cerró -en éste u otro período posterior-con puertas de madera en la arquería $S$. (A 1114, fig. 8). De esta forma se independizaron las naves laterales, quedando como nuevas habitaciones con una nueva funcionalidad, por ejemplo funeraria a la vista del sarcófago de la nave N. El macizado de los arcos orientales fue eliminado por Ferrant ya que simplemente se adosaba a las pilastras contiguas sin llegar a integrarlas en su estructu- ra, algo que no ocurre en el macizado occidental, donde la parte baja del pilar antiguo queda subsumida en la nueva construcción. Gómez Moreno confundió la hilada inferior de este refuerzo en el arco del E. con los muros originales, como lo representa en sus dibujos (Gómez Moreno 1906: fig. en p. 366) y así aparece en una maqueta hoy desaparecida $(\mathrm{Ca}-$ ballero 1990: foto 1).

Los muros de las naves laterales, como decíamos, también son reparados con la misma técnica constructiva. Las partes rehechas unen perfectamente unas con otras, tan sólo separadas por la actual puerta remodelada en la restauración, la cual habría sido seguramente también cegada en este período. Las ventanas originales abiertas en estos muros, tres a cada lado, a pesar de estar perdidas en mayor o menor medida, siguieron ocupando el mismo lugar y teniendo similares dimensiones que las antiguas. Con la misma técnica y material se reconstruyeron los muros de la habitación $\mathrm{N}$.

El elemento que nos sirve para encuadrar de un modo relativo y muy genérico esta fase son unos canecillos de época románica (A 1011, fig. 3) integrados - más bien reaprovechados-en un momento posterior (período VII).

PERÍODO VI. TERCERA RUINA. La última ruina que hemos podido documentar afecta a las estructuras comprendidas entre el crucero y el hastial. Los muros de la nave central y laterales colapsan de nuevo aunque no de forma tan traumática como en ocasiones anteriores.

PERÍODO VII. RESTAURACIÓN TARDOMEDIEVAL (A 1013). Los materiales empleados en esta reconstrucción son el granito, cortado en sillares mal escuadrados y heterogéneos en tamaño, la pizarra en forma de lajas estrechas y alargadas excepto en los muros de las naves laterales- y materiales originales de la fábrica más rodados, deteriorados y cortados a menor tamaño. La pizarra es la piedra utilizada para levantar los muros de la nave central a excepción de las ventanas abiertas en el lado S., confeccionadas a base de sillares, algunos de arenisca reaprovechados y otros de granito. Idéntica combinación pétrea presenta el arco apuntado de la arquería S., junto con su simétrico en la arquería $\mathrm{N}$., este último que sin embargo no es ojival (figs. 7 y 8). Este lienzo pizarroso se encuentra cortado y en parte sustentado por los arcos de ladrillo recreados por Ferrant, por lo que debemos imaginar su verdadero aspecto prescindiendo de los mencionados arcos y apoyando, en su zona oriental, en el macizado que el arquitecto eliminó. Al exterior la 
cornisa apoyaba en una serie de canecillos, algunos reaprovechados de la etapa previa y otros, de granito con forma y talla muy groseras, hechos en ese momento (figs. 3 y 5). La presencia del arco apuntado y las ventanas nos permite datar este período como tardomedieval.

A través de antiguas fotografías y por el tipo de material empleado hemos encontrado pruebas de esta fase, luego eliminadas por Ferrant, en los porches, donde se veía cómo apoya sobre la parte reparada la última cubierta de madera (Heptener, Corzo: fig. 55), al igual que la espadaña y el cubo que albergaba su escalera (Duero, Corzo: fig. 37).

PERÍODO VIII. REESTRUCTURACIÓN MO$D E R N A$ (fig. 6 a 10). Las actuaciones que reestructuraron la iglesia en esta época desaparecieron íntegramente cuando la iglesia fue desmontada. En las fotografías previas al traslado (Heptener, Corzo: figs. 33 y 34) se puede observar un recrecido de los muros de las naves laterales hasta una altura que permitió la realización de un tejado a dos aguas que ocultó exteriormente los muros de la nave central. Esta intervención fue posterior al período VII por la sencilla razón de que en ese momento se incorporaron las ventanas altas, lo que no tendría ningún sentido si existiese otro muro que impidiera la entrada de luz. Además se adecuaron las naves laterales para espacios cultuales. De esta forma encontramos en ambas naves los anclajes de un entramado de madera en el que se desarrollaría una bóveda de cañizo y estuco (A 1022) que daría más empaque a las nuevas estancias litúrgicas (fig. 6). También observamos la impronta de lo que pudo ser un altar (A 1024) pegado al muro E. de la nave N. (fig. 11). Para crear una mayor privacidad de estos espacios se taparon los vanos en forma de parejas de arcos que comunican las naves con el crucero. A los pies de la iglesia se hizo un coro alto de madera (A 1023) perfectamente reconocible en las fotos de época (Archivo Mas, Corzo: fig. 47), que Ferrant prescindió de recrearlo pero teniendo el cuidado de dejar intactos los cajeados de sus vigas. Finalmente, en esta fase se abrieron unos arcos que permitieron el tránsito desde el crucero a las habitaciones delanteras, alterándose muy posiblemente su funcionalidad (figs. 6, 9 y 10).

ACTIVIDADES FUERA DE PERÍODO. EXterior. La utilización del entorno inmediato de la iglesia, por la parte más cercana a la cabecera, como cementerio, iniciado en época muy antigua, queda atestiguada por las rozas que sirvieron para encajar sendas cubiertas de tumba, una en el muro $S$. del ábside (A 1042) y la otra en el mismo paramento de la habitación meridional (A 1043).

Los desagües graníticos de la cubierta y la segunda reparación de la habitación N. (A 1007, fig. 3) son elementos a los que no hemos encontrado forma de asignarles una fase concreta. La única certeza que tenemos es que son posteriores al período $\mathrm{V}$ y anteriores al traslado (período IX).

Tampoco es posible ubicar con certeza en la secuencia una serie de habitaciones adosadas a los muros exteriores de la iglesia. Seis mechinales (A 1116, fig. 5) en el muro N. de la nave septentrional indican una habitación de la que sólo podemos decir que es posterior al período VII ya que algunos de los huecos están abiertos en la reparación del muro correspondiente a esta fase. En el muro SO. del transepto hay un par de rozas (A 1087 y 1121, fig. 4) en posible relación con la caja de la escalera que allí existió antes del desmonte. Finalmente, en el muro NE. del transepto son visibles dos líneas de mechinales a diferente altura (A 1046 y 1047, fig. 2) cada una asociada a una estancia diferente. Imposible saber cuál es anterior y posterior.

Interior. En el ábside, el retablo y altar existentes antes del traslado pueden asociarse, respectivamente, a cortes de las paredes (A 1032 y 1034, fig. 7). En este mismo entorno hay al menos dos suelos (A 1031 y 1030), el primero de ellos formando un escalón. Las ventanas N. y S. han sido burdamente retalladas rompiendo parte de la decoración para hacer más grande el paso de la luz (A 1062). Por último, en la embocadura interior tenemos dos agujeros para un cierre (A 1035).

Se aprecian también otras líneas de suelo, la A 1014, visible en el muro $\mathrm{S}$. del anteábside, y la A 1025 en el muro NO. del transepto (figs. 7, 8 y 11). De nuevo es muy arriesgado pronunciarse respecto a su datación si bien la A 1025 , debido a su posible relación con las zapatas de la parte baja del muro en el que aparece, podría ser original.

En el anteábside hay trabes para colgaduras (A 1005,1037 y 1107 , figs. 7 y 8 ), la primera sobre el friso decorado junto al muro $\mathrm{O}$. del ábside, la segụnda encima de los cimacios de su arco de triunfo y la última sobre el cimacio de las columnas orientales del crucero. Alguna de estas cortinas pudieron ser de época primitiva y quizás expliquen la ausencia de canceles. En relación con una ruina y restauración de la bóveda del anteábside detectamos unos cajeados (A 1054, figs. 7 y 8) sobre la línea de cornisa.

Otra actuación destacada es la reparación de los $\operatorname{arcos}$ N. y S. del crucero (A 1108). El desplazamiento de la parte occidental de esta estructura hizo que los arcos de dirección E-O. perdiesen tensión y 
se vinieran abajo. El material empleado para la restauración provenía de la propia fábrica aunque retallándolo. Esto es perfectamente percibible en el arco meridional, cuyas dovelas son notoriamente más pequeñas que las originales. Finalmente hay compartimentaciones en las naves laterales (A 1017, figs. 6 y 9).

Los porches (figs. 10 y 11) poseen una serie de elementos imposibles de secuencializar pero cargados de información sobre su uso histórico. En el N. tenemos varias líneas de mechinales que podrían corresponder a tejados (A 1029) así como a sobrados a diferentes alturas (A 1075, 1085 y 1095). La persistencia de este elemento - altillo o camaranchón-a lo largo del tiempo evidencia la reiteración de un uso que se nos escapa pero que no se repite en el otro porche, carente de huellas parecidas. Otro elemento recurrente en el porche septentrional son los cierres tallados en las puertas de comunicación con el transepto (A 1081, 1080, 1098, 1020). Bien es cierto que en el meridional pudo darse la misma circunstancia y que no seamos capaces de percibir nada más que el profundo hueco de tranca del primer cierre, a causa del corte (A 1018) que rebajó todo el vano, jambas incluidas. De lo que no hay duda es de la ausencia en esta puerta de soluciones de cierre desde el momento del retalle del arco. Sin embargo en el otro lado vemos que seguía existiendo una puerta hasta el instante justo del traslado (Archivo Mas, Corzo: fig. 45). De todo esto deducimos que el porche N., a partir de algún momento, se convirtió en depósito o almacén con una planta adicional, aislándose del resto del edificio e impidiendo el paso por él a la iglesia, con lo que puede que a partir de cierta fecha el único acceso que le quedó a la iglesia fue el del porche S., pues el de los pies, como ya apuntamos, se cegó posiblemente en el período V. Esta deducción está confirmada por las fotos inmediatas al traslado del edificio, en que se ve cómo el acceso al porche N. está cegado de obra (Gómez Moreno 1906: fig. 36 y Corzo: fig. 39, de Heptener).

En el porche S. es digno de destacar el corte producido en la puerta de comunicación con el crucero (A 1018, figs. 9-11), que transformó profundamente la fisonomía del vano, eliminando, sino lo estaba ya, el dintel y el tímpano así como rebajando las dovelas del arco hasta hacerlo escarzano. En el acceso exterior de este porche se labró una roza (A 1071) para colocar una puerta de madera de la que estamos seguros no es original ya que destruye parte de la decoración de las impostas. El límite inferior de este corte nos habla de la altura del suelo en el momento de colocar la puerta.
La degradación de la piedra ha sido igualmente diferenciada mediante un número específico de Actividad (A 1027). A pesar de lo blando del material predominante, la arenisca, el estado de conservación de los muros es bastante bueno, excepto en las partes más bajas donde, inevitablemente, el contacto directo con el suelo propició su degradación gracias a las humedades producidas por su secular soterramiento y probablemente su alto contenido en materias orgánicas.

PERÍODO IX. DESMONTE Y TRASLADO DE LA IGLESIA (A 1125; figs. 2-4, 7, 8 y 11). Es obvio que todas las partes del edificio que se decidieron conservar se vieron afectadas por esta actividad. Lo que aquí queremos poner de manifiesto son las actuaciones específicas relacionadas con este hecho. Por ejemplo las marcas hechas con pintura roja en los sillares que, según una clave de números y signos, indicaría la ubicación de cada uno de ellos en la fábrica, apenas reconocible pues hemos de suponer se prefirió señalar alguna de las caras que quedarían ocultas tras el montaje. Por ello sólo las conocemos en una de las dovelas del arco central de la arquería $\mathrm{N}$., en la ventana al anteábside de la habitación delantera y en las jambas y el umbral del arco de triunfo. También son visibles estos signos en la viga de madera hoy conservada en el Museo de Zamora donde aparece una flecha apuntando a un signo en forma de omega levantada, el número 574 quizás correspondiente a la numeración seguida de los elementos trasladados, una letra $\mathrm{C}$ y gotas de pintura. La flecha pudo marcar una orientación geográfica, quizás el Este si la omega fuera en realidad una E. La cara marcada, que corresponde con la de las cajas para grapas, debió ser la visible al desmontar las hiladas y por lo tanto la superior.

Otra evidencia del traslado, con vistas a la recolocación de la iglesia, son unas líneas de nivelado, paralelas al suelo e incisas a diferentes alturas en los muros exteriores.

PERÍODO X. LA RESTAURACIÓN. (A 1127; figs. 2-11). La reconstrucción de la iglesia dio como resultado el edificio tal como hoy lo conocemos. Dirigidos los trabajos por el arquitecto Ferrant, siempre con el cercano asesoramiento de Gómez Moreno, el objetivo que presidió esta labor fue devolver al edificio el aspecto que, a juicio de este equipo, había tenido la iglesia en su origen. Esto supuso la recreación de las partes desaparecidas así como la eliminación de aquellas otras que enmascaraban los paramentos primitivos. Este último hecho 
significó la eliminación de todas aquellas construcciones que a lo largo de la historia se habían ido adosando y superponiendo. Sin embargo, cuando las partes antiguas se encontraban prácticamente perdidas y sustituidas por otras más modernas, como en la zona de la nave central, Ferrant decidió conservarlas parcialmente en vez de reemplazarlas por reconstrucciones ideales, manteniendo la misma exquisitez y cuidado en su reintegración formal y material. En cuanto a aquellos muros, arcos y bóvedas que sí fueron obra del restaurador, se utilizaron materiales - piedra de conglomerado en los muros, ladrillo en arcos y bóvedas y cimborrio y madera en las cubiertas - perfectamente distinguibles de los primigenios con una clara intención de evidenciar qué es nuevo y qué antiguo. Gracias a esta franqueza en la intervención resulta fácil conocer con exactitud dónde se ha producido ésta y cuál ha sido su alcance.

El resultado es un edificio «interpretado» a partir, por un lado, de evidencias arqueológicas aparecidas durante el desmonte del edificio y, por otro lado, conjeturas constructivas del propio arquitecto. Al primer grupo corresponden, por ejemplo, la reapertura de la puerta del hastial, el altar sustentado por pilastrillas, la recuperación desde el exterior del juego de alturas de las naves, el desbloqueo de algunos vanos, la reconstrucción de las bóvedas hundidas, etc. Lógicamente en el aula, aunque un técnico tan autorizado como Torres Balbás pensaba que el edificio primitivo estaba abovedado también en esta zona, se mantuvo la cubierta de madera que terminó imponiendo su imagen al análisis del edificio. En cuanto a las partes conjeturadas tenemos el cimborrio y la reconstrucción en altura de los porches. La recreación del cimborrio fue antes que nada de tipo volumétrico. Suponiendo los problemas que dicho elemento había causado a la estabilidad del edificio, Ferrant levantó su cimborrio con materiales ligeros y renunció a ensayar ninguna solución cupulada. Los porches, por su parte, fueron recrecidos hasta alcanzar la cota de la nave central y anteábside. En su interior mantuvo unas piezas de granito sobresaliendo de la línea del muro en las que según Gómez Moreno se apoyaban los forjados de los altillos (A 1012, figs. 10 y 11). A través de la documentación de Heptener se comprueba la existencia de estas piezas y cómo Ferrant eliminó todo lo que no fuera primitivo (Corzo: figs. 54, 55 y 60). También cerró con un tabiquillo los huecos de paso abiertos entre las habitaciones y el transepto, recuperando la volumetría del edificio primitivo, pero manteniendo la lectura de esta intervención histórica. A él o a una intervención inmediata deben per- tenecer también los cierres metálicos y con cristal de ventanas y de las habitaciones. En un sillar de la nave central, correspondiente al primer arco, Ferrant utilizó el cosido con grapa metálica para salvarlo en su integridad.

PERÍODO XI (A 1111,1130 a 1135; figs. 2 a 8 , 10 y 11). Desde los trabajos de restauración de comienzos de los años 30 hasta el momento actual se han producido algunas actuaciones puntuales. Algunas de las piezas de escultura decorativa originales - capiteles, fragmentos de friso- que Ferrant rescató de su reutilización en muros más modernos y había colocado como retablo sobre la mesa del altar, tras la reforma litúrgica fueron reubicadas con mayor o menor fortuna en diferentes lugares de la iglesia, en concreto en las esquinas interiores NE. y SE. del ábside y el muro E. de la habitación N. (A 1130). Muy reciente es la colocación del parteluz de la ventana $O$. del porche N. (A 1134). La intervención de mayor envergadura pero que no cambió el aspecto de la iglesia fue un retejo llevado a cabo en los años 80 (A 1132). Otra acción que, en cambio, sí atentó contra la integridad del edificio fue la colocación de las actuales puertas de los porches, para lo cual se abrieron cajas en los muros (A 1135). Por último se han producido unas grietas - no parece que alarmantes- en los muros reintegrados con ladrillo del cimborrio.

\section{ANÁLISIS Y CONCLUSIONES}

La lectura efectuada no aporta una fecha para la construcción del edificio. Sin embargo, sirve para acercarse a una comprensión prácticamente definitiva sobre qué nos queda del edificio primitivo y sobre los problemas que plantea aún no resueltos. A la vez, nos permite comprender su secuencia histórica, los elementos que no forman parte del edificio primitivo, a qué obedecen y por lo tanto su relación genética con la vida del primer edificio. A través de este estudio se puede argumentar sobre las partes perdidas.

\section{Argumentación a favor de un único proyecto constructivo}

Historiográficamente el edificio de La Nave ha llamado la atención por las aparentes incorrecciones que presentaba y que se han intentado explicar por medio de dos etapas diferentes en su primera construcción. Gómez Moreno ya señala estas incorrec- 


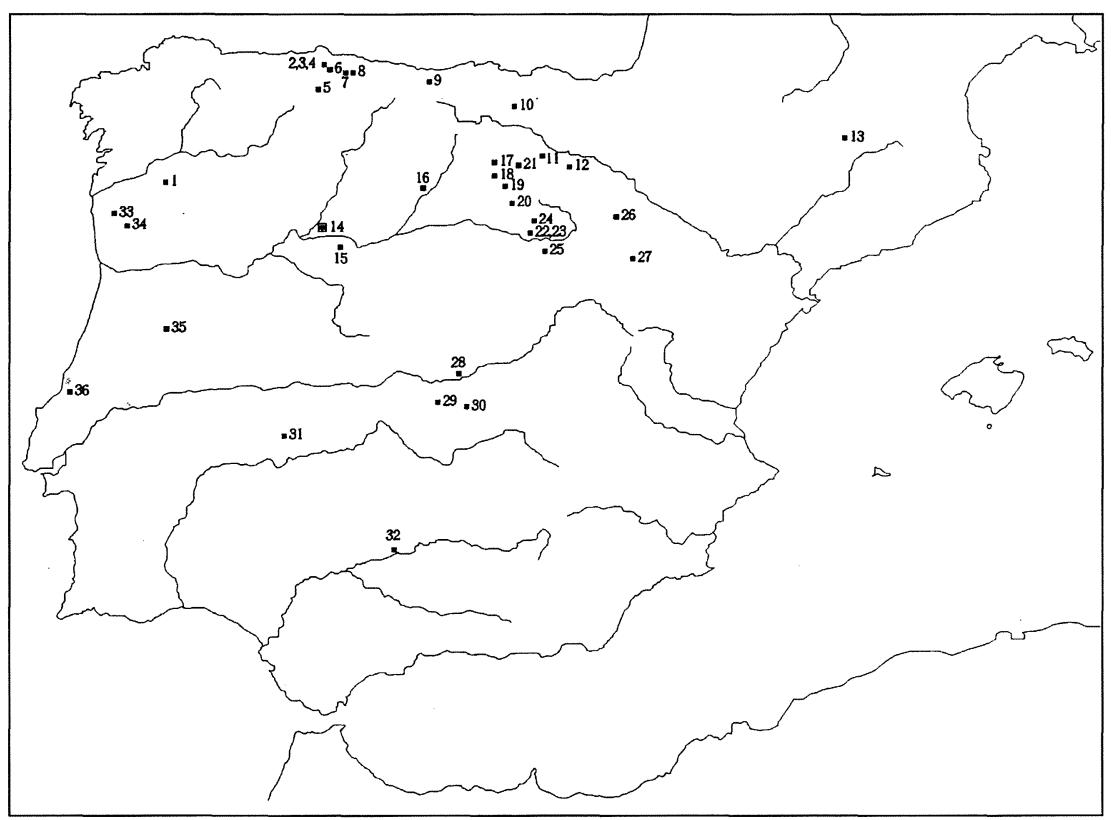

Fig. 16-Mapa de la península ibérica con los lugares citados en el texto. 1. Sta. Comba de Bande (Orense); 2. S. Miguel de Lillo; 3. Sta. María; 4. S. Julián de los Prados o Santullano, Oviedo; 5. Sta. Cristina de Lena; 6. Sta. María de Bendones; 7. S. Salvador de Valdediós; 8. S. Salvador de Priesca (Asturias); 9. Sta. María de Lebeña (Santander); 10. S. Román de Tobillas (Vitoria); 11. Sta. María de los Arcos, Tricio; 12. Ventas Blancas (La Rioja); 13. S. Lliser de Viròs, Pallars Sobirà (Barcelona); 14. S. Pedro de la Nave (Zamora); 15. Sta. María de Bamba (Valladolid); 16. S. Juan de Baños (Palencia); 17. S. Felices de Oca; 18. Quintanilla de las Viñas; 19. S. Pedro el Viejo de Arlanza; 20. Sta. Cecilia de Barriouso; 21. S. Vicente del Valle (Burgos); 22. Castillo de Gormaz; 23. S. Miguel de Gormaz; 24. Fuentearmengil; 25. S. Baudelio de Berlanga; 26. Ágreda (Soria); 27. Calatayud (Zaragoza); 28. Toledo; 29. Sta. María de Melque, S. Martín de Montalbán; 30. S. Pedro de La Mata Sonseca (Toledo); 31. Sta. Lucía del Trampal, Alcuéscar (Cáceres); 32. Córdoba; 33. S. Frutuoso de Montelios; 34. Guimarâes, Braga; 35. S. Pedro de Lourosa; 36. S. Giâo de Nazaré (Portugal).

ciones y las diferencias decorativas, definiendo dos maestros escultores y el cambio de proyecto en la obra, aunque sin llegar a plantear dos etapas diferentes, sino una corrección o adecuación del proyecto a los problemas que surgían según se avanzaba en la construcción, resueltos por el segundo maestro con un estilo decorativo distinto, colocando las columnas y abovedando el crucero (Gómez Moreno 1906: 307 y 1966: 129-30). Camps Cazorla (1940: 634, n. 46), sin embargo, propone la unidad del edificio, aceptando lógicamente la presencia de dos maestros decoradores que incluso utilizarían «un repertorio muy semejante». Corzo (p. 147) desarrolla la idea de Gómez Moreno, pero diferenciando, como él mismo señala, que el cambio no fue algo producido dentro de un mismo proceso de obra, sino un cambio radical de proyecto y de plan constructivo. Además se puede aducir otra diferencia con Gómez Moreno, ya que Corzo parte de un primer proyecto totalmente abovedado - diríamos que a la bizantina- para llegar a otro segundo también abovedado; mientras que de la postura de Gómez Moreno puede deducirse que el primer edificio no era abovedado. En contra de la opinión de Corzo, Caballero siempre ha defendido la unidad estricta del edificio, justificando las aparentes incorrecciones y los dos maestros por deficiencias y modos de hacer propios del sistema constructivo empleado (Caballero 1995: 334-5 con un resumen de Gómez Moreno y Corzo). Nuestro trabajo aplica un método de lectura que intenta resolver esta ambivalencia en la comprensión del edificio primitivo. Dada la importancia del estudio de Corzo y la contradicción con nuestras conclusiones resumimos a continuación su postura.

Según Corzo, la iglesia fue construida en dos fases consecutivas pero diferenciadas, separadas por una interrupción de los trabajos y un cambio de equipo y de proyecto. El primer proyecto, que pretendía construir una iglesia cruciforme totalmente abovedada, en el instante del repentino cambio de planes sólo había avanzado hasta la séptima hilada en la parte oriental —con algunos bloques decorados todavía sin colocar- y hasta la tercera o cuarta en la zona occidental del crucero. Desde ahí hasta los pies nada estaba hecho. La siguiente fase em- 


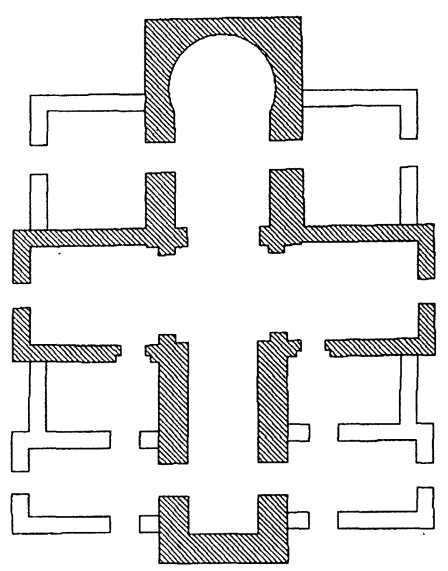

SAN PEDRO DE LA MATA

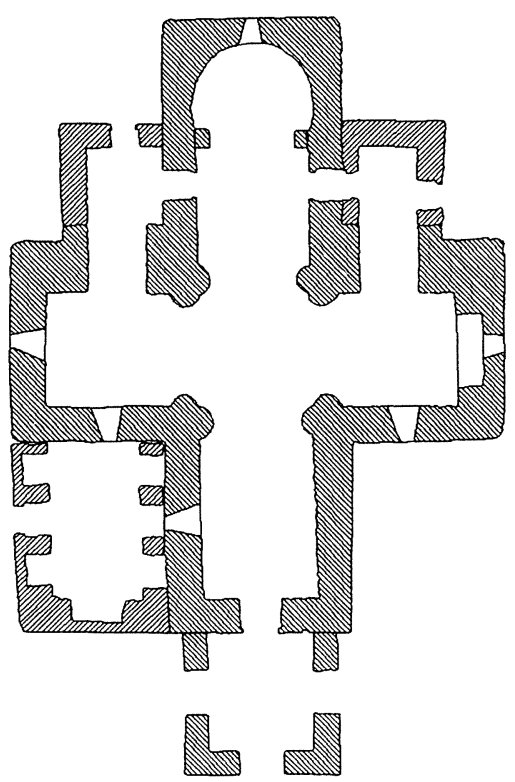

STA. MARÍA DE MELQUE
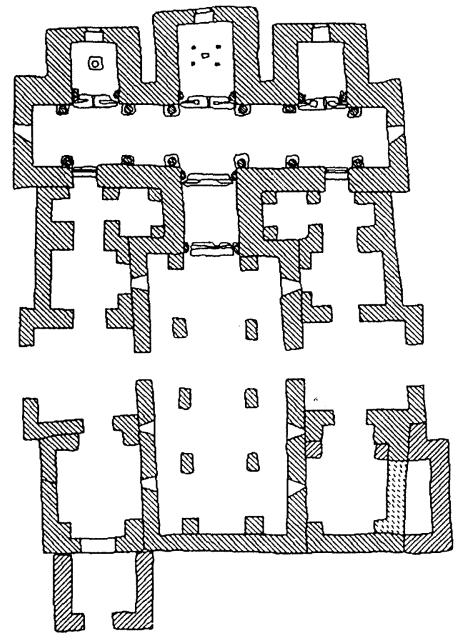

STA. LUCÍA DEL TRAMPAL

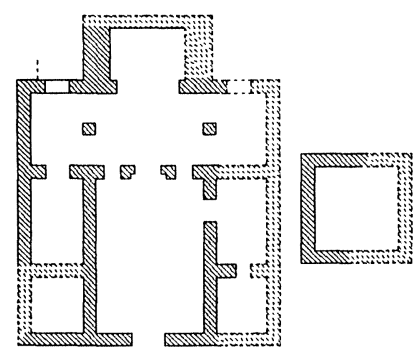

NAZARÉ
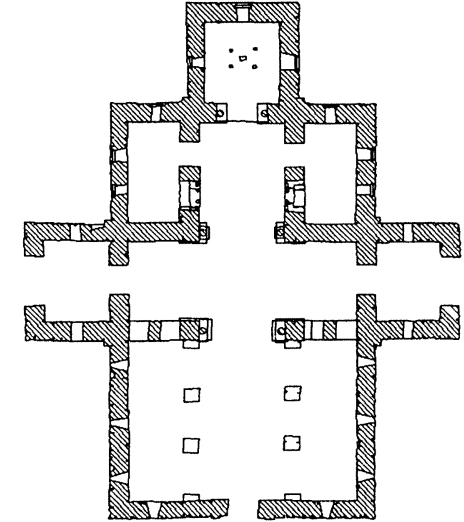

SAN PEDRO DE LA NAVE

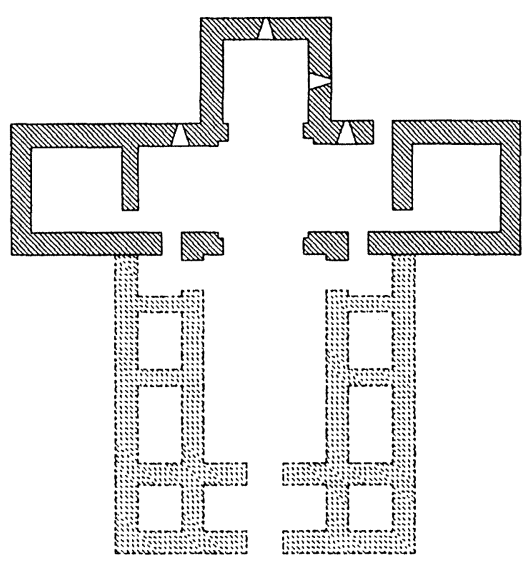

QUINTANILLA DE LAS VINAAS

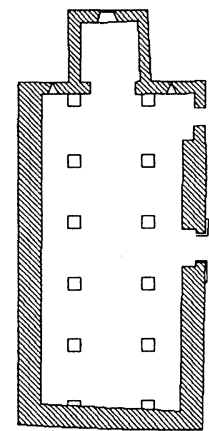

SAN PEDRO DE ARLANZA

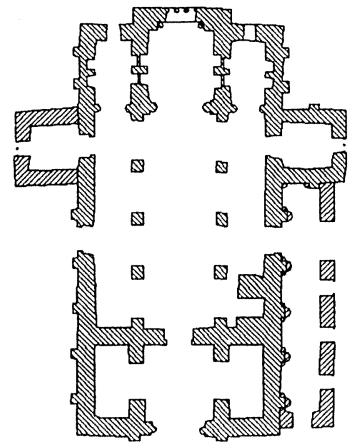

SAN SALVADOR DE VALDEDIOS

Fig. 17. - Planos de las principales iglesias citadas. E. 1/400. 
prendería su acción constructiva a partir del punto en que quedó la anterior, terminando de colocar la decoración que aún estaba suelta y aportando además su propio repertorio escultórico. Esta segunda iglesia, de planta cruciforme abovedada en la cabecera y con aula posiblemente abovedada añadida a los pies, apunta Corzo que tampoco llegaría a rematarse, o bien que sufrió una temprana ruina, al no encontrarse evidencias de su existencia en la parte occidental del templo salvo las hiladas inferiores del hastial. Corzo (p. 171-3) reconoce las diferencias entre los dos proyectos por una serie de hechos como la errónea colocación de piezas del friso del primer maestro, el retalle de sillares y el distinto trazado, despiece y módulo — peraltado- de los arcos que comunican el transepto con los porches. Sin embargo tácitamente sostiene que técnica y materialmente no hay ninguna diferencia entre los dos planes, hasta el punto que la parte oriental se llegó a rematar según se concibió en el proyecto primitivo y que en el crucero y las naves se practicaron las alteraciones mínimas imprescindibles. Con este razonamiento el propio autor está negando la existencia de una diferencia físicamente percibible, apoyando su discurso en criterios tipológicos.

En nuestra lectura de la secuencia estratigráfica de la iglesia, no hemos encontrado ninguna cesura que permita distinguir las dos etapas señaladas por Corzo en las partes más antiguas del edificio, por muy inmediatas que hubieran sido, al estilo de las detectadas, por ejemplo, en San Pedro el Viejo de Arlanza -interfaz, cambio de módulo de sillares, aparición de mechinales-, aunque en este caso se supone que lo que hubo entre ellas fue una ruina y no un cambio de plan (Caballero y otros 1991-92: 142-3; Caballero y Cámara: 85-6). Nuestra observación es que el edificio constructiva y arquitectónicamente es unitario, al margen de su mayor o menor grado de conservación y con excepción de las arquerías de la nave central que, en su estado actual, pertenecen a una restauración posterior. La continuidad de la fábrica original está presente en todos los muros lo que implica aceptar que el edificio debió culminarse de una vez según un único plan. Un edificio de planta como la actual, con dos escultores simultáneos, plausiblemente con arquerías sobre pilastras y abovedado por completo. Los materiales y las técnicas constructivas son hasta el detalle semejantes en todo el edificio. La conclusión unitaria aportada por la lectura de paramentos obliga, al contrario, a buscar una explicación a las aparentes diferencias, que deben achacarse a la organización y al trabajo propio del momento en que se construye el edificio, como los dos maestros; la manera de orga- nizar la decoración el primero, de modo que todos y cada uno de los sillares son independientes entre sí, tallados específicamente para su lugar, aunque parte de la decoración quedara oculta; la riqueza en los tipos de ventanas y puertas; la organización del crucero con sus columnas o la del aula, etc.

\section{Sobre la forma de las arquerías y el abovedamiento de la iglesia}

Existen otros problemas no resueltos directamente por la lectura pero a los cuales ésta aporta datos nuevos con los que argumentar soluciones. Uno de ellos es el de las arquerías. Nuestra conclusión, no definitiva porque no han llegado a nosotros elementos indubitablemente correspondientes al momento primitivo (como ya señaló Corzo: p. 105), pero deducida de la primera restauración histórica, es que debieron existir arcadas sobre pilastras que sostenían bóvedas (también propuestas por Corzo) tanto en la nave central como en las laterales. Las arcadas, tampoco de un modo que no deje cierto margen a la duda, debían partir de pilastras o semipilastras adosadas al muro del transepto y enjarjadas al de hastial de fachada, basándonos en la posterior presencia de pilastras, la falta de decoración de los cimacios/impostas de las columnas occidentales del crucero y en la presencia de un cajeado coetáneo al muro primitivo del hastial.

Este sistema es muy corriente en nuestra arquitectura altomedieval. El aula de Sta. Lucía del Trampal (Cáceres) se organiza en tres naves separadas por arcadas de cinco pilastras, las primera y última adosadas a los muros del transepto y del hastial, que debían soportar cuatro arcos, relacionados con las ventanas y puerta laterales aunque no exactamente a sus ejes, y una cubierta que, en este caso, no debía ser abovedada dada la altura que tuvieron los muros laterales, conservado el del lado N. en su totalidad como atestiguan las ventanas colocadas en su cima (Almagro y otros: 98-9). Quintanilla de las Viñas todavía conserva una semipilastra de $0,25 \mathrm{~m}$ de salida, trabada y encajada en el muro del transepto con arranque de un arco de herradura, sobre cuyo significado luego volveremos (Arbeiter 1990: 411). En lo asturiano Valdediós es el ejemplo mas cercano, con las arcadas sobre pilastras, las extremas adosadas. Igual tiene Santullano, que arrancan de media pilastra y terminan en un muro equivalente a medio arco, y Lillo sobre columnas que rematan en semicolumna y que según la reconstrucción más fundada, la de Arias, arrancarían del mismo modo.

Es evidente que la solución no es segura ya que 


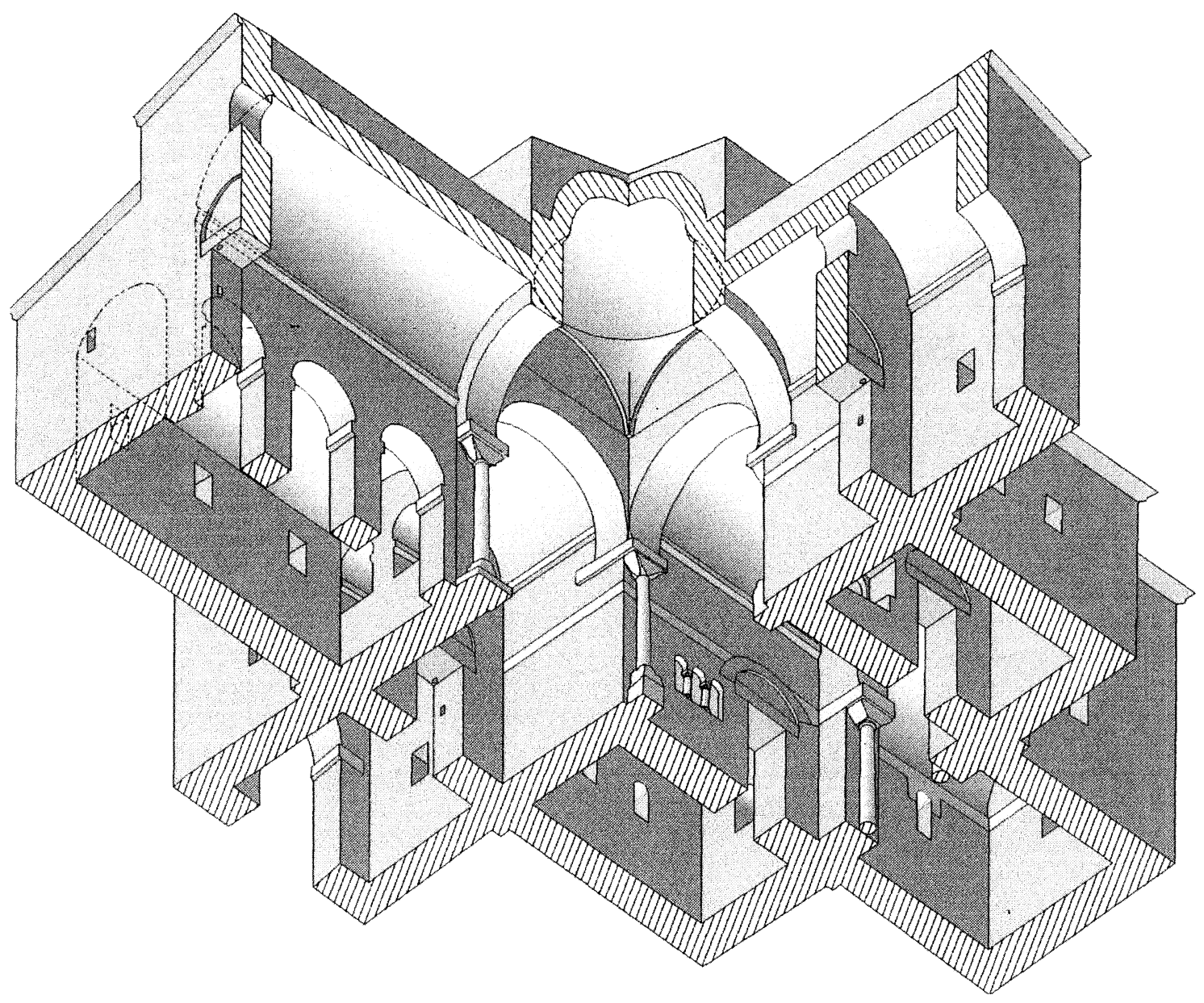

Fig. 18.-Perspectiva de la reconstrucción de La Nave.

analizamos un edificio trasladado, del que no conocemos con exactitud ni las circunstancias exactas de su ruina ni las de sus restauraciones. Además, de un modo estricto, ni el cajeado ni el resto de argumentos pueden asegurar la existencia de arcada en el edificio primitivo, pues puede argüirse la existencia de otras soluciones como la existencia de un muro con puerta o arco, igual que en la portuguesa $\mathrm{S}$. Giâo de Nazaré o posiblemente, como veremos, en Quintanilla. Pero esta solución parece improbable pues los paralelos citados, y quizás El Trampal y S. Pedro de la Mata (Toledo), hacen pensar en puertas de paso desde las habitaciones al transepto.

Tampoco es una cuestión indubitable el que la iglesia estuviera totalmente abovedada, pues no queda ninguna evidencia de ello. Pero la brutal ruina documentada, desde un análisis estructural, es un dato empírico que apunta a esta probabilidad ${ }^{8}$. Ante todo la ruina no parece achacable a un supuesto empuje del cimborrio, como tradicionalmente se admite, sino a que las bóvedas de la nave central, tanto en la cabecera como en el aula, estaban descargadas incorrectamente por las bóvedas laterales, probablemente por una excesiva diferencia de altura entre ellas. Ello haría que las bóvedas centrales se abrieran entre sus arranques y sus riñones. La única constancia conservada de esto es la ruina de la bóveda del anteábside, con sus apoyos abiertos como parece verse en las figs. 40 y 44 de Corzo, antes de su traslado. A continuación, mientras la ruina se estabilizó en la cabecera, otras causas intervinieron en la zona de pies haciendo que allí continuara el proceso. Es muy probable que las arcadas del aula -insuficientes para soportar a la vez la ruina de la bóveda central y el empuje adicional de las bóvedas laterales, privadas del contrarresto de la central- fueran la causa diferenciadora que hizo

${ }^{8}$ Seguimos en esta explicación las diretrices dadas por Leandro Cámara. 
que se hundieran las bóvedas laterales, arruinándose ellas mismas y los muros del aula. Al contrario, los muros de las habitaciones delanteras lograron soportar esta primera ruina. Sólo fue entonces cuando, falta de estribo al desaparecer por completo el aula, pudo moverse el muro O. del transepto ${ }^{9}$, cayendo las bóvedas lo primero, abriéndose luego los arcos laterales del cimborrio y hundiéndose, finalmente, su cubierta. Resumiendo, los argumentos en que se apoya esta explicación son la ruina de la bóveda del anteábside con la inclinación hacia afuera de sus apoyos, la ruina absoluta del aula y el supuesto de que tenía arcadas y la inclinación hacia los pies del muro O. del transepto.

Torres Balbás, inmediatamente después del traslado y testigo de éste, mantenía en 1933 una explicación muy parecida (p. 131-2): al estar abovedado el edificio, las condiciones de su estabilidad eran deficientísimas y empujando continuamente las bóvedas sobre muros de piedras sueltas, grande el peligro de destrucción por volcamiento. Ello explica que de las bóvedas no se conserven nada más que las primeras hiladas... y (de) la de la nave de pies, ni aún esos restos: la ruina, sin duda, no debió ser muy posterior a su construcción. Análoga causa debió motivar que en la ermita de Quintanilla de las Viñas hayan desaparecido la parte de los pies y todas las bóvedas... En ese brazo de los pies no subsistía resto alguno de abovedamiento, destruida la obra primitiva hasta el nivel de los ar$\cos ^{10}$.

Un proceso similar tuvo que ocurrir en Quintanilla cuyo hundimiento no se debería al empuje del cimborrio, sino al indebido estribo de la nave central por las laterales, igual que debió pasar en Arlanza y S. Vicente del Valle (Burgos), como veremos enseguida. Si el aula de La Nave hubiera estado cubierta de madera sus muros hubieran aguantado en mejor estado, como ocurrió en El Trampal.

Supuesto el abovedamiento del aula como condición necesaria para que se diera el tipo de ruina

9 Schlunk (1971b: 424) observa la norma de que las naves transversales de las iglesias españolas corresponden exactamente a la anchura de las tres naves. Posiblemente por esta razón constructiva, que al $\mathrm{E}$. correspondería normalmente con el anteábside y sus habitaciones o con tres ábsides.

${ }_{10}$ Puede ser sintomática la duda inicial de Gómez Moreno (1906: 368) cuando argumenta que dichas tres naves de los pies llevaron seguramente armaduras y no bóvedas, porque, de haberlas, alguna señal conservarian los testeros... También es posible que Schlunk (1971a: 523) mantuviera alguna duda sobre la verdadera cubierta: se ha hecho siempre destacar como especialmente digno de atención que ante las partes orientales y los brazos del crucero... abovedados unos $y$ otros, se encuentran al $O$. tres naves que, por lo menos hoy, presentan un techo plano. documentado, podemos plantearnos con más detalle cómo pudo ser el edificio (fig. 18). Lógicamente su estructura e imagen debía ser similar de la cabecera a los pies, por lo que debemos suponer que las bóvedas del aula tendrían el tamaño y altura de las del anteábside y las habitaciones. Para ello las arcadas no podían tener más altura que la que hoy mantienen los arcos de las puertas de acceso a las habitaciones. Si trasladamos estos arcos al aula, prácticamente encajan con el prorrateo que hicimos tomando como base la distancia entre los ejes de las ventanas, que quedan además centradas con el centro geométrico de los arcos. No obstante existe, medido sobre nuestros planos, una ligera diferencia, pues (si recordamos, supra p. ....) los diámetros de los arcos según los ejes de las ventanas serían de 1,70 $\mathrm{m}$ resultando unas pilastrillas de arranque de $0,15 \mathrm{~m}$, demasiado estrechas; mientras que, usando la dimensión del arco de las habitaciones, las semipilastras serían de $0,30 \mathrm{~m}$, los tres arcos tendrían diámetros de 1,60, las dos pilastras intermedias de 0,60 y la longitud total $6,60 \mathrm{~m}$. Lógicamente no sabemos la forma de estos arcos, quizás de herradura como los actuales o, en caso de ser como los propuestos de medio punto -o ligeramente peraltados, a la asturiana-, obligarían a considerar los actuales resultado de la restauración inmediata.

Sobre la cubierta de los porches existen varias opiniones, bien que estaban abiertos (Corzo: 176), que poseían cubierta de madera colocada a la altura del transepto con habitaciones bajo ella (Gómez Moreno, 1906: 368 ), o a una altura más baja que el tejado de las naves (Caballero, 1990: 330, fig. 4). También podemos pensar que estuvieron abovedados. Veamos qué pueden decirnos a este respecto los datos que poseemos. Las piezas de granito, colocadas interiormente a media altura de los muros laterales, pertenecen a una reforma posterior (como también afirma Corzo: 176) y no son apoyo de una hipotética armadura primitiva (opinión equivocada de Caballero 1990), ni justifican la existencia de altillos de madera coetáneos a la construcción de la iglesia (como pensaba Gómez Moreno). En los paramentos exteriores ningún sillar permite afirmar la existencia de esquinas que formarían las fachadas de las naves si los porches tuvieran sus tejados más bajos que los del transepto. La rotura interior de los muros primitivos está justamente a la altura de la imposta del transepto, lo que puede justificar la inexistencia de bóveda, pues de haber existido habrían colapsado de inmediato falta de contrarresto, según el proceso normal de ruina de las del transepto y anteábside, abriéndose los muros en cabecera, conservando la imposta, si existía, la fila de salme- 


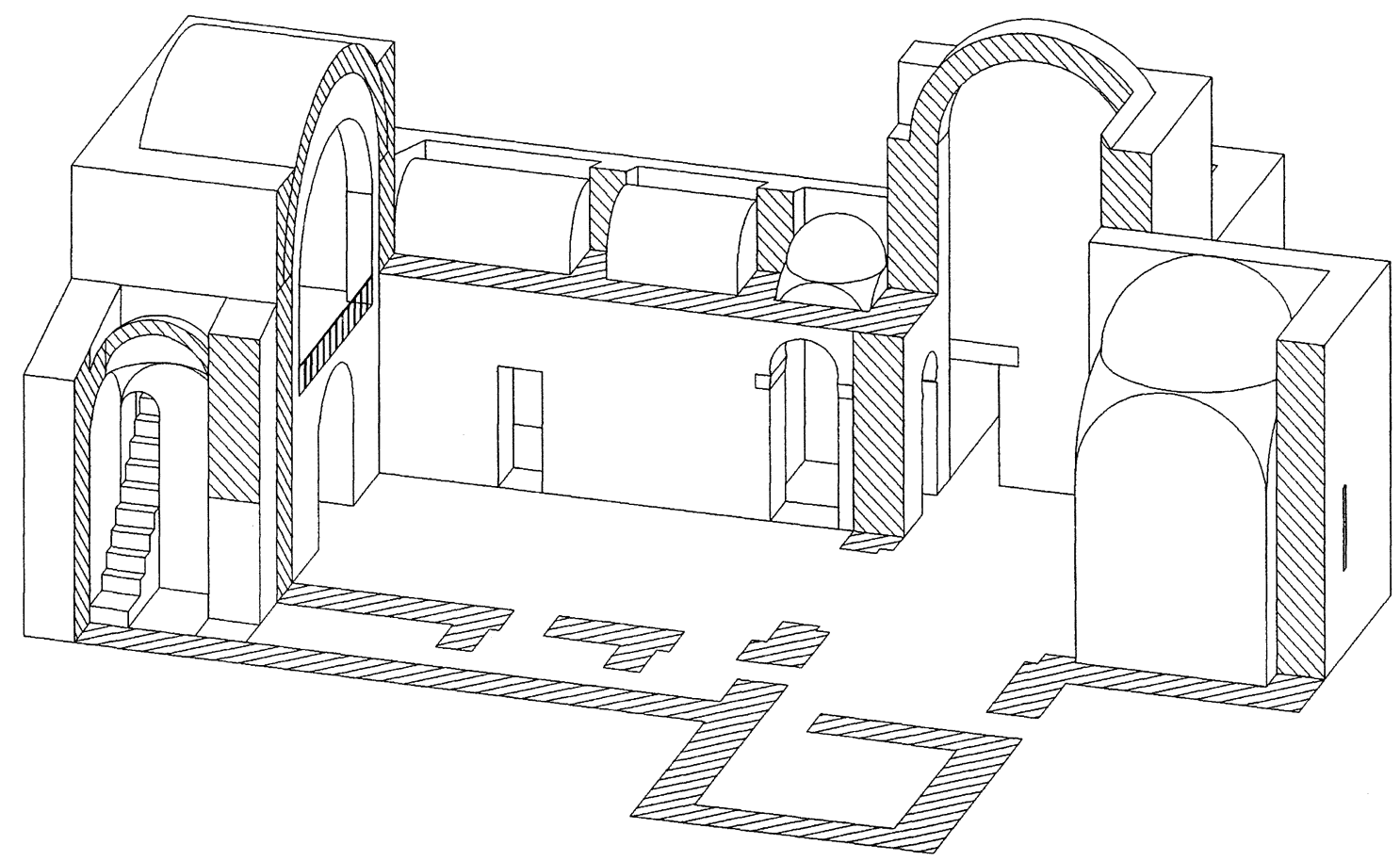

Fig. 19.-Perspectiva de la reconstrucción de Quintanilla.

res y la primera de dovelas. Pero si se supone que la línea de rotura era la altura máxima que tuvieron los muros - lo que no parece seguro-, una cubierta de madera que pretendiera sobrepasar las ventanas de los testeros del transepto (como de hecho pretendía Caballero en 1990: 330, fig.4) debería tener una inclinación mucho más acusada que la que hoy tienen los tejados de las naves, realmente excesiva. Es evidente que no existe una razón más favorable a una u otra solución. Solamente el argumento de la unidad estructural del edificio puede hacernos suponer la solución abovedada si suponemos aceptable la misma solución para la cubierta del aula. Porches abovedados son el de Melque, aunque hundido, y los asturianos de Sta. Cristina de Lena y Valdediós. Pero también pudo tener una cubierta de madera, levantando los muros laterales lo necesario para que pasara la cubierta por encima de la ventana - quizás una o dos hiladas más-, o hasta la altura actual restaurada por Ferrant para colocar la cubierta a la misma altura que la del transepto.

Del cimborrio tampoco tenemos ninguna referencia pero, plausiblemente, también estaría abovedado coincidiendo en ello todos los investigadores desde Gómez Moreno (1906: 368-9), quien, igual que Camps y Schlunk (1971b: 414), suponía que lo estaría por arista igual que Bande que hoy sabemos una restauración histórica (Caballero 1991: 88 y 94, con la opinión similar de Palol). Los cimborrios de Melque y quizás S. Frutuoso de Montelios (Braga) y los ábsides de Quintanilla y su grupo, Arlanza y S. Felices de Oca (Burgos), Sta. María de Arcos de Tricio y Ventas Blancas (La Rioja), etc., aunque ausentes en lo asturiano, aportan la solución más probable, una bóveda sobre pechinas (Caballero y otros 1991-92: 153-7).

La imagen de La Nave como una iglesia completamente abovedada, con una cruz de naves a la misma altura, centrada por el cimborrio más alto, y las habitaciones y las naves laterales más bajas, como proponemos, choca con la imagen tradicionalmente admitida de la arquitectura llamada visigoda, cubierta a medias con bóveda en la cabecera y con armadura en las naves de los pies (Schlunk 1971b: 413-4). Esta imagen ya fue cambiada para La Nave por Corzo, hipótesis que hoy nos parece muy probable aunque variando la forma que él proponía. De aceptarse así, La Nave entraría a formar parte, como una variante más, de todo un grupo de iglesias altomedievales abovedadas sobre arquerías. Así las asturianas ya citadas de Valdediós y Lillo, a las que falta para conseguir la propuesta imagen de La Nave, el crucero y el cimborrio. Y las de Bamba (Valladolid) y Sta. María de Lebeña (Santander), 
ésta cruciforme, abovedada y con cimborrio de doble tramo, aunque sobre pilares compuestos y sin las naves de aula a la zona de los pies.

\section{El abovedamiento de las iglesias de Quintanilla y Arlanza}

Para completar la argumentación sobre el abovedamiento de La Nave vamos a discutir brevemente sobre el de otras dos iglesias, Quintanilla y Arlanza. Para La Nave, Camps primero para toda ella (1963: 639-40) y luego Arbeiter (1990: 418-9 y 4267, fig. 4) propusieron su abovedamiento, recordando sus semejanzas con Quintanilla. Arbeiter supuso que los espacios laterales estarían abovedadas con cupulillas sobre cuatro tramos, apoyándose en la evidencia del tímpano conservado en el paramento occidental del muro de transepto. Tras admitir el desconcierto que produce la distribución irregular de sus cimientos transversales, corrige idealmente la planta de Íñiguez (fig. 103) haciendo iguales estos espacios para poder cubrirlos todos con bovedillas vaídas o de crucería, solución que no sólo tiene en su contra lo documentado por Íñiguez, sino también la dirección atravesada de los cimientos, más propia de muros aéreos que de tirantes enterrados, y la falta de paralelos hispanos para la sucesión de bovedillas. Finalmente se plantea la posibilidad de abovedar la nave central, optando por suponerla cubierta con armadura de madera dada su luz. Efectivamente con sus cerca de 4,90 m es la nave más ancha de todas las altomedievales, con muros de un metro de ancho, superando incluso a Melque cuya nave tiene $4,50 \mathrm{~m}$ de luz para muros de $1,50 \mathrm{~m}$. Schlunk (1971b: 435) ya se apoyó en esta dificultad, señalando que antes del año 1000 no se conocen espacios abovedados en la Península por encima de los 3,50 ó 4,00 m de luz.

A nuestro parecer Quintanilla, dada la «organización tripartita de su tramo occidental» debía poseer allí con mucha probabilidad una tribuna alta al modo asturiano de las de Sta. María de Oviedo, Li1lo, Lena, Valdediós y S. Salvador de Priesca o al de Nazaré (Schlunk 1971a: 513), soportada por bóvedas de cañón y a las que se accedería por escaleras (Caballero 1987: 41-2) ${ }^{11}$. Aceptamos con Arbeiter que los espacios laterales estuvieran abovedados, pero, dado que los cimientos documentados por Íñi-

"La iglesia de Nazaré es considerada tradicionalmente de cronología visigoda (Schlunk 1971a), pero cada vez son más las opiniones discrepantes con esta datación. Ferreira de Almeida: 136 y ss.; Garen 1992b, en su recensión a Dodds; Caballero 1992: 183; y Real 1995: 62. El propio Palol en 1991 (p. 377) manifiesta sus reservas cronológicas. guez forman tramos de longitudes distintas y plantas alargadas, creemos que no pudieron ser naves, sino habitaciones separadas de la nave central por un muro, como en Nazaré, y por ello cubiertas de modo distinto, la primera, y quizás la última, sobre bóveda seudovaída y las demás de cañón ${ }^{12}$. Además, si se mantenía la lógica unitaria del edificio, la nave central se cubriría también con bóveda descargada por las habitaciones laterales, también abovedadas, que serían un soporte mucho más efectivo que el del simple muro (fig. 20). Al estar toda ella abovedada se hundiría siguiendo el mismo funcionamiento descrito en La Nave, empezando por la bóveda longitudinal, con la diferencia de que, al no estar atados ni «engrapados» los sillares ${ }^{13}$, los muros de las habitaciones de los pies no resistieron, al contrario de lo ocurrido con los de las habitaciones de La Nave. Luego se pandeó e inclinó el muro O. del transepto, igual que en La Nave (Arbeiter 1990: figs. 11-2), hundiéndose las bóvedas del transepto y los arcos y la bóveda del cimborrio.

Las iglesias de Arlanza y S. Vicente del Valle presentan la característica de tener ventanas en el testero oriental de sus aulas, a ambos lados del ábside, que pueden responder a la existencia de naves laterales a cuyo eje estarían situadas (Caballero y otros 1991-92: 157-8, fig. 7, lám. I,2y3; en S. Vicente, no recogidas por Aparicio, son anteriores a la construcción del actual ábside que las tapa). La planta de estas iglesias respondería a un esquema similar aunque más sencillo que el de Valdediós, pudiendo estar por lo tanto abovedadas. El abovedamiento habría supuesto su ruina. En ambos casos la ruina pudo ser muy cercana al momento de la construcción, lo que en Arlanza estaría atestiguado por la existencia de dos etapas, Ia y Ib, de técnica muy similar y la fuerte remoción lateral de los sillares que no llegaron a caer. El estudio de la modulación, ad quadratum, parece confirmar la existencia de las naves (Caballero y Cámara: 88, fig. 13; nuestra fig. 19). En S. Vicente del Valle, la hipótesis debe contrastarse. Para asegurar tres naves abovedadas, la central de las cuales tendría unos cuatro metros de luz, habría que suponer dos etapas constructivas, que pueden estar reflejadas en los dos niveles de ventanas de sus muros laterales, la primera con las naves laterales más bajas.

12 Palol 1991: 378 propone cuatro cámaras laterales, aunque define la iglesia como de tres naves de estructura basilical.

${ }_{13}$ Gómez Moreno (1966: 131) indica que la técnica constructiva de Quintanilla es semejante a la de La Nave salvo que los sillares cortos seguramente no estaban engrapados de lo que resultó su ruina. 

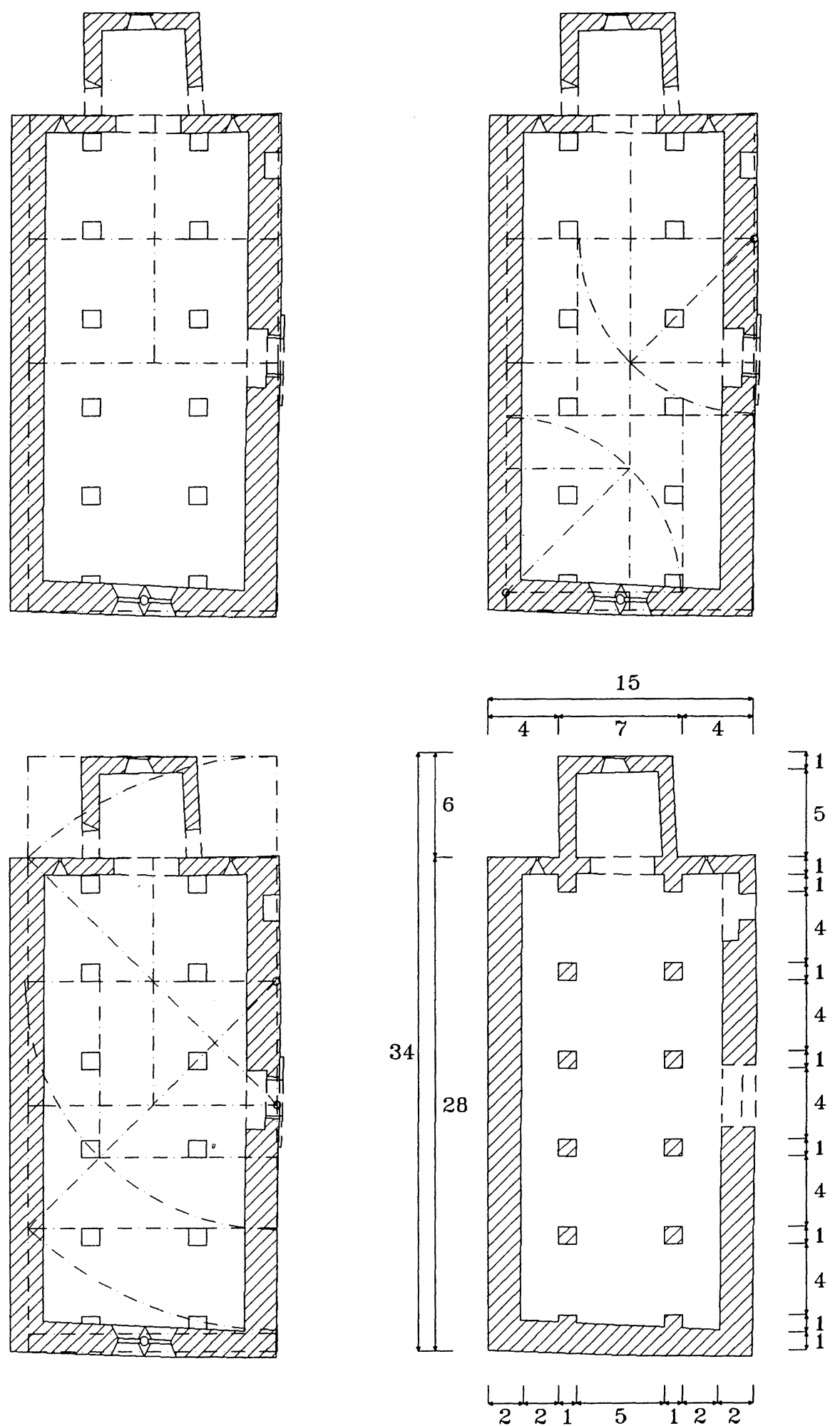

E 1:200

Fig. 20.-Modulación de S. Pedro de Arlanza (Burgos). E. 1/200. 


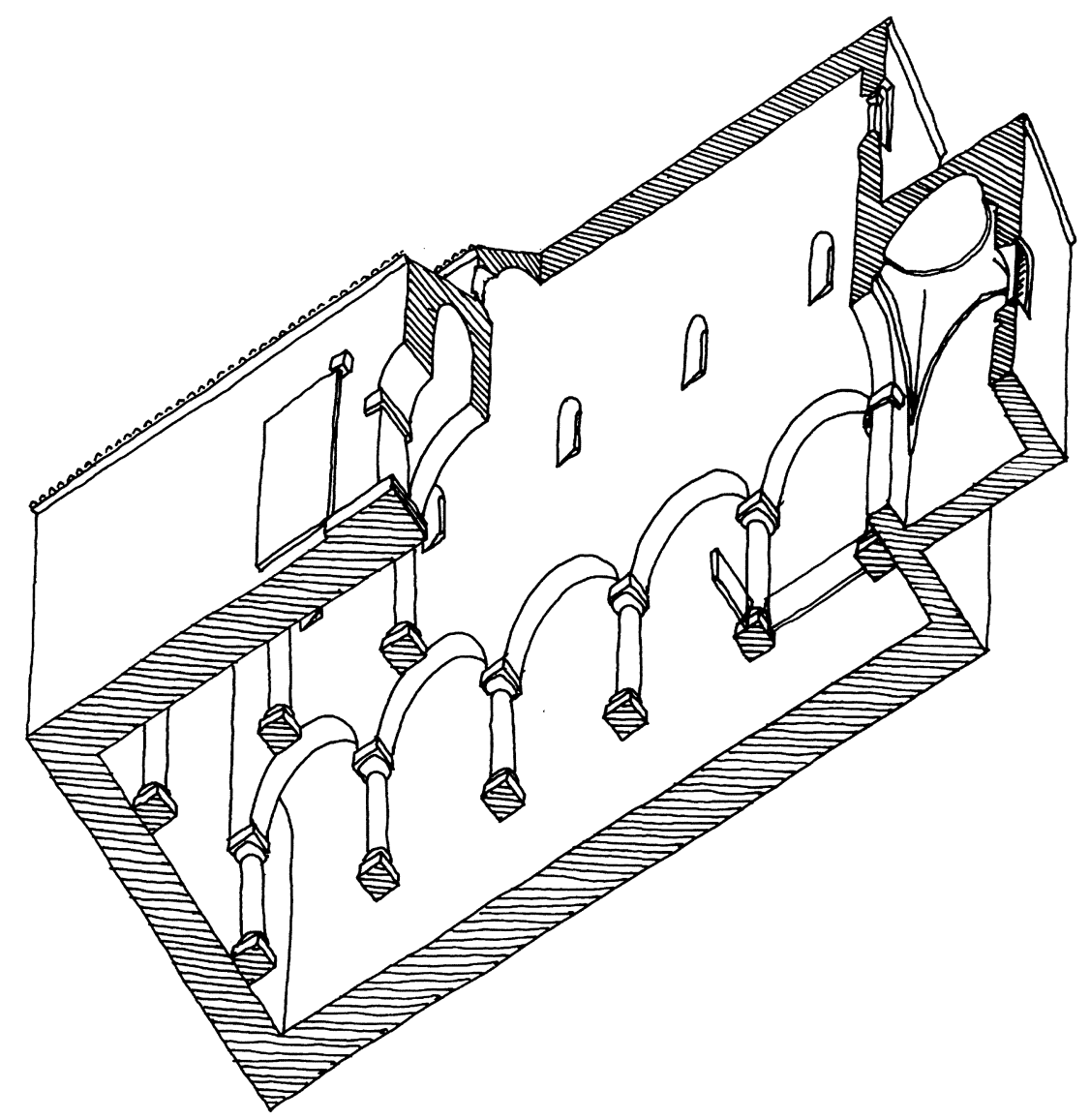

Fig. 21.-Perspectiva de la reconstrucción de S. Pedro de Arlạnza (Burgos), según Cámara (Caballero y Cámara: fig. 13).

Sobre los sillares enterizos de atado o pasantes

La técnica constructiva recuerda la de otras iglesias, por la talla, tamaño, forma, colocación y alternancia de los sillares dentro del paramento, forma de las hiladas, codos y dintel de descarga - en forma de sillar adovelado- encima de los arcos (Camps 1940: 611). Por ejemplo en Quintanilla los sillares tienen igual tipo de talla y existen sillares doblados en las esquinas (Arbeiter 1990: 405 y lám. 56b). Los sillares doblados están también presentes en Melque, mientras que no aparecen en Arlanza ni en S. Vicente del Valle (Cámara).

Sin embargo entre La Nave y Quintanilla se acusan dos diferencias. Una los sillares de atado. Arbeiter analiza meticulosamente su ausencia en Quintanilla y llega a la conclusión de que, a pesar de su aparente necesidad constructiva y de la correspondencia que los sillares tienen en la altura de las hiladas, no existe nada más que un caso en que se pueda demostrar esta existencia. En cambio hemos visto cómo en La Nave existen abundantes corres- pondencias entre los sillares tanto en altura como en longitud, a la vez que tenemos el testimonio del plano de Ferrant al desmontar el edificio que presenta con regularidad sillares pasantes a media distancia entre las ventanas y las esquinas ${ }^{14}$. La otra diferen-

\footnotetext{
${ }^{14}$ Contraponiendo los planos publicados por Arbeiter de Quintanilla se puede comprobar la certeza de su observación sobre la ausencia de sillares enterizos. Teniendo como referencia la cara externa, en la pareja de figs. $6 / 10$ sólo coinciden en el tramo N. un estrechísimo calzo de la séptima hilada, en el ábside sendos de las hiladas séptima, octava - decorado - y décima y en el tramo S. uno de la décima; en la $7 / 11$ sólo coinciden el segundo y cuarto sillar de la jamba E. y el dintel de la puerta, y el centrado de la primera hilada bajo la ventana; en la $8 / 12$ existe una rara excepción en el testero $\mathrm{N}$. del transepto donde coinciden todos los sillares de las hiladas primera a tercera al E. de la puerta, además de, encima, tres sillares de la séptima, quizás recolocados, y uno también de la séptima del ábside; y en la 9/13 coinciden, en aparente simetría, los sillares de las pilastras del crucero de las hiladas tercera, quinta, sexta, octava, décima y $13^{\mathrm{a}}$ del N. y segunda, quinta, séptima y $12^{a}$ del S., además de dos de la primera hilada y uno de la quinta de la jamba $S$. y el de la tercera de la jamba N. de la puerta. Como señala Arbeiter todas estas coincidencias no tienen por qué ser de sillares pasantes, aunque alguna puede serlo como, quizás, los del tes-
} 
cia con Quintanilla y Arlanza es que los sillares no fueran reutilizados dada la absoluta ausencia de huellas de reutilización - aunque esto tampoco sea absolutamente seguro pues los sillares reaprovechados pudieron no tener huellas que los significaran como tales-. Estas dos diferencias parecen suficientemente acusadas como para relativizar la exacta correspondencia entre las técnicas constructivas de los dos edificios paradigmáticos, Quintanilla y La Nave (Arbeiter 1990: 404-5; Hauschild: 274-8 y 284). Podrían argüirse otras, como la distinta forma de las ventanas, aunque monolíticas en los dos casos; la ausencia en Quintanilla de ajimeces ${ }^{15}$, de «alfices» o de dinteles descargados por arcos que ahora veremos. Pero son argumentos negativos que no sabemos hasta qué punto fueron así y, si lo fueron, si suponían verdaderas diferencias o apenas variantes.

Las puertas de La Nave. Los arcos de arranque retraído y su relación con los «arcs a gouttières» y los «arcos superpuestos a dinteles»

Todas las puertas de La Nave tienen jambas lisas sin mocheta, pero no es la única iglesia alto-medieval que presenta esta característica. Por ejemplo, en Quintanilla ocurre lo mismo en todas las puertas conocidas. Y en La Mata en las del anteábside y la nave, lo que hizo que se supusiera, con el paralelo de los huecos de paso del transepto de Melque, que estaban siempre abiertas. Esta propuesta fue corroborada por las puertas de la iglesia de El Trampal, de jamba lisa (Caballero 1992: 153). Sólo las puertas occidentales del transepto de El Trampal, Quintanilla y La Mata podían cerrarse, en el primer caso, a pesar de sus jambas lisas, por tener mochetas en el dintel y el umbral, y en las otras dos, a las que luego nos referiremos, por tener dintel en una cara del muro y, en la otra, arco de herradura.

Pero en La Nave las puertas tienen una forma peculiar y distinta a las de estas iglesias, con arco peraltado de arranques retraídos -excepto las de los porches con arcos de medio punto-. Se puede asegurar que todas estas puertas de La Nave con arco retraído poseyeron dintel - hoy desapareci-

tero N. del transepto, los de las pilastras del crucero y algún otro aislado. Llama la atención, al contrario, la falta de concurrencia horizontal de bastantes hiladas.

15 Sobre la posible cronología postvisigótica de los ajimeces ver Barroca, que debilita su argumento al olvidar los de La Nave y Baños; Real 1995: 63-4; y Caballero 1994/95: 347-8. do- que se apoyaba en la superficie de imposta dejada libre por el retraimiento del arco y, sobre él, tímpano macizado. Lo sabemos, en el caso de las puertas del hastial y el transepto, porque tenían trancas y por lo tanto se cerraban para lo cual necesitan dintel, quizás con mocheta, para alojar los quicios de las hojas de madera; y, en el caso de las puertas de las habitaciones ${ }^{16}$, que no presentan huellas y por lo tanto podían estar siempre accesibles, porque el intradós de la puerta de la $\mathrm{S}$. aún conserva la marca del macizado primitivo de su tímpano, ligeramente remetido de la superficie del muro como suele ser normal en estos tímpanos. No se puede asegurar que la puerta del hastial tuviera la forma de arco retraído, dada la destrucción sufrida por su muro, pero como es seguro que estaba preparada para cerrarse $y$, por lo tanto, necesitaba dintel, lo más probable es que se asemejara a sus compañeras, con la excepción dicha de las de los porches que, como los de El Trampal, tenían arcos de medio punto primitivamente previstos para ser siempre accesibles.

Los típicos arcos retraídos de La Nave son los que estudia Ponsich como «arcs a gouttières»; pero, al cerrarlos con un dintel y un tímpano, se convierten en lo que Pavón denomina «arco superpuesto al dintel», o sea un dintel descargado por un arco, como ya explica Gómez Moreno (1906: 369).

Tanto uno como otro tipo son corrientes en la alta Edad Media y son numerosas sus variantes en las que no vamos a entrar, todas generalizadas, como el arco de herradura, entre otras razones por una primaria de carácter constructivo, que facilita cimbrar el arco ${ }^{17}$. Ponsich supone que el arco retraído, sin dintel, extendido en Cataluña y la Septimania carolingia, deriva de Ctesifonte a través de los ejemplos de Rávena y del tipo supuestamente visigodo de La Nave. Por su parte Pavón deriva el arco descargando un dintel de modelos romanos a través de los palacios omeyas, con un amplio desarrollo en la España musulmana desde la implantación de la dinastía. En nuestra arquitectura cristiana este modelo, apoyándose el arco sobre los bordes del dintel monolítico, aparece en El Trampal, Nazaré y S. Pe-

16 Schlunk (1971b: 437) opina que las habitaciones se cerraban desde dentro y Corzo: 89 desde fuera, quizás ambos influidos por la conocida opinión de Gómez Moreno de que sirvieron para monjes reclusos. La realidad es que nunca tuvieron trancas ni cerrojos antiguos y por lo tanto pudieron también estar abiertas.

17 Las iglesias asturianas presentan una de estas variantes que nada tiene que ver con el tipo de La Nave y sí, en cambio, con la citada de El Trampal y Nazaré. En Asturias están ausentes también las puertas de jamba recta, salvo en los arcos de los porches. 
dro de Lourosa ${ }^{18}$, con un ejeinplo europeo en Soissons (Almagro y otros: 95, 107-8; Schlunk 1971a: 502, fig. 32; Gómez Moreno 1919: lám 37; Pavón: 352, fig. 1,5, que no cita Melque; en Cataluña, Barral: 95). Pero existe una variante típica andalusí en que el arco no apoya sobre los extremos del dintel - siempre una platabanda adovelada - sino que lo abraza lateralmente, de modo que el vano funciona como un arco aunque mantiene su forma adintelada (Pavón: 353-4, figs. 3 ss.). Sólo tenemos un caso cristiano - aunque muy probablemente mozárabe andalusí-, Melque, en que además el dintel es monolítico, no adovelado, e independiente del arco, de modo que si desaparece y con él su tímpano, el vano ofrece la forma de un arco retraído, lo que ocurrió de hecho al partirse el dintel, y desaparecer con él su tímpano, de la fachada de su puerta de entrada (Caballero y Latorre 1980: pls. 27, 29, 32 y $36^{19}$ ). Los dinteles con arco de descarga de La Nave, por lo tanto, parecen estar en una situación intermedia entre los dos tipos. No se puede asegurar que la situación fuera exactamente la de Melque, dado que - aparte la pérdida absoluta de los dinteles en La Nave y la conservación de todos menos uno en Melque-, existen con ella dos diferencias. En Melque el retraimiento de los arcos oscila entre 50 y $90 \mathrm{~cm}$, mientras que en La Nave, con unos arcos cuyo tamaño está en el límite inferior de los de Melque, es bastante menor, uniforme de $30 \mathrm{~cm}$. Por otra parte la definición formal del arco y su peralte en La Nave es perfecta, frente a Melque, en cuyos arranques los sillares del arco y del tímpano se ajustan entre sí, tallados y colocados a la vez. Estas diferencias y la pérdida de los dinteles justifica que Ponsich considere los arcos de La Nave retraídos; pero, a su vez, los arcos de La Nave se diferencian de los

${ }^{18}$ Otro ejemplo con esta solución. quizás semejante a los de Melque y Lourosa, descrito por Huidobro y hoy lamentablemente perdido era la pareja de arcos de S. Felices de Oca (Burgos; p. 368): lo más típico del edificio y que le relaciona con la iglesia de Lara-Quintanilla- son sus dos portadas, una enfrente de otra, cerca del arco triunfal, formadas por un hueco cubierto de un gran bloque cuadrangular de piedra y sobre él un arco de medio punto, relleno de sillares.

19 Garen (1992a: 298, n.53) utiliza la presencia de dinteles descargados para suponer Melque postvisigodo, supuesta su inexistencia en la arquitectura visigoda (olvidando la opinión de Gómez Moreno 1906: 369 y 1966: 129; Camps 1940: 602 y 615, aunque observa que en La Nave no hay rastros del dintel y recuerda los paralelos de Rávena sin él; y Caballero 1990: 331) y apoyándose en los ejemplos de la mezquita al-Aqsa de Jerusalén y de Jirbat al-Mafyar, que derivarían de la arquitectura bizantina siria. Pero estos y otros ejemplos no citados por Garen (prácticamente todos los palacios omeyas, $c f r$. por ejemplo Pavón) pertenecen a una variante distinta a la de Melque, con platabanda en vez de dintel monolítico y el arco apoyado en sus extremos. del grupo de Rávena, Cataluña y la Septimania por la segura existencia de los dinteles, que en Rávena cuando son necesarios se sustituyen por verdaderos marcos pétreos moldurados.

Aún debemos preguntarnos de qué material podían ser los supuestos dinteles perdidos de La Nave, si de piedra o madera, a la luz del tirante encontrado en el ábside y de los dinteles que veremos a continuación en otras iglesias. Parece que lo lógico es que fueran de piedra, pero no se puede descartar que lo fueran de madera.

\section{La utilización de la madera}

Las grapas de madera parecen un recurso dedicado a evitar que resbalen los sillares. Unas unían entre sí los sillares de las dos hojas del muro, colocadas transversalmente, y otras unían entre sí los sillares de cada hoja, a la larga. Como dice Cámara, corrientemente se acepta que las llaves debian resistir los empujes de las bóvedas, en un mecanismo que nadie ha explicado. Pero más bien que resistir estos empujes servirían para evitar la separación de las hojas por pandeo — como el de Quintanillahacia el exterior de cada una de ellas, ante cargas estrictamente verticales, pues su... dirección perpendicular al mismo no tiene que ver con las direcciones y puntos de aplicación de los empujes. Las llaves evitarían la separación reduciendo a la mitad la luz de pandeo de las dos hojas y tendrían que ver sólo con la componente vertical de la carga.

Función parecida debió tener la viga, de descarga para Torres Balbás y de trabazón para Camps ${ }^{20}$. Según Corzo las cajas de grapas que tiene servirían para atarla a los sillares. Esta solución parece exacta ya que por las marcas que conserva del desmonte y por la documentación, las cajas se situaban en la cara superior ${ }^{21}$. Según Cámara, actuaría como tirante de los empujes de la bóveda superpuesta que en aquel punto podían tender a abrir el muro debilita-

${ }^{20}$ Según la información de Ferrant pudo haber otra viga sobre ésta, en la parte posterior del frontis y en el muro opuesto del ábside, según palabras de Corzo: 81 .

${ }^{21}$ Agradecemos la discusión de esta parte a José Alonso Luengo quien observó que la viga medía media vara de ancho, que su talla era similar a la de los sillares, con destral de $5-6 \mathrm{~cm}$ de huella, y que las cajas de las llaves estaban abiertas con hacha y no con formón, datos todos ellos que considera arcaicos. La viga tiene una cara consumida por la humedad que nos hizo pensar que tenía que ser la inferior o la superior. Pero la situación de las marcas con pintura roja y la dificultad de que se hubiera consumido tan uniforme y profundamente dentro del muro, hace más verosímil que esta consunción ocurriera una vez recuperada. 
do por la ventana de acceso a la habitación superior y por el arco de triunfo, y no de descarga de los pesos que seguirían gravitando sobre el arco.

Mientras que las grapas parecen un elemento único en nuestra arquitectura altomedieval, la utilización de vigas como sistema de atado interior y de descarga de los muros parece un sistema más corriente de lo que se puede suponer en estas iglesias. S. Vicente del Valle, al parecer, poseía un zuncho perimetral de madera encajado en los sillares, a la altura de la línea de imposta de las ventanas superiores $^{22}$. Es posible que tuviera la misma función de zuncho una viga que aún se llega a ver en la cara exterior del muro de hastial de la nave central de $\mathrm{S}$. Juan de Baños, por encima del tejado del porche y en el arranque de su tímpano, aunque este elemento, a falta de su estudio, no es seguro que sea primitivo y pudo deberse a una restauración histórica. Un sistema parecido se ha usado para restaurar el aula/ transepto de Sta. María de Bendones (Asturias), aunque no parece que estuviera documentado en el edificio primitivo (Manzanares: 18, figs. 10, 11 y 21). Este uso de la madera no debió ser fortuito, sino que tuvo que ir dirigido a conseguir mayor estabilidad para unos edificios cuyas soluciones constructivas se descubren cada vez como más arriesgadas. Su procedencia parece islámica, recordando los dos encadenados con vigas de pino alojadas en cajas abiertas en los sillares documentadas en el alminar de 'Abd al-Raḥmân III en la mezquita mayor de Córdoba (946 d.C. Hernández: 49-50, figs. 9, 10 y 16). Parecidas las había en el alminar de Sevilla que se han puesto en relación con el uso de carreras de madera en la arquitectura antigua del próximo Oriente como elemento antisísmico (Arce: 43). Finalidad parecida debieron tener las vigas que zuncharon las bovedillas de la tribuna de S. Baudelio de Berlanga (Soria; Gómez Moreno: 315, fig. 183) y, sobre todo, las que a dos alturas zunchaban el cuerpo de su capillita sobresaliente como si de una pequeña torre se tratara.

\section{Dinteles de madera y puertas con arco de herradura exterior y cargadero interior.}

Vigas de madera también se utilizan en nuestra arquitectura altomedieval como cargaderos de puertas. Así aparecen en Baños, S. Miguel de Gormaz y Fuentearmengil recién descubierto ${ }^{23}$, Santiago de

${ }^{22}$ Noticia discutible que agradecemos a su excavador José Ángel Aparicio.

${ }^{23}$ Agradecemos a Consuelo Escribano, directora de la excavación de Gormaz, su conocimiento.

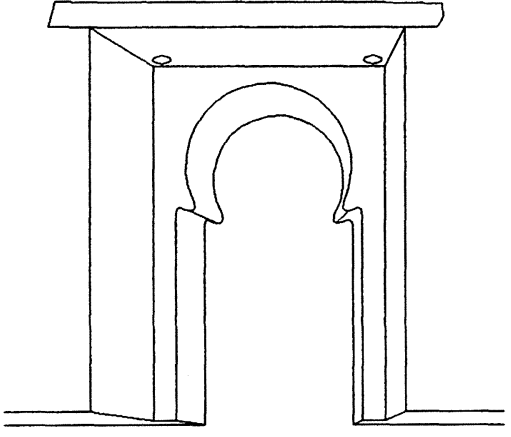

Fig. 22.-Modelo de puerta con arco de herradura exterior y cargadero de madera interior.

Peñalba (León), Berlanga (Soria), Sta. Cecilia de Barriosuso (Burgos) y en Sant Lliser de Virós (Pallars Sobirà, Barral: 170, fig. 166). Se distinguen dos tipos. Los cargaderos en la puerta principal de Baños, formado por dos vigas, y en las dos puertas extremas de Barriosuso actúan como dintel. El otro modelo se forma por un arco de herradura en la cara exterior y un cargadero o dintel de madera en la cara interior, ambos independientes (fig. 22). El cargadero aloja los quicios de las hojas de madera y el arco, al ser su vano menor que el del dintel, actúa de mocheta. La puerta que comunica el transepto con la habitación S. en Quintanilla, preparada para cerrarse desde la habitación, presenta ya este modelo, pero con dintel de piedra en vez de madera y sin mocheta, con la jamba aún lisa, quizás por ello el modelo más primitivo e inicio de una evolución (Arbeiter 1990: 416, figs. 9 y 13, láms. 44 y 51). Otras puertas similares son la de La Mata, supuestamente visigoda, de semejante situación en el transepto y también preparada para cerrar desde O., esto es desde el exterior, a no ser que antiguamente hubiera allí habitaciones hoy perdidas (Caballero y Latorre 1980: 511, láms. 57-8). Aquí ya tienen el arco resaltado en la jamba como mocheta, pero, dado que está incompleta, no sabemos si poseía dintel de madera o de piedra como Quintanilla. Otra variante sustituye el dintel por una platabanda en forma de arco muy plano. Conocemos dos ejemplos, el del palacio condal portugués de Guimarâes, fechado en la segunda mitad del s. x (Real 1985: 17-30, fig. 6 y 1995: $67^{24}$ ) y

${ }^{24}$ Coinciden este arco y el de S. Miguel de Gormaz en rematar en molduras resaltadas (fig. 22) en vez de arrancar sobre nacelas, recordando un tipo de arco representado en los Beatos, como el de Magio fechado en 962, o el de Facundo de 1047 (Stierlin: 76, 201, 235) y las ventanas monolíticas de S. Pedro de Rocas y Sta. Eufemia de Ambía, consideradas de época mozárabe, entre los ss. x y xI (Rivas: 89; García Camino y otros: 18-9) 
las dos puertas de Berlanga fechada por Gómez Moreno (1919: 317) a mediados del s. XI y con viga empotrada en la platabanda para sujetar las hojas.

Es probable que todos los ejemplos, o al menos los de Guimarâes y Berlanga con platabanda escarzana, se relacionen con un modelo de puerta militar andalusí, el de la puerta de Bisagra de las murallas de Toledo, Calatayud (Zaragoza), Ágreda (Soria; Pavón) y la puerta principal del castillo de Gormaz, todas con arco de herradura exterior y bóveda rebajada interior que es la sustituida en nuestros ejemplos por la platabanda o el dintel. En cualquier caso, este tipo de puerta, con sus variantes, pasa a ser un elemento más, representativo de este grupo de igle$\operatorname{sias}^{25}$.

La lectura de esta iglesia y la consecuente reordenación de los paralelos que proponen los nuevos datos logra que se acerquen las iglesias altomedievales españolas cada vez más entre sí. Las semejanzas entre las supuestas visigodas, asturianas y de Reconquista, de la zona burgalesa y soriana, de Toledo y extremeñas, son cada vez más evidentes. Hasta ahora se utilizan dos modelos para explicar este hecho. Según el tradicional, las circunstancias históricas ocurridas a partir del s. viII apenas influyeron en la evolución de los modelos que arrancan del s. viI. Según el que nosotros creemos más factible, las semejanzas son propias de un grupo novedoso, prerrománico, que, con sus variantes regionales, se extiende entre los siglos IX y el XI.

\section{BIBLIOGRAFÍA}

Agapito y Revilla, J. 1906: De San Pedro de La Nave. Una rectificación, Boletín de la Sociedad Castellana de Excursiones IV 452-454.

${ }^{25}$ A los usos de madera citados hay que añadir las vigas sobre los arcos del cimborrio de Bamba y sobre el de triunfo de Sto. Tomás de las Ollas (León), que Gómez Moreno considera trabes o pérgulas y que pudieron tener la función de carreras o zunchos; el madero del iconostasio de S. Miguel de Escalada (León); y el catamarán de los cimientos del castillo de Gormaz (Gómez Moreno 1919: 199, fig. 94; 223, lám. 80-1; y 145, lám. 42; Zozaya: 59-60, fig. 3). Las puertas estudiadas nada tienen que ver con los dinteles de madera empotrados en los arcos de ladrillo de las puertas de Bendones, dudosos a pesar del sugestivo argumento utilizado por Manzanares (p. 16-7, figs. 19-22). Excepto la carrera citada de Bendones, en la arquitectura asturiana no recordamos una utilización de la madera del modo visto en los grupos «visigodo» y mozárabe. Finalmente, las puertas principales de los muros S. de Barriosuso y Gormaz también tienen dinteles que no sabemos si son los primitivos o si fueron renovados al añadir las portadas románicas actuales.
Almagro Gorbea, A., Caballero Zoreda, L., Cámara Muñoz, L. y Latorre González-Moro, P. 1991: Investigación y restauración de la iglesia visigoda de Santa Lucía del Trampal, Alcuéscar (Cáceres), II Simposi Actuacions en el Patrimoni Edificat: la Restauració de l'Arquitectura dels Segles IX i X, Quaderns Cientifics i Tècnics 4 95-110.

Aparicio Bastardo, J. A. 1995: La iglesia de Santa María. San Vicente del Valle. Una construcción de época visigoda, Revista de Arqueología 174 56-59.

Arbeiter, A. 1990: Die Westgotenzeitliche Kirche von Quintanilla de Las Viñas. Kommentar zur architektonischen Gestalt, Madrider Mitteilungen 31 393-427 y láms. 39-56.

ID. 1994: con Pöffgen, B. y Karas, U., Die vor-und frühromanische Kirche San Julián y Santa Basilisa de Aistra bei Zalduondo (Álava), Madrider Mitteilungen 35 418-439.

Arce, I. 1996: Elementos y sistemas constructivos antisísmicos en la Antigüedad. Aplicación a la restauración de estructuras históricas, I Congreso Nacional de la Construcción 39-47.

Arias PÁramo, L. 1992: Recursos geométricos de dibujo, composición y proporción en la pintura mural de la iglesia prerrománica de San Julián de los Prados (Oviedo), Archivo Español de Arqueología 65 179-221.

ID. 1993: Geometría y proporción en la arquitectura prerrománica asturiana. El Palacio de Santa María del Naranco, Madrider Mitteilungen 34 282307.

ID. 1995: Prerrománico Asturiano. Diez años como Patrimonio de la Humanidad. Levantamientos planimétricos, Caja de Asturias, Oviedo.

Azkarate Garai-Olaun, A. 1995: Aportaciones al debate sobre la arquitectura prerrománica peninsular: la iglesia de San Román de Tobillas (Álava), Archivo Español de Arqueología 68 188-214.

Bango Torviso, I. G. 1974: Arquitectura de la décima centuria: ¿repoblación o mozárabe?, Goya 12269 ss.

Barral i Altet, X. 1981: L'Art Pre-romànic a Catalunya. Segles IX-X, Edicions 62, Barcelona.

Barroca, M. J. 1990: Contribuiçâo para o Estudo des Testemunhos PréRomânicos de Entre-Douroe-Minho. 1. Ajimezes, Gelosias e Modilhôes de Rolos, IX Centenário da Dedicaçâo da Sé de Braga vol. I 101-145.

Brogiolo, G. P. 1988: Archeologia dell'edilizia storica, Como.

Caballero Zoreda, L. 1987: Arquitectura de culto cristiano y época visigoda en la Península Ibéri- 
ca, 34 Corso di Cultura sull'Arte Ravennate $e$ Bizantina 31-84.

ID. 1990: Una conjetura sobre la iglesia visigoda de San Pedro de La Nave (prov. Zamora), Primer Congreso de Historia de Zamora, Actas (1988), vol. 2 317-355.

ID. 1991: Sobre Santa Comba de Bande (Orense) y las placas de Saamasas (Lugo), Galicia no tempo, Xunta de Galicia, 73-114.

ID. 1992: ¿Visigodo o asturiano? Nuevos hallazgos en Mérida y otros datos para un nuevo «marco de referencia» de la arquitectura y la escultura altomedieval en el Norte y Oeste de la Península Ibérica, 39 Corso di Cultura sull'Arte Ravennate e Bizantina 139-190.

ID. 1994 y 1995: Un canal de transmisión de lo clásico en la alta Edad Media española. Arquitectura y escultura de influjo omeya en la Península Ibérica entre mediados del s. vill e inicios del $\mathrm{x}$, Al-Qantara 15 321-348 y 16 107-124.

Id. 1995: Zamora en el tránsito de la Edad Antigua a la Edad Media, siglos v-x, en Delibes, G., Moreta, S., Gutiérrez, J. I. y Mateos, M. A. (coordinadores), Historia de Zamora, Instituto de Estudios Zamoranos, Zamora, To I 339-430.

ID. y CÁmARA MuÑoz, L. 1995: Un caso de lectura de paramentos y argumentación científica. San Pedro el Viejo de Arlanza, Burgos, Informes de la Construcción 435 79-89.

ID., CÁmara, L., Latorre González-Moro, P. y MATESANZ VERA, P. 1991-92: La iglesia prerrománica de S. Pedro el Viejo de Arlanza (Hortigüela, Burgos), Numantia 5 139-165.

ID. y EsCRIBANo, C. (coordinadores) 1997: Curso de Arqueología de la Arquitectura. El método arqueológico aplicado al proceso de estudio y de intervención en edificios históricos, (Burgos 1996) Junta de Castilla y León (en prensa).

ID. y FERNÁNDEZ MIER, M. 1997: Análisis arqueológico de construcciones históricas en España. Estado de la cuestión, Archeologia dell'Architettura 2 (en prensa).

ID. y LATORRE GONZÁlEZ-MORO (coordinadores) 1995: Leer el documento construido, numero monográfico de Informes de la Construcción 435.

ID. y LATORRE MACARRón, J. I. 1980: La iglesia y el monasterio visigodo de Santa María de Melque (Toledo). Arqueología y arquitectura. San Pedro de la Mata (Toledo) y Santa Comba de Bande (Orense), Excavaciones Arqueológicas en Espa$\tilde{n} a, 109$.

Cámara, L. 1996: Las iglesias altomedievales de sillería, comunicación al I Eongreso de Historia de la Construcción, Instituto Juan de Herrera, Madrid.

Camón Aznar, J. 1963: Arquitectura española del siglo x. Mozárabe y de la repoblación, Goya 52 163-219.

Camps Cazorla, E. 1940: San Pedro de La Nave, El arte hispano-visigodo en Historia de España dirigida por Menéndez Pidal, Espasa Calpe, Madrid (1963), vol. III, 598-629.

CAmps CAzorla, E. 1963: El arte hispanovisigodo, en España Visigoda, Historia de España dirigida por R. Menéndez Pidal, Madrid, T. ${ }^{\circ}$ III, 491-724.

ID. 1940-41: El visigotismo de San Pedro de La Nave, Boletín del Seminario de Estudios de Arte y Arqueología 7 73-80.

Corzo SÁnchez, R. 1986: San Pedro de La Nave. Estudio histórico y arqueológico de la iglesia visigoda, Zamora.

Cruz Villalón, M. y Cerrillo Martín de Cáceres, E. 1988: La iconografía arquitectónica desde la Antigüedad a la época visigoda: ábsides, nichos, veneras y arcos, Anas 1 187-203.

Ferreira de Almeida, C. A. 1986: Arte da Alta Idade Media, en História da Arte em Portugal, $\mathrm{Pu}-$ blicaçoes Alfa, Lisboa, vol. 2.

García Camino, I., González Cembellín, J. M. y SANTANA EzQuerra, A. 1987: La arquitectura prerrománica vizcaína, Kobie (Serie Bellas Artes) Bilbao 4 7-37.

Garen, S. 1992a: Santa María de Melque and Church Construction under Muslim Rule, Journal of Society of Architectural Historiens 51 208-305.

ID. 1993b: Recensión a Dodds 1990: Architetture and Ideology in Early Medieval Spain, Journal of Society of Architectural Historiens 52.

Gómez Moreno M., M. 1906: San Pedro de La Nave. Iglesia visigoda, Boletín de la Sociedad Castellana de Excursiones IV 365-373.

ID. 1919: Iglesias Mozárabes, Centro de Estudios Históricos, Madrid.

ID. 1966: Primicias del Arte Cristiano Español, Archivo Español de Arte 39 101-139.

HausChILD, Th. 1972: Westgotische Quaderbauten des 7. Jarhunderts auf der Iberischen Halbinsel, Madrider Mitteilungen 13 270-285.

Hernández Giménez, F. 1975: El alminar de 'Abd al-Rahmân III en la mezquita mayor de Córdo$b a$, Granada.

Huidobro, L. 1926-29: El arte visigótico y de Reconquista en Castilla, Boletín de la Comisión Provincial de Monumentos de Burgos 361-368.

Íñguez Almech, F. 1955: Algunos problemas de las viejas iglesias españolas, Cuadernos de Trabajos 
de la Escuela Española de Historia y Arqueología en Roma 7 8-100.

Mannoni, T. 1984: Metodi di datazione dell'edilizia storica, Archeologia Medievale 11 396-403.

Manzanares Rodríguez-Mir, J. 1957: Santa María de Bendones. Identificación y estudio de sus ruinas, Tabularium Artis Asturiensis, Oviedo.

Mateos Rodríguez, A. y Esteban Ramírez, A. L. 1980: San Pedro de la Nave, Colegio Oficial de Aparejadores y Arquitectos Técnicos de Zamora, Zamora.

Monumentos Arquitectónicos de España 1872: T $\mathrm{V}$, Madrid.

Morín, J. y Barroso, R. 1993: El árbol de la Vida. Un estudio de iconografía visigoda: S. Pedro de la Nave y Quintanilla de las Viñas, Madrid.

NAVASCUÉS Y DE JUAN, J. Mª de. 1937: Nuevas inscripciones de San Pedro de la Nave (Zamora), Archivo Español de Arte y Arqueología 37 61-71.

Noack-Haley, S. y Arbeiter, A. 1994: Asturische Königsbauten des 9. Jahrhunderts, Madrider Beiträge 22.

Orueta, R. de. 1928: La ermita de Quintanilla de las Viñas, en el campo de la antigua Lara: estudio de su escultura, Archivo Español de Arte y Arqueología 4 169-178.

Palol, P. de. 1991: Arte y Arqueología, en MenÉnDEZ PIDAL, R. (dirigida por), Historia de España, vol. III, 2, España visigoda. La Monarquía. La Cultura. Las Artes, Espasa Calpe S. A., Madrid, 269-428.

PARENTI, R. 1988: La technique di documentazione per una lettura stratigrafica dell'elevato, Archeologia e restauro dei monumenti (Siena 1987), Università di Siena, Florencia, 249-279.

Pavón, B. 1987: Las puertas de ingreso directo en la arquitectura musulmana. La superposición arcodintel de la puerta de Bisagra de Toledo, Al-Qantara 8347 ss.

Ponsich, M. 1971: L'Architecture prerromane de Saint-Michel de Cuxa et sa veritable signification, Les Cahiers de Saint-Michel de Cuxa 2 17-27.

Puig i Cadafalch, J. 1937: Les églises des Asturies et leur origine, Comptes rendus de l'Académie des Inscriptions et Belles Lettres 450-454.
ID. 1961: L'Art Wisigothique et ses survivences, Paris.

Real, M. L. 1985: Pousada de Santa Marinha. Guimarâes. Santa Marinha da Costa. Notícia Histórica, en Boletim da Direcçâo-Geral dos Edifícios e Monumentos Nacionais 130 7-58.

ID. 1995: Inovaçâo e resistência: dados recentes sobre a antiguedade cristâ no ocidente peninsular, IV Reunió d'Arqueologia Cristiana Hispànica (Lisboa 1992), Barcelona, 17-68.

Rivas Fernández, J. C. 1971: Algunas consideraciones sobre el prerrománico gallego y sus arcos de herradura geminados, Boletín Auriense 1 61114.

Selgas, F. de 1909-10: Análisis arqueológico de los monumentos ovetenses, Boletín de la Sociedad Española de Excursiones XVII 81-105, 165-193 y 21-40.

SCHLUnK, H. 1945: Observaciones en torno al problema de la miniatura visigoda, Archivo Español de Arte 71, 241-265.

ID. 1970a: Beiträge zur kunstgeschichtlichen Stellung Toledos im 7. Jahrhundert, Madrider Mitteilungen 11 161-186.

ID. 1970b: Estudios iconográficos en la iglesia de San Pedro de la Nave, Archivo Español de Arte 43 245-270.

ID. 1971a: La iglesia de S. Giâo, cerca de Nazaré, II Congreso Nacional de Arqueologia, Coimbra, 509-528.

ID. 1971b: La iglesia de San Julián de los Prados (Oviedo) y la arquitectura de Alfonso el Casto, Estudios sobre la Monarquía Asturiana, Oviedo, 407-477.

Selgas, F. de 1909: Análisis arqueológico de monumentos ovetenses, Boletín de la Sociedad Española de Excursiones, 165-193.

Stierlin, H. 1983: Los Beatos de Liébana y el Arte Mozárabe, Editora Nacional, Madrid.

TorRes BalbÁs, L. 1933: La reparación de los monumentos antiguos en España II, Arquitectura. Colegio Oficial de Arquitectos, XV 129 ss.

ZOZAYA, J. 1996: Fortification Building in al-Andalus, Spanien und der Orient im frühen und hohen Mittelalter (1991), 55-74. 


\section{LISTADO DE ACTIVIDADES}

\begin{tabular}{|c|c|c|c|c|c|}
\hline ACTV & NOMBRE & ANTERIOR A & POSTERIOR A & PERIODO & PLANO \\
\hline 1001 & Posibles elementos anteriores a obra original & 1002 & & 0 & 1018 \\
\hline 1002 & Paramentos piezas y huellas de obra original & 1003 y ss. & 1001 & I & $1 / 22$ \\
\hline 1003 & Corte en la ventana oriental del ábside & & 1002 & $\Rightarrow>I=<I I I$ & 9105 \\
\hline 1004 & Pilastras del aula y corte de las orientales & $\begin{array}{l}100610091019102711121114 \\
1127\end{array}$ & 1002 & III & $8 / 112122$ \\
\hline 1005 & Cortina en arco de triunfo & & 1002 & $\Rightarrow \mathrm{I}<\mathrm{V}$ & 91017 \\
\hline 1006 & Parte superior pilastras centrales arquerías & 1009101310271114 & 1004 & $\Rightarrow>I I I=<V$ & $8 / 11$ \\
\hline 1008 & Restauración exterior de la habitación $\mathrm{N}$ & 10071127 & 1002 & $\mathrm{~V}$ & 14 \\
\hline 1009 & Primera resturación del aula & $\begin{array}{l}1013 \quad 1017 \quad 1022 \quad 10231027 \quad 1089 \\
1100 \quad 1116 \quad 1122 \quad 1127 \quad 1133\end{array}$ & 100210041006 & $\mathrm{~V}$ & $2 / 47 / 1222$ \\
\hline 1010 & Juego de tres en raya en arquería $S$ & & 1009 & $\mathrm{~V}$ & 11 \\
\hline 1011 & Canecillos románicos en muro $\mathrm{S}$ nave central & 10131127 & & $\mathrm{~V}$ & 2 \\
\hline 1012 & Cubierta de porches Norte y Sur & 1127 & 100210281029 & VII & 5613141920 \\
\hline 1013 & Segunda restauración del aula & 1022102311271132 & 10021004100610091011 & VII & $2 / 47 / 1122$ \\
\hline 1066 & Hueco y estuco en esquina NE crucero Norte & 1021 & 1002 & VII & 719 \\
\hline 1014 & Suelo de anteábside & 1027 & 1002 & $>\mathrm{I}<$ VIII & 1017 \\
\hline 1020 & Última puerta interior del porche Norte & 1127 & 1002 & $>\mathrm{I}=<\mathrm{VIII}$ & 61920 \\
\hline 1015 & Rebaje para grafito muro $\mathrm{E}$ crucero $\mathrm{N}$ int. & & 1002 & $\Rightarrow \mathrm{V}<$ VIII & 19 \\
\hline 1016 & Huecos y corte arco N "lettner" crucero S & & 1002 & $\Rightarrow \mathrm{V}<\mathrm{VIII}$ & 2021 \\
\hline 1017 & Cierre transversal de las naves laterales & & 10021009 & $\Rightarrow V=<$ VIII & 712 \\
\hline 1018 & Corte de la puerta int. porche $S$ & 10271086 & 1002 & $\Rightarrow$ VII $=<$ VIII & 12131920 \\
\hline 1019 & Ventana cierre arco oriental arquería $\mathrm{N}$ & 1127 & 1004 & $\Rightarrow$ VII $=<$ VIII & 8921 \\
\hline 1021 & Huecos de paso entre habitaciones y crucero & 1127 & 10021066 & VIII & 7811121819 \\
\hline 1022 & Bóvedas en naves laterales & & 100210091013 & VIII & 72122 \\
\hline 1023 & Coro alto en nave central & & 10091013 & VIII & $8 / 1122$ \\
\hline 1024 & Retablo y altar testero nave $\mathrm{N}$ & & 1002 & VIII & 2021 \\
\hline 1025 & Suelo en crucero $\mathrm{N}$ int. & 1027 & 1002 & $\Rightarrow \mathrm{I}<\mathrm{IX}$ & 20 \\
\hline 1026 & Sillar dudoso de la obra original & & & $\Rightarrow>\mathrm{I}<\mathrm{IX}$ & 3 \\
\hline 1028 & Sobrado o cubierta en porche $S$ & & 1002 & $\Rightarrow \mathrm{I}<\mathrm{IX}$ & 1920 \\
\hline 1029 & Sobrado o cubierta en porche $\mathrm{N}$ & & 1002 & $\Rightarrow \mathrm{I}<\mathrm{IX}$ & 1920 \\
\hline 1027 & Degradación por humedad y elevación del suelo & 1025112511311135 & 10021004100910181071 & $>\mathrm{I}<\mathrm{IX}$ & $1 / 22$ \\
\hline 1030 & Segundo nivel de suelo en ábside & 103111251130 & 1002 & $>\mathrm{l}<\mathrm{IX}$ & 910 \\
\hline 1031 & Tercer nivel de suelo en ábside & & 10021030 & $>\mathrm{I}<\mathrm{IX}$ & 910 \\
\hline 1032 & Roza en muro $\mathrm{N}$ ábside int. & & 1002 & $>\mathrm{I}<\mathrm{IX}$ & 9 \\
\hline 1033 & Otro resto de suelo en ábside & & 1002 & $>\mathrm{I}<\mathrm{IX}$ & 9 \\
\hline 1034 & Hueco en el muro $\mathrm{N}$ ábside int. & & 1002 & $>\mathrm{I}<\mathrm{IX}$ & 9 \\
\hline 1035 & Otra cortina en el arco de triunfo & & 1002 & $>\mathrm{I}<\mathrm{IX}$ & 910 \\
\hline 1036 & Huecos para textos en el muro 0 ábside & & 1002 & $>\mathrm{I}<\mathrm{IX}$ & 91016 \\
\hline 1037 & Otra cortina en arco de triunfo & & 1002 & $>\mathrm{I}<\mathrm{IX}$ & 910 \\
\hline 1038 & Hueco en muro $\mathrm{S}$ ábside int. & & 1002 & $>\mathrm{I}<\mathrm{IX}$ & 10 \\
\hline 1039 & Hueco sobre imposta muro S ábside & & 1002 & $>\mathrm{I}<\mathrm{IX}$ & 10 \\
\hline 1041 & Otro posible suelo en ábside & & 1002 & $>\mathrm{I}<\mathrm{IX}$ & 17 \\
\hline 1042 & Sarcófago adosado al muro $\mathrm{S}$ ábside ext. & 1027 & 1002 & $>\mathrm{I}<\mathrm{IX}$ & 2 \\
\hline 1043 & Sarcófago adosado a la habitación $S$ ext. & 1027 & 1002 & $>\mathrm{I}<\mathrm{IX}$ & 2 \\
\hline 1044 & Hueco en muro $\mathrm{N}$ ábside ext. & & 1002 & $>\mathrm{I}<\mathrm{IX}$ & 4 \\
\hline 1045 & Corte en ventana $\mathrm{E}$ muro $\mathrm{N}$ habitación $\mathrm{N}$ & 1064 & 1002 & $>\mathrm{I}<\mathrm{IX}$ & 4717 \\
\hline 1046 & Construcción adosada a $\mathrm{E}$ del porche $\mathrm{N}$ & & 1002 & $>\mathrm{I}<\mathrm{IX}$ & 1 \\
\hline 1047 & Otra construcción adosada a E porche $\mathrm{N}$ & & 1002 & $>\mathrm{I}<\mathrm{IX}$ & 1 \\
\hline 1048 & Vasar construcciones adosadas a $\mathrm{E}$ porche $\mathrm{N}$ & & 1002 & $>\mathrm{I}<\mathrm{IX}$ & 1 \\
\hline 1049 & Suelo habitación $S$ ext. & 1027 & 1002 & $>\mathrm{I}<\mathrm{IX}$ & 2 \\
\hline 1050 & Construcción adosada a $S$ de porche $S$ & & 1002 & $>\mathrm{I}<\mathrm{IX}$ & 2 \\
\hline 1051 & Picado en muro $S$ habitación ext. & 1027 & 1002 & $>\mathrm{I}<\mathrm{IX}$ & 2 \\
\hline 1052 & Hueco en muro $\mathrm{N}$ ábside ext. & & 1002 & $>\mathrm{I}<\mathrm{IX}$ & 4 \\
\hline 1053 & Hueco en muro $\mathrm{S}$ anteábside & & 1002 & $>\mathrm{I}<\mathrm{IX}$ & 10 \\
\hline 1054 & Restauración de la bóveda del anteábside & & 1002 & $>\mathrm{I}<\mathrm{IX}$ & 910 \\
\hline 1055 & Cierre de ajimez habitación $S$ & & 1002 & $>\mathrm{I}<\mathrm{IX}$ & 11 \\
\hline 1056 & Hueco en muro $\mathrm{N}$ anteábside & & 1002 & $>\mathrm{I}<\mathrm{IX}$ & 9 \\
\hline 1057 & Puerta en la habitación $S$ & & 1002 & $>\mathrm{I}<\mathrm{IX}$ & 910 \\
\hline 1058 & Rebaje en ajimez habitación $\mathrm{N}$ & & 1002 & $>\mathrm{I}<\mathrm{IX}$ & 8 \\
\hline 1059 & Hueco en ajimez habitación $\mathrm{N}$ & & 1002 & $>\mathrm{I}<\mathrm{IX}$ & 8 \\
\hline 1060 & Mechinal en bóveda habitación $\mathrm{N}$ & & 1002 & $>\mathrm{I}<\mathrm{IX}$ & 8 \\
\hline 1061 & Cortes en ventana $\mathrm{E}$ habitación $\mathrm{N}$ & . & 1002 & $>\mathrm{I}<\mathrm{IX}$ & 17 \\
\hline 1062 & Cortes en ventanas N y S ábside & & 1002 & $>\mathrm{I}<\mathrm{IX}$ & 24910 \\
\hline 1063 & Huecos en muro $S$ habitación $S$ & & 1002 & $>\mathrm{I}<\mathrm{IX}$ & 12 \\
\hline 1064 & Otro corte en ventana $\mathrm{E}$ muro $\mathrm{N}$ habitación $\mathrm{N}$ & & 10021045 & $>\mathrm{I}<\mathrm{IX}$ & 7 \\
\hline 1065 & Hueco en muro $\mathrm{E}$ crucero $\mathrm{N}$ & & 1002 & $>\mathrm{I}<\mathrm{IX}$ & 19 \\
\hline 1067 & Restauración de las bóvedas del crucero & & 1002 & $>\mathrm{I}<\mathrm{IX}$ & 1920 \\
\hline 1068 & Hueco en muro E crucero $S$ & & 1002 & $>\mathrm{I}<\mathrm{IX}$ & 19 \\
\hline 1069 & Otro hueco en muro $E$ porche $S$ int. & & 1002 & $>\mathrm{I}<\mathrm{IX}$ & 19 \\
\hline
\end{tabular}




\section{LISTADO DE ACTIVIDADES (Cont.)}

\begin{tabular}{|c|c|c|c|c|c|}
\hline ACTV & NOMBRE & ANTERIOR A & POSTERIOR A & PERIODO & PLANO \\
\hline 1070 & Retalle en salmer esquina SE arco crucero $S$ & & 1002 & $>\mathrm{I}<\mathrm{IX}$ & 11,19 \\
\hline 1071 & Puerta exterior y suelo porche $S$ & 1027 & 1002 & $>\mathrm{I}<\mathrm{IX}$ & 141920 \\
\hline 1072 & Cierre de la puerta exterior porche $S$ & & 1002 & $>\mathrm{I}<\mathrm{IX}$ & 1920 \\
\hline 1073 & Hueco en esquina NE porche $\mathrm{N}$ int. & & 1002 & $>\mathrm{I}<\mathrm{IX}$ & 6 \\
\hline 1074 & Sobrado en porche $\mathrm{N}$ & 1127 & 1002 & $>\mathrm{I}<\mathrm{IX}$ & 56 \\
\hline 1075 & Último nivel de sobrado en porche $\mathrm{N}$ & 1127 & 1002 & $>\mathrm{I}<\mathrm{IX}$ & 561920 \\
\hline 1076 & Hueco en esquina NE porche $\mathrm{N}$ & & 1002 & $>\mathrm{I}<\mathrm{IX}$ & 5 \\
\hline 1077 & Otro hueco en esquina NE porche $\mathrm{N}$ int. & & 1002 & $>\mathrm{I}<\mathrm{IX}$ & 5 \\
\hline 1078 & Hueco en arco puerta interior porche $\mathrm{N}$ & 1127 & 1002 & $>\mathrm{I}<\mathrm{IX}$ & 619 \\
\hline 1079 & Cierre de puerta interior porche $\mathrm{N}$ & & 1002 & $>\mathrm{I}<\mathrm{IX}$ & 20 \\
\hline 1080 & Picado jambas puerta interior porche $\mathrm{N}$ & & 1002 & $>\mathrm{I}<\mathrm{IX}$ & 1920 \\
\hline 1081 & Puerta interior del porche $\mathrm{N}$ & & 1002 & $>\mathrm{I}<\mathrm{IX}$ & 19 \\
\hline 1082 & Huecos en ventana 0 porche $\mathrm{N}$ int. & & 1002 & $>\mathrm{I}<\mathrm{IX}$ & 20 \\
\hline 1083 & Posible escalera de sobrado porche $\mathrm{N}$ & & 1002 & $>\mathrm{I}<\mathrm{IX}$ & 20 \\
\hline 1084 & Hueco en muro 0 porche $N$ int. & & 1002 & $>\mathrm{I}<\mathrm{IX}$ & 20 \\
\hline 1085 & Posible hueco de sobrado porche $\mathrm{N}$ & & 1002 & $>\mathrm{I}<\mathrm{IX}$ & 19 \\
\hline 1086 & Otro posible hueco de sobrado porche $\mathrm{N}$ & & 1002 & $>\mathrm{I}<\mathrm{IX}$ & 20 \\
\hline 1087 & Hueco en muro 0 porche $S$ ext. & & 10021121 & $>\mathrm{I}<\mathrm{IX}$ & 23 \\
\hline 1088 & Corte de ventana 0 porche $S$ & & 1002 & $>\mathrm{I}<\mathrm{IX}$ & 320 \\
\hline 1089 & Agujeros circulares en porche $S$ y aula ext. & & 10021009 & $>\mathrm{I}<\mathrm{IX}$ & 34 \\
\hline 1090 & Rebaje en muro 0 porche $S$ ext. & & 1002 & $>\mathrm{I}<\mathrm{IX}$ & 3 \\
\hline 1091 & Cerrojo en muro 0 porche $S$ ext. & 1027 & 1002 & $>\mathrm{I}<\mathrm{IX}$ & 3 \\
\hline 1092 & Muesca en muro $S$ nave $S$ ext. & 1027 & 1002 & $>\mathrm{I}<\mathrm{IX}$ & 2 \\
\hline 1093 & Corte en alféizar de ventana muro $S$ crucero & & 1002 & $>\mathrm{I}<\mathrm{IX}$ & 1213 \\
\hline 1094 & Hueco en muro 0 porche $\mathrm{N}$ int. & & 1002 & $>\mathrm{I}<\mathrm{IX}$ & 20 \\
\hline 1095 & Viguería en porche $\mathrm{N}$ & & 1002 & $>\mathrm{I}<\mathrm{IX}$ & 61920 \\
\hline 1096 & Hueco en muro 0 porche $\mathrm{N}$ int. & & 1002 & $>\mathrm{I}<\mathrm{IX}$ & 20 \\
\hline 1097 & Puerta interior de porche $S$ int. & & 1002 & $>\mathrm{I}<\mathrm{IX}$ & 20 \\
\hline 1098 & Puerta interior de porche $\mathrm{N}$ & 1020 & 10021099 & $>\mathrm{I}<\mathrm{IX}$ & 1920 \\
\hline 1099 & Corte salmeres puerta interior porche $\mathrm{N}$ & 10201098 & 10021081 & $>\mathrm{I}<\mathrm{IX}$ & 1920 \\
\hline 1100 & Hueco en muro 0 nave $\mathrm{N}$ int. & & 1002 & $>\mathrm{I}<\mathrm{IX}$ & 22 \\
\hline 1102 & Caja en muro 0 nave $S$ int. & & 1002 & $>\mathrm{I}<\mathrm{IX}$ & 22 \\
\hline 1103 & Hueco y roza en muro 0 nave $S$ int. & & 1002 & $>\mathrm{I}<\mathrm{IX}$ & 22 \\
\hline 1104 & Caja en muro $\mathrm{N}$ nave $\mathrm{S}$ int. & & 1002 & $>\mathrm{I}<\mathrm{IX}$ & 11 \\
\hline 1105 & Roza en esquina SO entre porche y aula ext. & & 1002 & $>\mathrm{I}<\mathrm{IX}$ & 34 \\
\hline 1106 & Agujero en muro 0 porche $S$ int. & & 1002 & $>\mathrm{I}<\mathrm{IX}$ & 20 \\
\hline 1107 & Cortina en el arco oriental del crucero & & 1002 & $>\mathrm{I}<\mathrm{IX}$ & 910 \\
\hline 1121 & Construcción adosada al muro 0 porche $S$ & 1087 & 1002 & $>\mathrm{I}<\mathrm{IX}$ & 3 \\
\hline 1137 & Corte en ventana $\mathrm{E}$ muro $\mathrm{S}$ habitación $\mathrm{S}$ & & 1002 & $>\mathrm{I}<\mathrm{IX}$ & 12 \\
\hline 1108 & Restauración de arcos brazos N y S de crucero & & 1002 & $>\mathrm{II}<\mathrm{IX}$ & 9101920 \\
\hline 1109 & Retalle de ventanas $\mathrm{E}$ y $\mathrm{Q}$ muro $\mathrm{N}$ nave $\mathrm{N}$ int. & & 1002 & $\Rightarrow>I I I<I X$ & 7 \\
\hline 1110 & Última cubierta del porche $S$ & & 1002 & $\Rightarrow \mathrm{III}<\mathrm{IX}$ & 13 \\
\hline 1112 & Corte en dovela arco $\mathrm{E}$ arquería $S$ & & 1006 & $>\mathrm{III}<\mathrm{IX}$ & 1021 \\
\hline 1113 & Caja en pilastra central arquería $\mathrm{N}$ & 1127 & 1004 & $>$ III $<\mathrm{IX}$ & 9 \\
\hline 1115 & Caja en pilastra central arquería $\mathrm{N}$ & 1127 & 1004 & $>\mathrm{III}<\mathrm{IX}$ & 8 \\
\hline 1126 & Caja en pilastra 0 arquería $\mathrm{N}$ & 1127 & 1004 & $>$ III $<$ IX & 922 \\
\hline 1007 & Gárgolas y restauración habitaciones ext. & 1127 & 10021008 & $\Rightarrow \mathrm{V}<\mathrm{IX}$ & 124 \\
\hline 1114 & Puerta en arco central arquería $S$ & & 10041006 & $\Rightarrow \mathrm{V}<\mathrm{IX}$ & 10 \\
\hline 1116 & Construcción adosada a $\mathrm{N}$ nave $\mathrm{N}$ & & 10021009 & $>\mathrm{V}<\mathrm{IX}$ & 34 \\
\hline 1117 & Hueco en muro $\mathrm{N}$ nave $\mathrm{N}$ ext. & & 1002 & $>\mathrm{V}<\mathrm{IX}$ & 4 \\
\hline 1118 & Otro hueco en muro $\mathrm{N}$ nave $\mathrm{N}$ ext. & & 1002 & $>\mathrm{V}<\mathrm{IX}$ & 4 \\
\hline 1119 & Hueco en muro 0 porche $\mathrm{N}$ ext. & & 1002 & $>\mathrm{V}<\mathrm{IX}$ & 3 \\
\hline 1120 & Agujeros en muro 0 porche $\mathrm{N}$ ext. & & 1002 & $>\mathrm{V}<\mathrm{IX}$ & 3 \\
\hline 1122 & Caja en derrame ventana $E$ muro $S$ nave $S$ int. & & 1009 & $>\mathrm{V}<\mathrm{IX}$ & 12 \\
\hline 1123 & Campanario en porche 0 & & 1002 & $>\mathrm{VII}<\mathrm{IX}$ & 14 \\
\hline 1124 & Otra construcción adosada a $\mathrm{N}$ nave $\mathrm{N}$ & & 1002 & $>$ VII $<\mathrm{IX}$ & 3 \\
\hline 1125 & Marcas y nivelación para traslado & 11271130 & 100210271030 & IX & $1 / 39101520$ \\
\hline 1127 & Traslado y restauración de Ferrant & 111111291132 & 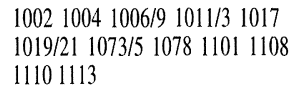 & $\mathrm{X}$ & $1 / 141719 / 22$ \\
\hline 1128 & Tendido eléctrico en porche $\mathrm{N}$ & & 1002 & $\mathrm{X} / \mathrm{XI}$ & $4 / 619$ \\
\hline 1129 & Restauración plintos columnas 0 de crucero & & 100210271127 & $\mathrm{X} / \mathrm{XI}$ & 9102021 \\
\hline 1111 & Grietas en cimborrio & & 10021027 & $\mathrm{XI}$ & 9101920 \\
\hline 1130 & Montaje de escultura en ábside y habitación $\mathrm{N}$ & & 1002102710301125 & $\mathrm{XI}$ & 9101517 \\
\hline 1131 & Nivelación contemporánea ext. & & 10021027 & $\mathrm{XI}$ & 124 \\
\hline 1132 & Retejado de los años -80 & & 1127 & $\mathrm{XI}$ & $! / 22$ \\
\hline 1133 & Huellas de afilado en paredes ext. & & 1009 & $\mathrm{XI}$ & 3 \\
\hline 1134 & Parteluz de ajimez 0 porche $\mathrm{N}$ & & 1002 & $\mathrm{XI}$ & 320 \\
\hline 1135 & Puertas actuales de los porches & & 10021027 & XI & 5 \\
\hline
\end{tabular}

